\title{
Preirradiation Data Summary for the GRIT-II HTGR Irradiation Test Specimens
}

\author{
J. L. Hollenbeck \\ DE-AC11-93PN38195 \\ Printed in the United States of America \\ Available from the \\ National Technical Information Service \\ U. S. Department of Commerce \\ 5285 Port Royal Road \\ Springfield, Virginia 22151
}

This document is an interim memorandum prepared primarily for internal reference and does not represent a final expression of the opinion of Westinghouse. When this memorandum is distributed externally, it is with the express understanding that Westinghouse makes no representation as to completeness, accuracy, or usability of information contained therein. 
WAPD-TM-1633

Page 2

\section{NOTICE}

This report was prepared as an account of work sponsored by the United States Government. Neither the United States, nor the United States Department of Energy, nor any of their employees, nor any of their contractors, subcontractors, or their employees makes any warranty, express or implied, or assumes any legal liability or responsibility for the accuracy, completeness or usefulness of any information, apparatus, produce or process disclosed, or represents that its use would not infringe privately owned rights. 


\section{DISCLAIMER}

Portions of this document may be illegible in electronic image products. Images are produced from the best available original document. 


\section{TABLE OF CONTENTS}

Page

I. Introduction and Background $\ldots \ldots \ldots \ldots \ldots \ldots \ldots \ldots \ldots$

II. Test Objectives $\ldots \ldots \ldots \ldots \ldots \ldots \ldots \ldots \ldots \ldots \ldots \ldots \ldots \ldots \ldots \ldots$

III. Technical Requirements $\ldots \ldots \ldots \ldots \ldots \ldots \ldots \ldots \ldots \ldots \ldots$. 5

IV. Implementation $\ldots \ldots \ldots \ldots \ldots \ldots \ldots \ldots \ldots \ldots \ldots \ldots \ldots \ldots$

V. Assurance of Compliance $\ldots \ldots \ldots \ldots \ldots \ldots \ldots \ldots \ldots \ldots$

VI. Test Fabrication $\ldots \ldots \ldots \ldots \ldots \ldots \ldots \ldots \ldots \ldots \ldots \ldots \ldots$

A. Fuel Particle Preparation/Evaluation $\ldots \ldots \ldots \ldots \ldots \ldots \ldots .8$

B. Tube Assembly Fabrication .................... 8

C. Specimen (Holder) Preparation and Assembly ............ 9

VII. As-Built Data for Post-Irradiation Evaluation .............. 10

A. Metallography ........................... 10

B. Microprobe .......................... 10

C. Crush Strength $\ldots \ldots \ldots \ldots \ldots \ldots \ldots \ldots \ldots \ldots \ldots \ldots, 11$

D. Radiography .......................... 11

E. Corrosion .............................. 11

F. Photography $\ldots \ldots \ldots \ldots \ldots \ldots \ldots \ldots \ldots \ldots \ldots \ldots \ldots \ldots, 11$ 
WAPD-TM-1633

Page 4

Intentionally Blank 
WAPD-TM-1633

Page 5

\section{Preirradiation Data Summary for the GRIT-II HTGR Irradiation Test Specimens}

\section{Introduction and Background}

This document and the associated Attachment comprises a report of Preirradiation Data on the NPR-5 and NPR-8 fuel types tested in the GRIT-II High Temperature Gas Reactor (HTGR) Irradiation Test. These two fuel types were provided to Bettis through the DOE New Production Reactor (NPR) Modular High Temperature Gas Reactor (MHTGR) Program. A summary and schematic of these two HTGR fuel designs are shown in Table 1 and Figure 1 respectively. A significant development to establish new techniques and procedures to perform Irradiation Testing of HTGR fuel in the Advanced Test Reactor (ATR) was required in order to meet HTGR fuel testing objectives. A summary of fuel characterization, GRIT-II test fabrication data, outlines of the fabrication procedures and a discussion of the GRIT technique for individual fuel bead testing is presented.

The most critical performance requirement of an HTGR fuel bead is the retention of fission products throughout the operational life of the core. To establish retention criteria, a maximum probability of fuel bead failure and release of fission products can be developed based on radiological concerns. The requirement of each individual fuel bead to retain fission products is a result of the poor fission product retention characteristics of conventional graphitic matrix materials used in High Temperature Gas Reactors.

\section{Test Objectives}

The objective of the GRIT-Il test was to provide individual irradiated HTGR fuel beads for post irradiation evaluation with total target burn-ups of $25 \%, 50 \%$ and $75 \%$ Fissions of Initial Metal Atoms (FIMA).

III. Technical Requirements

Securely retaining the individual fuel beads in the Advanced Test Reactor (ATR) to avoid the loss of test material in a loop required the design of new test fixturing. Such fixturing was required to provide adequate heat transfer and coolant flow, provide volume for expansion of materials due to temperatures changes, and minimize interaction between individual fuel beads and their adjacent environment. To provide these requirements, as well as increasing the potential availability of testing space, a system was developed to enclose fuel beads in thin walled tubing for irradiation in the ATR. After irradiation, the fuel tubes can be removed from the ATR and individual fuel beads and fission gas removed through cutting open of the individual tube assemblies. Using this technique approximately 100 to 200 individual HTGR fuel beads could be irradiated in each tube assembly to provide material for individual particle post-irradiation testing. Based upon a typical $10^{-6}$ failure fraction fuel design, it was not expected that testing 200 particles would result in any bead failures. However, the test was designed to accommodate failures and facilitate the ready measurement and quantification of such failures. 
Page 6

IV. Implementation

Drawings of a single fuel tube and holder capable of holding six fuel tubes are shown in Figures 2 and 3 respectively. Fuel tube length was set at 4.85 inches by the space available in the ATR and the holder design. Pins which were inserted into the closed tube ends and the welds required to seal tubes further limited the length of tube available for fuel to approximately 4.0 inches. Each tube was backfilled with one atmosphere of helium to provide a dry inert environment inside the tubes and each tube was individually leak tested. To minimize fuel bead to fuel bead contact the tube inside diameter was chosen to be slightly greater than the fuel bead diameter. This ensured that a single column of fuel beads resulted when the tubes were loaded. The wall thickness of the stainless steel tubing ( 20 mils) was chosen to provide adequate strength to eliminate concern of tube deformation resulting from external coolant pressure and any internal fission gas accumulation.

The maximum total fission gas pressure which could develop inside a tube from 50 $\mathrm{mg}$ of fully depleted $\mathrm{U}^{235}$ was calculated to be less than $1 \mathrm{Ksi}$. This internal pressure will not produce any deformation of the tube at the maximum coolant temperature to which they will be exposed. The nominal external coolant pressure will also not produce any significant deformation of the tube.

The D-pocket holders were fabricated from Zircaloy-4 and the fuel pins were made of 304 stainless steel. To ensure that thermal expansion mismatch between the holder and fuel pins could be accommodated the minimum space required for each pin in the holder was determined. Conservative thermal expansion coefficients were assumed for both the holder $\left(5.89 \times 10^{-6}\right)$ and pins $\left(17.8 \times 10^{-6}\right)$ and a conservatively high maximum coolant temperature of $600^{\circ} \mathrm{F}$ was assumed for the calculation. The minimum space required for each tube to accommodate the larger tube thermal expansion was 4.867 inches. (initial tube length $=4.850 \mathrm{in}$.). Using a factor of two as a design margin and allowing for peening variations a design minimum of 4.885 inches of available space for each tube was established.

The peak central temperature (PCT) of the HTGR fuel during irradiation in the ATR was estimated and varies with fuel type and position in the ATR. The highest PCT estimated was for the pins which will be located in high flux positions. Such pins were those targeted to reach 75\% FIMA. In this case the PCT was calculated to be approximately $1000^{\circ} \mathrm{F}$. Other fuel types and lower depletion positions result in lower PCT. Data on Fast Flux and PCT for each holder will be available when testing is complete. The temperature profile through a particle within the tube was not calculated in detail.

Fission gas pressure which develops inside the fuel particles has been determined as a function of burnup. Such gas pressure calculations are based on the following assumptions:

1) It is assumed that $100 \%$ release of all of the xenon and krypton fission products occur;

2) The fission product total yield for xenon and krypton is assumed to be $22.1 \%$; 
3) The total void within both the kernel and the porous buffer coating is assumed to be available to accommodate both gaseous and solid fission product swelling;

4) It is assumed that $1.2 \mathrm{v} / \mathrm{o}$ solid swelling will occur for each $1.0 \%$ burnup (FIMA) of U-235;

5) The total volume, $V_{T}$, available within the fuel particle for xenon and krypton is equal to the initial void volume minus the volume due to solid fission product swelling;

6) The pressure, $P$, within the fuel particle is related to the net void volume, $V_{N}$, temperature, $T$, and number of moles of fission gas, $n$, by the Van der Walls equation:

$$
P=\frac{n R T}{V_{N}-n b}-\frac{a n^{2}}{V^{2}}
$$

where $P$ is in atmospheres, $n$ is the number of moles of gas within the particle, $R$ is the gas constant $\left(0.082 \mathrm{l}\right.$-atm mole $\left.{ }^{-1} K^{-1}\right), V_{N}$ is the net void within the particle in liters, and $a$ and $b$ are gas constants for the element of interest. Since $\sim 80 \%$ of the fission gas is xenon, it was assumed that $a$ and $b$ for xenon applies, $\left(a=4.194 \mathrm{I}^{2} \mathrm{~atm}\right.$ mole $^{-2} ; \mathrm{b}=0.05105 \mathrm{Imole}^{-1}$.)

Gas pressures were calculated for the NPR fuel design as a function of fuel (U-235) burnup and the results are shown in Figure 4. The maximum hoop stress developed in the outer strength coating of the fuel bead due to the fission gas pressure developed inside is shown in Figure 5. These results indicate that the fuel beads will exhibit maximum hoop stresses in the strong coating well below the tensile strength of good quality carbide coatings ( 50,000-100,000 psi). Based on such analysis the nominal NPR fuel bead is anticipated to resist pressure vessel failures at FIMA up to the design goal of $75 \%$. This calculation does not consider any additional coating stresses which might exist as a result of the fabrication process, from thermal gradients which exist during irradiation, from the presence of $\mathrm{CO}$ or $\mathrm{CO}_{2}$ generation within the particle, or from interaction of the coating layers.

\section{Assurance of Compliance}

A process outline summarizing the fabrication sequence is provided in Table 2. The process outline includes sections for tubing preparation, fuel preparation/evaluation and tube assembly fabrication, and holder preparation and specimen assembly. A summary of the certified materials used in tube assemblies and holders is given in Table 3. The test was fabricated under the cognizance of the Core Materials Engineering group of Material Technology. All tube, tube assembly and specimen processing was performed on certified route cards. 


\section{Test Fabrication}

\section{A. Fuel Particle Preparation/Evaluation}

Fuel beads for testing were obtained from General Atomics. The as received fuel beads were tray sorted using a vibrating slanted table to remove any nonspherical or broken particles and to estimate the particle surface contamination by radiologically surveying the table surface contacted by the rolling particles. The contamination estimate in conjunction with micro-alpha/beta counting was useful in predicting the contamination levels of particle samples for loading. Although some particle surface contamination was detected at tray sorting, all loading samples of fuel beads and containers were predicted and found to be radiologically clean.

After tray sorting fuel beads were then sieved to provide a known size range of particles for counting, sampling and loading into tube assemblies. Samples were withdrawn from each of the two designs for particle evaluation. Evaluation included measurement of fuel bead crush strength, density and chemical analysis.

Based on the size range withdrawn at the sieving operation, the appropriate number of fuel beads were counted to provide a straight line fuel length of approximately 4.00 inches. NPR-5 fuel bead nominal size required 150 fuel beads to obtain the desired stack length, the NPR-8 fuel bead nominal size required 130 fuel beads. Fuel for each tube was individually counted and an additional sample of each fuel type selected for surface contamination evaluation by low level alpha counting. Each container was also surveyed internally and externally for contamination. All samples were surveyed to be radiologically clean and released for further processing.

\section{B. Tube Assembly Fabrication}

The tubes were assembled in a "clean" Assembly Glovebox. This glovebox provided a radiologically clean, atmospherically controlled (argon atmosphere) work area within which the fuel beads could be loaded into the tubes, surveyed and removed as clean assembled tubes.

The tubes were 304 stainless steel approximately 5.0 inches in length with an outside diameter of 0.078 inches and a wall thickness of 0.020 inches. This tube geometry provided an inside diameter (I.D.) of 0.038 inches. This provided easy loading of the NPR- 5 and NPR-8 fuel and insured a particle stacking angle less than $45^{\circ}$. The tubes were seal welded and machined to provide a spherical shape closure which approximates the tube outside diameter. To accommodate insertion of the test into D-pocket locations of the ATR, the tube lengths were shortened to 4.85 inches to meet the required assembled size. A representative sample of the tubes were dimensionally inspected to assure compliance with the procurement requirements. 
The samples were slowly poured into the tubes using a Zircaloy-4 funnel. The loading funnel used a two-stage exit hole to match the inside and outside diameters of the tubing. This assured a smooth, jam-free insertion of beads into the tubing.

A 308 stainless steel pin was placed in the bottom end of the tube prior to loading. The beads were poured into the funnel/tube assembly to load the tube. The funnel was removed from the tube and the loaded tube was capped with a 308 stainless steel end closure to temporarily close the tube. The end closure fits into the open end of the tube and rests on the shoulder of the tube. The end closure extends above the tube shoulder to accommodate later seal welding.

The loaded tube assembly was surveyed to assure it was radiologically clean and placed into a 3 inch $\times 7$ inch transport container with positional indicators to maintain the tube assembly and fuel material identity. The container was sealed and transferred to the Tungsten Inert Gas (TIG) welding glovebox for seal welding in a helium atmosphere.

The container was opened and each tube end closure was removed from the tubes to assure exposure of the tube internals first to the weldbox vacuum and then to the one (1) atmosphere backfill of helium. The tube end closures were returned to the tube assemblies and welded individually at 1.0 volt and 10.0 amps to seal the end closure to the tube ends. The welded assemblies were surveyed as radiologically clean and transferred to machine the weld area to the desired size and shape.

The finished assemblies were helium leak tested and radiographed to assure tubing and particle integrity and to confirm fuel bead loading. The leak tested and radiographed assemblies were corrosion tested in $680^{\circ} \mathrm{F}$ water for three (3) days to assure tubing and weld integrity of the assemblies. Table 4 provides the as-built data for the HTGR Irradiation Test tube assemblies.

\section{Specimen (Holder) Preparation and Assembly}

Twelve (12) fuel tube assemblies ( $T / A$ 's) were inserted into four (4) anodized Zircaloy-4 D-pocket holders supplied by Materials Technology Engineering Development and Testing. GRIT-II holder and tube assembly assignments with predicted U-235 burn-up estimates are identified in Table 5. Each of the tubes is secured in the holder by placing an indentation in each tube assembly location of the Zircaloy-4 holder. The peening indentations were confirmed to assure proper location and depth. The element and isotope weights for each tube assembly based on chemical analyses of the fuel materials are provided in Table 6. 


\section{As-Built Data for Post-Irradiation Evaluation}

A. Metallography

Bettis metallography was performed on a random sample of both NPR-5 and NPR-8 upon receipt. From the metallographic data fuel attributes were determined, including kernel diameter, total fuel bead diameter, ellipticity ratio, and Buffer, Inner Seal, Silicon Carbide and Outer Seal Thicknesses (Table 7). Representative areas are shown at 50X, 200X and 500X in Figures 6 and 7 for NPR-5, NPR-8 respectively.

Microstructural features of the NPR fuel to note includes some lack of sphericity, good SiC strength coating structure, and the two phase UCO kernel structure. The NPR-5 and NPR-8 fuel are identical (i.e., from the same lot) through the application of the outer pyrocarbon layer. The low density of the seal pyrocarbon coating on the NPR-8 fuel resulted in significant loss of this material during metallographic preparation. In addition, significant cracking and loss of outer pyrocarbon coating was observed in metallographic mounts of NPR-5 fuel, however, no cracking in the pyrocarbon coatings were observed during macroscopic examination of NPR fuel. There also appears to be density gradients in the buffer coating and significant void between the buffer and inner carbon coating. The thin $(<5 \mu \mathrm{m})$ seal pyrolytic coatings are also visible in the NPR designs at $500 \mathrm{X}$.

Metallography of the HTGR fuels allowed the kernel and coating dimensions to be readily determined and the quality of the coating materials to be qualitatively evaluated. Initial metallography of as received material will also be used to assist in the evaluation of post-irradiation metallography.

\section{B. Microprobe}

Microprobe examination was performed on NPA-8 fuel beads and is included as Attachment 1. Microprobe confirmed many of the microstructural features observed in the previous metallography as well as confirming that no unusual chemical features existed in the fuel. References to Figure numbers in this section will refer to Figures found in Attachment 1.

Secondary electron images of the NPR-8 fuel in Figures 5-8 show the presence of a void between the buffer and inner carbon coating, a large amount of void in the outer protective carbon layer, a uniform SiC coating and a two phase UCO kernal structure. The UCO kernal was examined at higher magnification using both secondary and backscattered imaging as shown in Figure 9. The central portion of the kernal was found to be a two phase mixture of $\mathrm{UC}_{\mathrm{x}}$ and $\mathrm{UO}_{2}$. Composition of the two phases was measured qualitatively with the lighter phase, as observed in backscattered images, corresponded to $U C_{x}$ and the darker phase corresponding to $\mathrm{UO}_{2}$. The outer "rim" of the kernal was observed to be the darker $\mathrm{UO}_{2}$ phase. High magnification images of the $\mathrm{SiC}$ coating in Figure 10 shows the coating to be very uniform and free of large porosity. Backscattered images indicate some oriented grain structure with grain boundaries aligned radially in the coating. 
X-ray analysis on all three particles detected no unusual or unexplained chemical species.

\section{Crush Strength}

Curves of stress vs. time during the loading of NPR-5 (6.45 lbs. avg., standard deviation $=0.67 \mathrm{lbs}$.) and NPR-8 ( $9.89 \mathrm{lbs}$. avg., standard deviation $=2.11 \mathrm{lbs}$.) fuel are shown in Figures 8 and 9 respectively. It is believed the outer carbon coatings of the NPR-8 fuel deform and break during loading of the particles resulting in a discontinuity observed in the loading curve prior to reaching maximum stress. The significantly higher ultimate strength of the NPR-8 fuel is believed to be a result of this coating deformation and the subsequent redistribution of stress on the strong coating. It is, therefore, difficult to directly correlate crush strength with intrinsic strong coating strength since the strong coating of the NPR-5 and NPR-8 material should be essentially the same. However, the higher crush strength of the NPR-8 fuel does demonstrate that outer carbon coatings will increase the durability of fuel during handling.

\section{Radiography}

Positive copies of the tube assembly radiographic film from all assemblies are included in Figure 10. The radiographic films were used during the fabrication process to confirm the number of fuel beads inserted into each tube assembly and to confirm the post-loading particle integrity and stacking conditions. Both items of interest were readily confirmable using standard radiographic techniques.

\section{E. Corrosion}

The tube assemblies were visually inspected after corrosion testing of the completed assemblies for three (3) days in $680^{\circ} \mathrm{F}$ water. A uniform film was exhibited on all fourteen units (including spares) without indications of leakage or abnormalities in tube surface conditions. No unusual surface conditions were observed.

F. Photography

A representative photograph of an assembled holder is provided in Figure 11. 
TABLE 1

Summary of HTGR Fuel Particle Designs

\begin{tabular}{|c|c|c|}
\hline & NPR-8 & NPR-5 \\
\hline $\begin{array}{l}\text { Kernel: } \\
\text { Material } \\
\text { Diameter }(\mu \mathrm{m}) \\
\text { Density }(\% \mathrm{td}) \\
\text { Enrichment (\%) }\end{array}$ & $\begin{array}{l}\text { UCO } \\
195 \\
>93 \\
93.15\end{array}$ & $\begin{array}{l}\text { UCO } \\
195 \\
>93 \\
93.15\end{array}$ \\
\hline $\begin{array}{l}\text { Seal PyC: } \\
\text { Thickness (um) } \\
\text { Density (\%td) }\end{array}$ & $\begin{array}{l}1-5 \\
>87 \\
\end{array}$ & $\begin{array}{l}1-5 \\
>87 \\
\end{array}$ \\
\hline $\begin{array}{l}\text { Buffer PyC: } \\
\text { Thickness }(\mu \mathrm{m}) \\
\text { Density }(\% \mathrm{td})\end{array}$ & $\begin{array}{c}90-110 \\
44\end{array}$ & $\begin{array}{c}90-110 \\
44 \\
\end{array}$ \\
\hline $\begin{array}{l}\text { IPyC: } \\
\text { Thickness }(\mu \mathrm{m}) \\
\text { Density }(\% \mathrm{td})\end{array}$ & $\begin{array}{c}40-60 \\
87 \\
\end{array}$ & $\begin{array}{c}40-60 \\
87 \\
\end{array}$ \\
\hline $\begin{array}{l}\text { Strong Coating: } \\
\text { Material } \\
\text { Thickness }(\mu \mathrm{m}) \\
\text { Density (\%td) }\end{array}$ & $\begin{array}{c}\mathrm{SiC} \\
30-40 \\
98 \\
\end{array}$ & $\begin{array}{c}\mathrm{SiC} \\
30-40 \\
98 \\
\end{array}$ \\
\hline $\begin{array}{l}\text { OPyC: } \\
\text { Thickness }(u \mathrm{~m}) \\
\text { Density (\%td) }\end{array}$ & $\begin{array}{c}30-40 \\
87 \\
\end{array}$ & $\begin{array}{c}30-40 \\
87 \\
\end{array}$ \\
\hline $\begin{array}{l}\text { Seal PyC: } \\
\text { Thickness }(u m) \\
\text { Density }(\% t d)\end{array}$ & $\begin{array}{l}1-5 \\
>87\end{array}$ & $\begin{array}{c}\text { None } \\
-\end{array}$ \\
\hline $\begin{array}{l}\text { Protective PyC: } \\
\text { Thickness }(\mu \mathrm{m}) \\
\text { Density }(\% \mathrm{td})\end{array}$ & $\begin{array}{c}35-45 \\
50 \\
\end{array}$ & $\begin{array}{c}\text { None } \\
-\end{array}$ \\
\hline $\begin{array}{l}\text { Seal PyC: } \\
\text { Thickness }(\mu \mathrm{m}) \\
\text { Density }(\% \mathrm{td}) \\
\end{array}$ & $\begin{array}{l}1-5 \\
>87 \\
\end{array}$ & $\begin{array}{c}\text { None } \\
- \\
\end{array}$ \\
\hline Total Diam. (um) & -725 & $\sim 645$ \\
\hline $\mathrm{gm} \mathrm{U} \mathrm{U}^{235} / \mathrm{cc}$ bead & 0.17 & 0.24 \\
\hline
\end{tabular}




\section{TABLE 2}

\section{Outline of Steps Used in Fabrication of the GRIT-II HTGR Irradiation Test Specimens}

Outline A - Tubing Preparation

1. Receive tubing.

2. Confirm receipt of order and material certification.

3. Inspect representative sample (10\%) for
a. outside diameter
b. inside diameter
c. length

Record all data.

4. Engineering review data and release tubes for further processing.

5. Radiograph all tubes to show end weld shape and thickness. Record thickness.

6. Machine tubes to length.

7. Clean tubes.

8. Hold tubes for further processing. 
TABLE 2 (Cont'd)

\section{Outline B - Fuel Preparation/Evaluation and Tube Assembly Fabrication}

1. Clean and radiologically survey as clean all gloveboxes and equipment.

2. Receive finished material.

3. Tray sort material to remove non-spherical material.

4. Sieve material to obtain desired size.

5. Withdraw particle samples for loading into tube assemblies and for Alpha/Beta counting in chemistry and testing as "clean" material.

6. Survey all samples of the finished material as "clean" for transfer to the loading glovebox.

7. Review chemistry results with Radiological Control and Engineering (RC\&E) to release material for further processing.

8. Transfer samples to loading glovebox.

9. Sample on-size material for:
a. Metallographic Evaluation
b. Chemical Evaluation - Total Uranium and Isotopic
c. Particle Density
d. Particle Strength

10. Place stainless steel pin into bottom of tube.

11. Load "clean" sized fuel beads into tube.

12. Cap loaded tube with end closure.

13. Survey loaded Tube Assembly (T/A) as "clean".

14. Repeat steps 11-14 for each T/A.

15. Transfer samples to welding box.

16. Evacuate and backfill with 1 atmosphere helium.

17. TIG weld tube assemblies.

18. Machine weld area of tube assembly to finished size and shape. 
WAPD-TM-1633

Page 15

TABLE 2 (Cont'd)

Outline B - Fuel Preparation/Evaluation and Tube Assembly Fabrication (Cont'd)

19. Radiograph each $T / A$ to show internal particle location and weld condition of welds.

20. Engineering review radiographs to confirm fuel bead number and condition. Release $T / A$ 's for further processing.

21. Weigh $T / A^{\prime}$ 's assemblies. Record results.

22. Helium leak test welded T/A's. Reject $T / A^{\prime}$ 's indicating leaks. Record results on Helium Leak Data Form.

23. Corrosion Test $T / A^{\prime}$ s for 3 days in $680^{\circ} \mathrm{F}$ water.

24. Weight $T / A$ 's. Record results.

25. Engineers visually inspect $T / A^{\prime}$ s.

26. Measure overall length. Record results.

27. Measure minimum and maximum diameters. Record results.

28. Photograph tube assemblies.

Outline C - GRIT-II Holder Preparation and Specimen Assembly

1. Obtain Zr-4 GRIT-II D-Pocket Adapters (holders).

2. Place $T / A$ 's into holders.

3. Crimp holders to secure $T / A^{\prime}$ 's in place.

4. Inspect crimping detents.

5. Photograph assembled GRIT-II holders.

6. Package completed holders for shipment to ECF. 
WAPD-TM-1633

Page 16

\section{TABLE 3}

Materials for HTGR Irradiation Test Tube Assemblies and GRIT-Il Holders

Material

Fuel

NPR-8 Fuel Beads

NPR-5 Fuel Beads
Use

T/A's 88769-301

Thru 306

T/A's 8769-401

Thru 408

Tubing

304 Stainless Steel $.078^{\prime \prime}$ Dia. $\times .038^{\prime \prime}$ ID $.078^{\prime \prime}$ Dia. $\times .046^{\prime \prime}$ ID

P.O. 73-821473

All T/A'S

Enclosures and Pins

$1 / 8$ Inch Diameter

P.O. 73-604780

All $T / A$ 's

308 Stainless Steel

Holders

GRIT-II D-Pocket

P.O. 73-816920

76-9980

$76-9981$

$76-9982$

*No Bettis purchase order, material received from General Atomics under subcontract No. C91-103681. 


\section{TABLE 4}

HTGR Irradiation Test Tube Assemblies As-Built Data

\begin{tabular}{|c|c|c|c|c|c|c|}
\hline$T / A$ & Fuel & $\begin{array}{l}\text { Number of } \\
\text { Particles }\end{array}$ & $\begin{array}{l}\text { Finished Tube } \\
\text { Length (in.) }\end{array}$ & $\begin{array}{l}\text { Min. Dia. } \\
\text { (in.) }\end{array}$ & $\begin{array}{l}\text { Max. Dia. } \\
\text { (in.) }\end{array}$ & $\begin{array}{l}T / A \\
\text { Weight (gm) }\end{array}$ \\
\hline $8769-301$ & NPR-8 & 130 & 4.84545 & .0767 & .0775 & 2.29840 \\
\hline $8769-302$ & NPR-8 & 130 & 4.84571 & .0768 & .0771 & 2.30221 \\
\hline $8769-303$ & NPR-8 & 130 & 4.84468 & .0768 & .0770 & 2.30575 \\
\hline $8769-304$ & NPR-8 & 130 & 4.84330 & .0767 & .0773 & 2.32541 \\
\hline $8769-305$ & NPR-8 & 130 & 4.84593 & .0767 & .0772 & 2.30646 \\
\hline $8769-306$ & NPR-8 & 130 & 4.84506 & .0766 & .0779 & 2.33421 \\
\hline $8769-401$ & NPR-5 & 155 & 4.84549 & .0768 & .0770 & 2.28899 \\
\hline $8769-402$ & NPR-5 & 155 & 4.84439 & .0767 & .0772 & 2.30679 \\
\hline $8769-403$ & NPR-5 & 155 & 4.84483 & .0768 & .0770 & 2.29519 \\
\hline $8769-404$ & NPR-5 & 155 & 4.84822 & .0768 & .0783 & 2.29412 \\
\hline $8769-405$ & NPR-5 & 155 & 4.84832 & .0768 & .0778 & 2.31751 \\
\hline $8769-406$ & NPR-5 & 155 & 4.84727 & .0767 & .0770 & 2.30534 \\
\hline $8769-407$ & NPR-5 & 155 & 4.84996 & .0767 & .0773 & 2.30317 \\
\hline $8769-408$ & NPR-5 & 155 & 4.84253 & .0766 & .0780 & 2.29493 \\
\hline
\end{tabular}


WAPD-TM-1633

Page 18

\section{TABLE 5}

GRIT-II Holder and Tube Assembly Assignments

\begin{tabular}{|c|c|c|c|c|}
\hline $\begin{array}{c}\text { GRIT-1 } \\
\text { Holder No. }\end{array}$ & $\begin{array}{l}\text { Position } \\
\text { Number }\end{array}$ & $\begin{array}{c}\text { Tube } \\
\text { Assembly No. }\end{array}$ & Fuel Type & $\begin{array}{c}\text { Predicted } \\
\text { Range of } \\
\mathrm{U}^{235} \text { Burnup }\end{array}$ \\
\hline $76-9980$ & $\begin{array}{l}3 . \\
4 . \\
5 . \\
6 .\end{array}$ & $\begin{array}{l}8769-301 \\
8769-401 \\
8769-302 \\
8769-402\end{array}$ & $\begin{array}{l}\text { NPR-8 } \\
\text { NPR-5 } \\
\text { NPR-8 } \\
\text { NPR-5 }\end{array}$ & $20-30 \%$ \\
\hline $76-9981$ & $\begin{array}{l}3 . \\
4 . \\
5 . \\
6 .\end{array}$ & $\begin{array}{l}8769-303 \\
8769-403 \\
8769-304 \\
8769-404\end{array}$ & $\begin{array}{l}\text { NPR-8 } \\
\text { NPR-5 } \\
\text { NPR-8 } \\
\text { NPR-5 }\end{array}$ & $45-55 \%$ \\
\hline $76-9982$ & $\begin{array}{l}3 . \\
4 . \\
5 . \\
6 .\end{array}$ & $\begin{array}{l}8769-305 \\
8769-405 \\
8769-306 \\
8769-406\end{array}$ & $\begin{array}{l}\text { NPR-8 } \\
\text { NPR-5 } \\
\text { NPR-8 } \\
\text { NPR-5 } \\
\end{array}$ & $70-80 \%$ \\
\hline $\begin{array}{l}\text { Spare } \\
\text { Assemblies }\end{array}$ & - & $\begin{array}{l}8769-407 \\
8769-408\end{array}$ & $\begin{array}{l}\text { NPR-5 } \\
\text { NPR-5 }\end{array}$ & $N / A$ \\
\hline
\end{tabular}


WAPD-TM-1633

Page 19

TABLE 6

Element and Isotope Weights for HTGR Tube Assembly Holders

$\frac{\begin{array}{c}\text { Specimen } \\ \text { Identity }\end{array}}{76-9980}$

76-9981

$76-9982$

\begin{tabular}{c}
$\begin{array}{c}\text { Tube Assy } \\
\text { Identities }\end{array}$ \\
\hline $8769-301$ \\
$8769-401$ \\
$8769-302$ \\
$8769-402$
\end{tabular}

8769-303

$8769-403$

8769-304

8769-404

8769-305

8769-405

8769-306

8769-406

\begin{tabular}{c}
$\begin{array}{c}\text { Enrichment } \\
\text { (Percent) }\end{array}$ \\
\hline 93.15 \\
93.15 \\
93.15 \\
93.15
\end{tabular}

93.15

93.15

93.15

93.15

93.15

93.15

93.15

93.15

\begin{tabular}{c}
$\begin{array}{c}\text { Element } \\
\text { Wgt. (gms) }\end{array}$ \\
\hline .00481 \\
.00557 \\
.00481 \\
.00557
\end{tabular}

.00481

.00557

.00481

.00557

.00481

.00557

.00481

.00557
Isotope

Wgt. (gms)

.00448

.00519

.00448

.00519

.00448

.00519

.00448

.00519

.00448

.00519

.00448

.00519 


\section{TABLE 7}

As Fabricated Fuel Bead Attributes - GRIT-\| Test

Attribute

\begin{tabular}{cccc} 
NPR-5 & & NPR-8 \\
\cline { 1 - 1 } 655 & & & 760 \\
& & & \\
$640-670$ & & $750-770$ \\
1.021 & & 1.021 \\
UCO & & UCO \\
SiC & & SiC \\
& & \\
& & \\
- & & - \\
102 & & 102 \\
53 & & 53 \\
35 & & 35 \\
39 & & 39 \\
- & & 47 \\
200 & & 200 \\
$11.46^{*}$ & & $9.40^{*}$ \\
93.13 & & 93.14
\end{tabular}

10. Isotopic Weight Percent

\section{U-234}

$\mathrm{U}-236$

1.02

1.02

U-238

0.403

0.404

5.45

5.44

11. Coated Fuel Bead Density ( $/ \mathrm{cc}$ )

2.20

1.81

12. Average Coated Crush Strength (Lbs)

6.45

9.89

13. Grams $U^{235} /$ Fuel Bead

$3.65 \times 10^{-5}$

$3.65 \times 10^{-5}$

14. Grams $U^{235} / \mathrm{cc}$

0.25

0.16

15. Fuel Stack Height in Tube (in.)

3.550

3.731

16. Number of Beads per Tube

155

130

Vendor Certification 
WAPD-TM-1633

Page 21

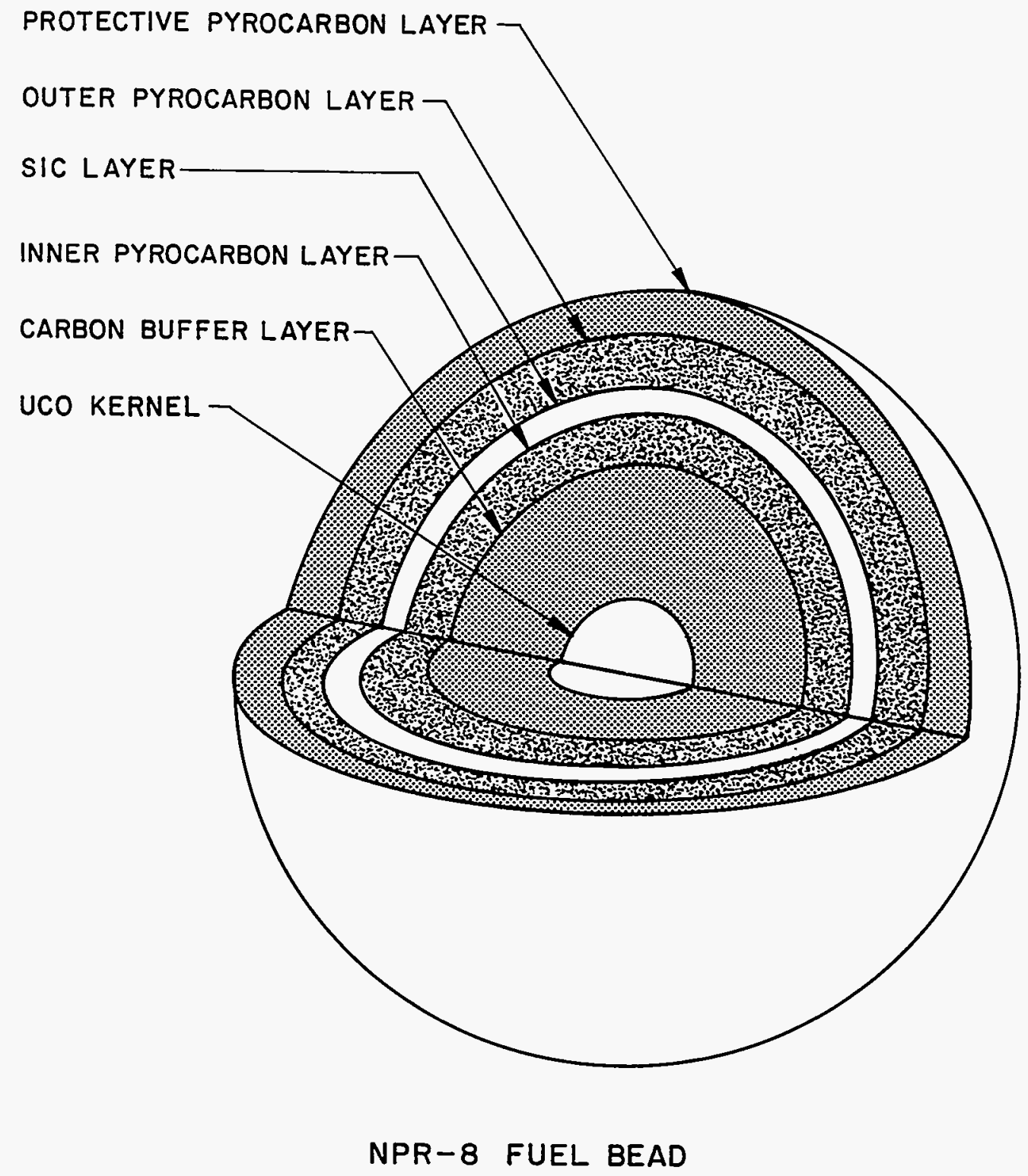

Schematic Illustration of NPR-8 HTGR Fuel Bead

Figure 1 
WAPD-TM-1633

Page 22

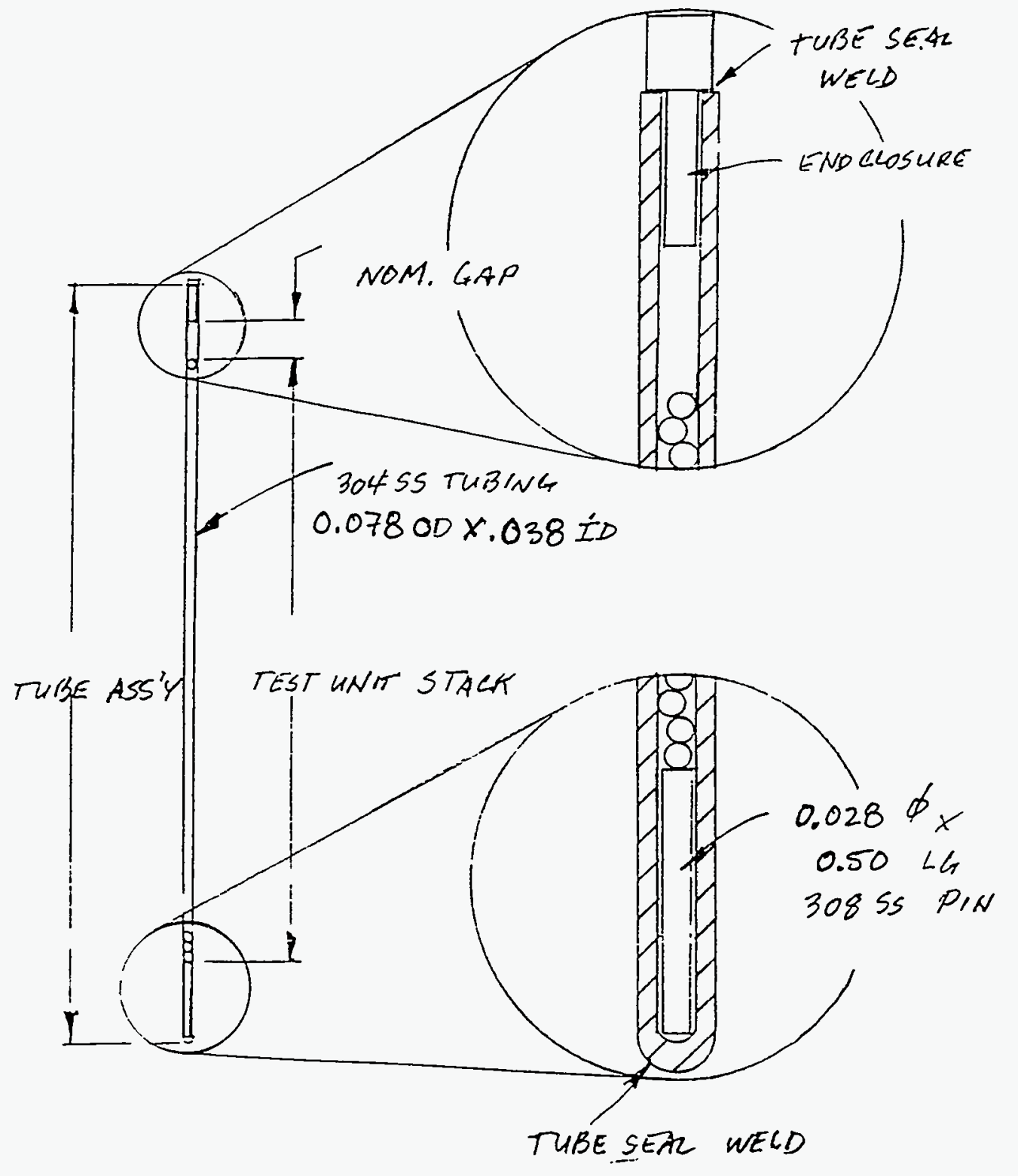

HTGR IRRACATION TEST TUBE ASSEMBLH

WTE: ALL DIMENSIONS IN INGHES

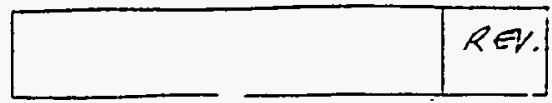

Drawing of Single Assembled Fuel Tube

Figure 2 

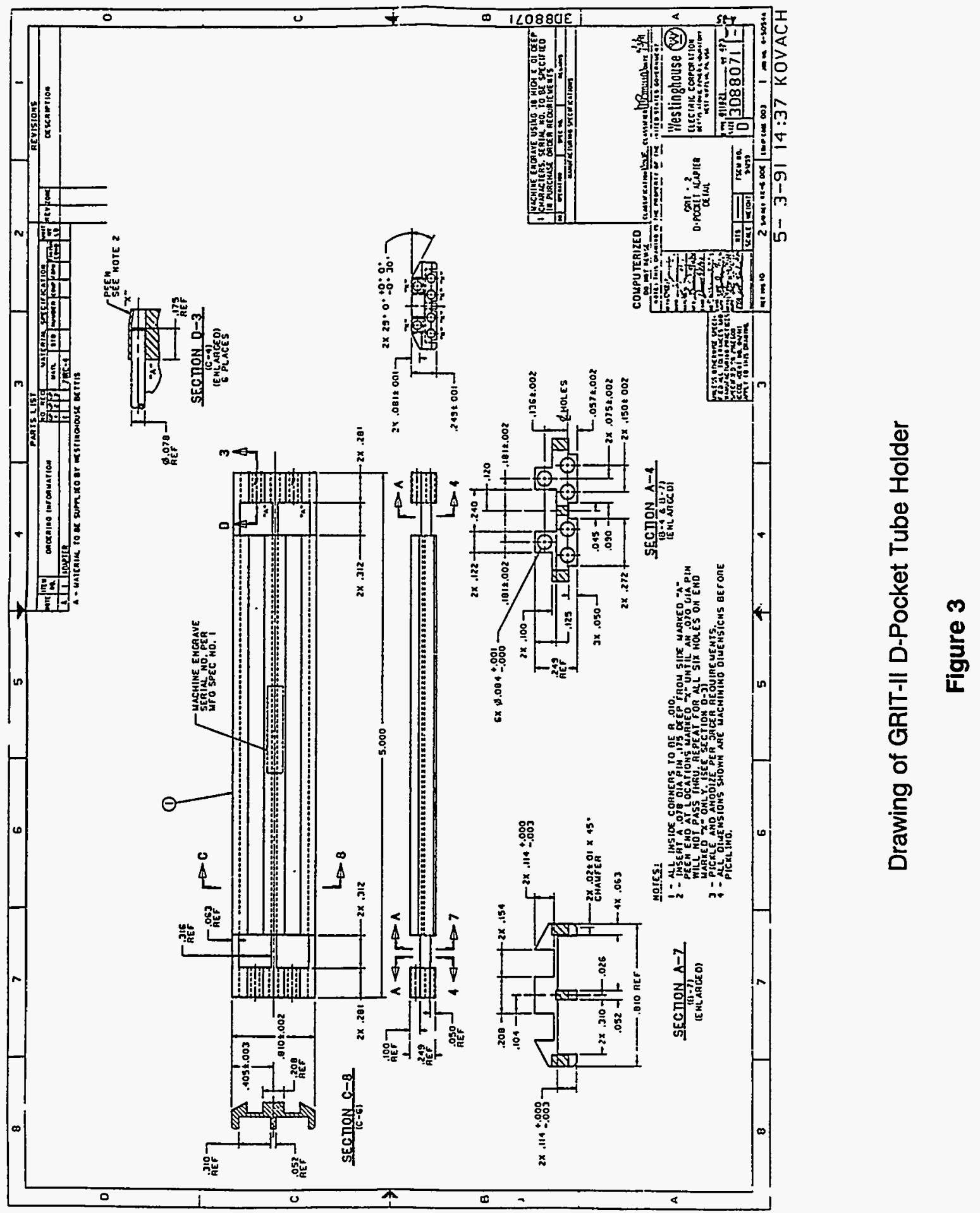
Page 24

Fission Gas Pressure vs. Fuel Burnup (1000 F)

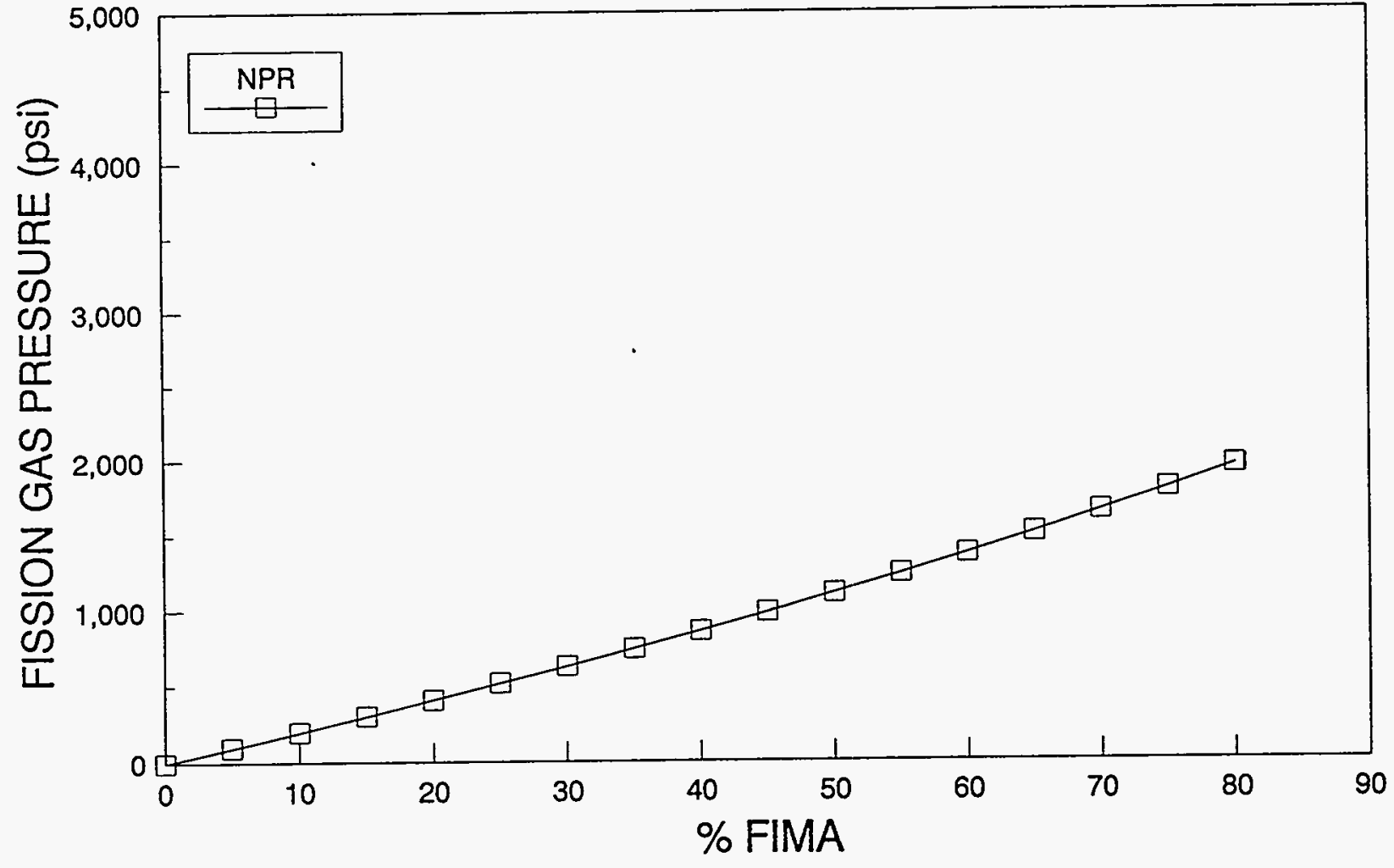

Fission Gas Pressure Generated in NPR Fuel Beads

Figure 4 
WAPD-TM-1633

Page 25

\section{Coating Stress vs. Fuel Burnup} (1000 F)

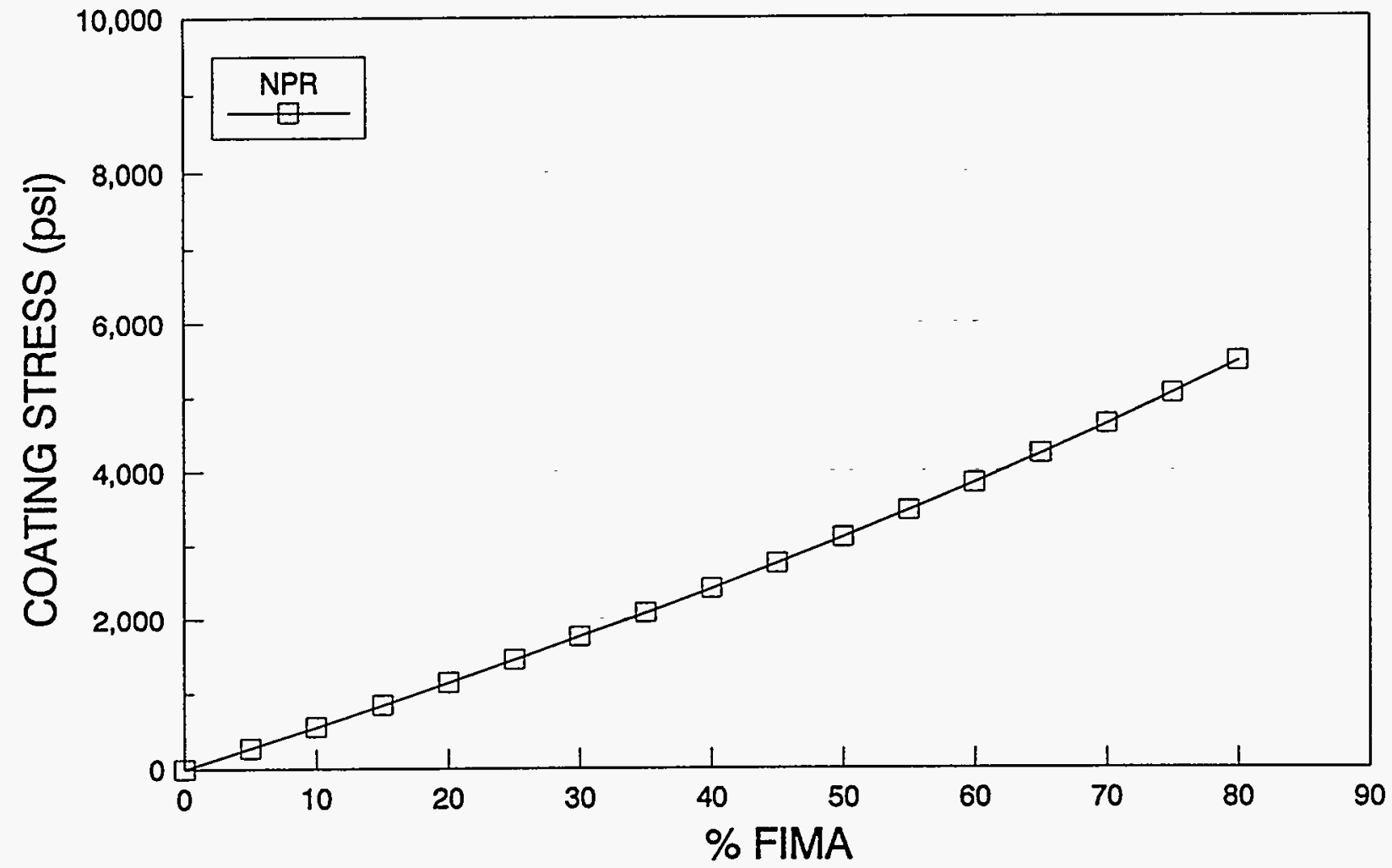

Maximum Hoop Stress in the Outer Coating of NPR HTGR Fuel Beads

Figure 5 
WAPD-TM-1633

Page 26

$(50 X)$

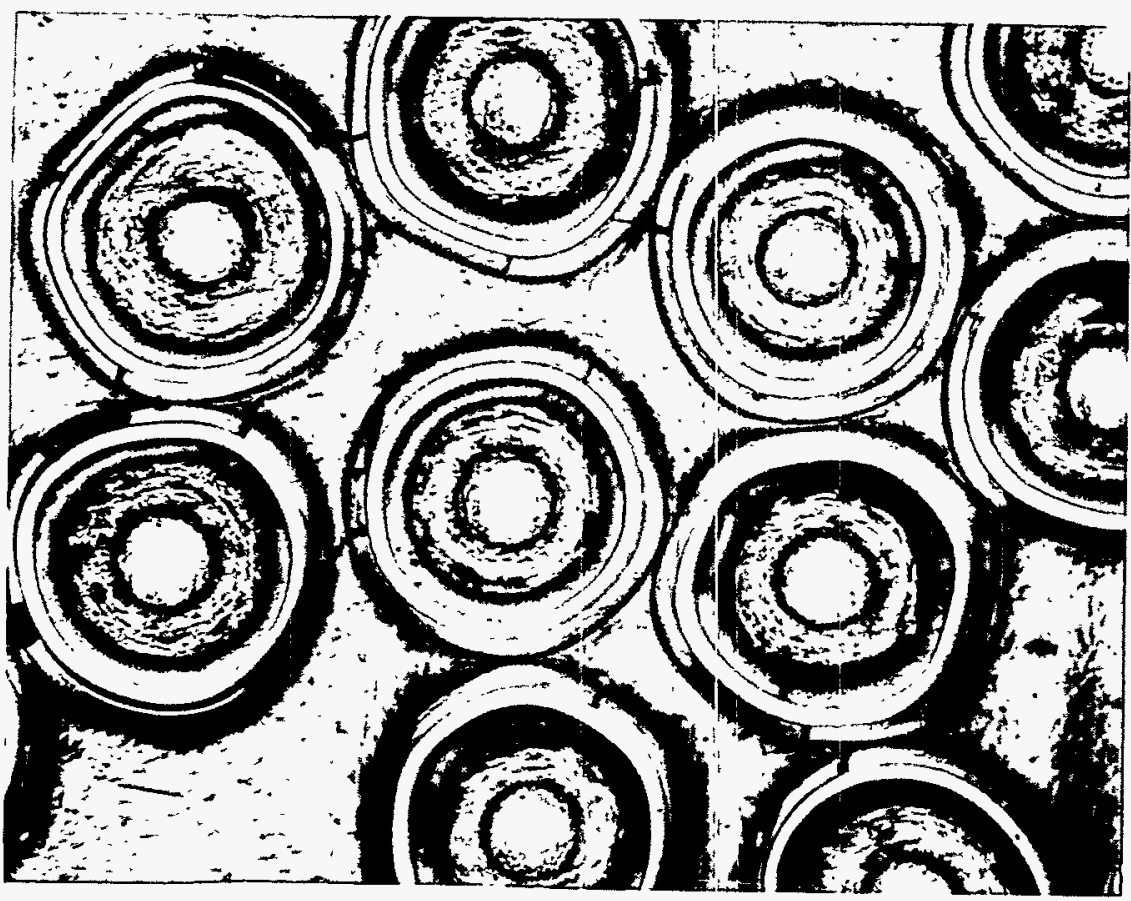

(200X)

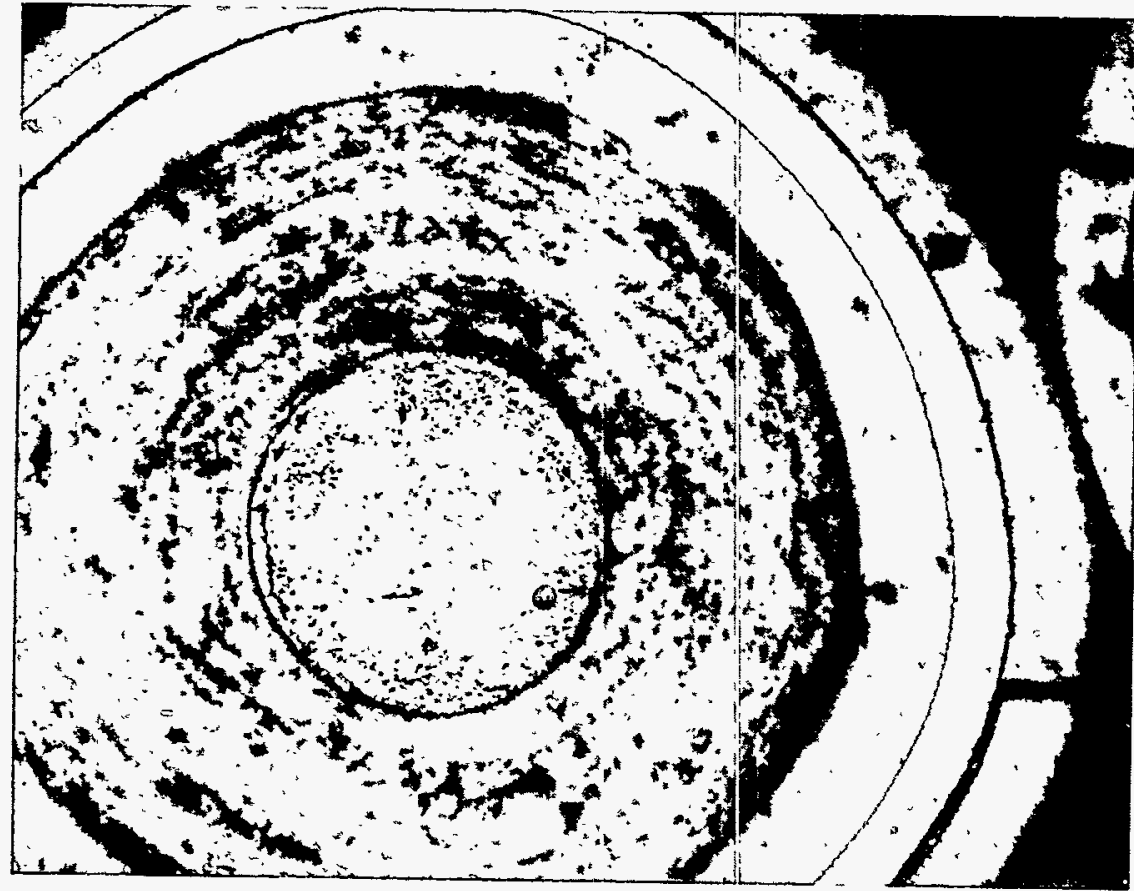

Representative Metallography From As Received

NPR-5 Fuel Beads

Figure 6 
$(200 X)$

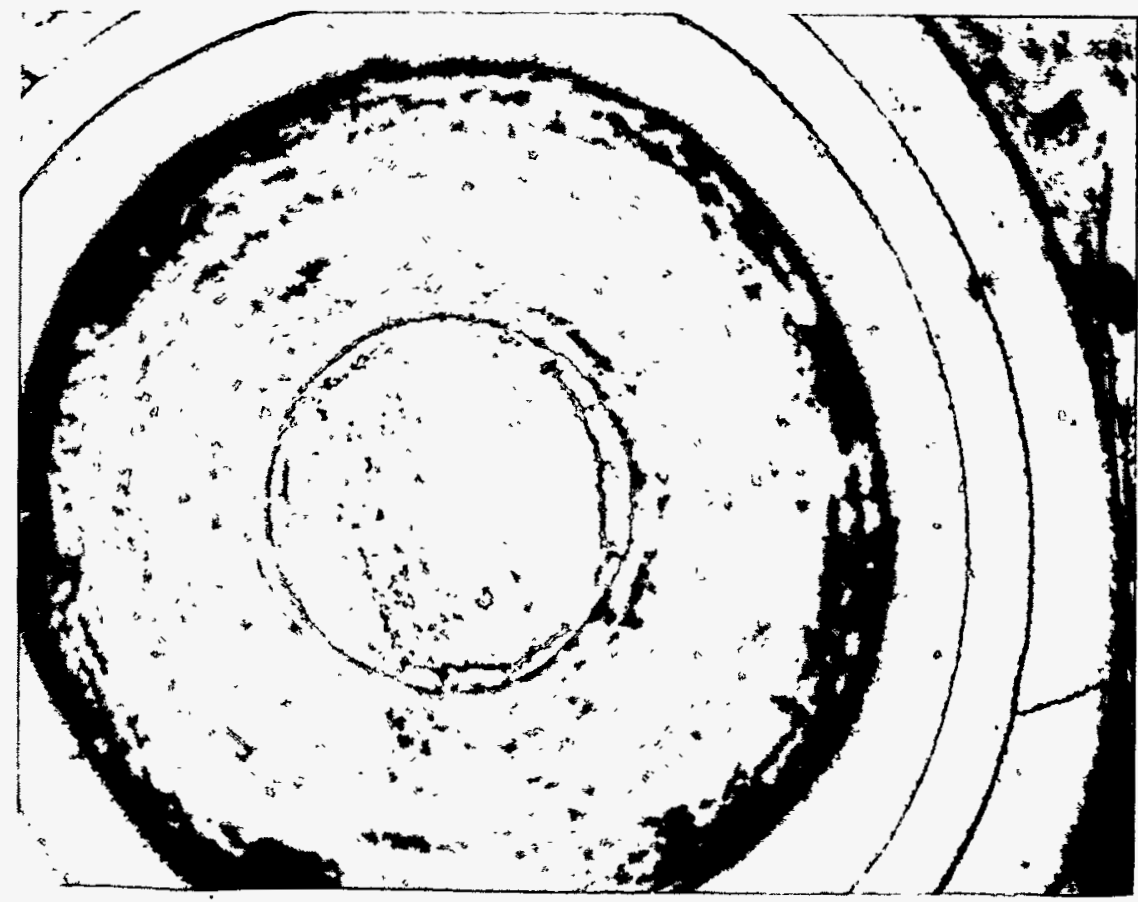

$(500 X)$

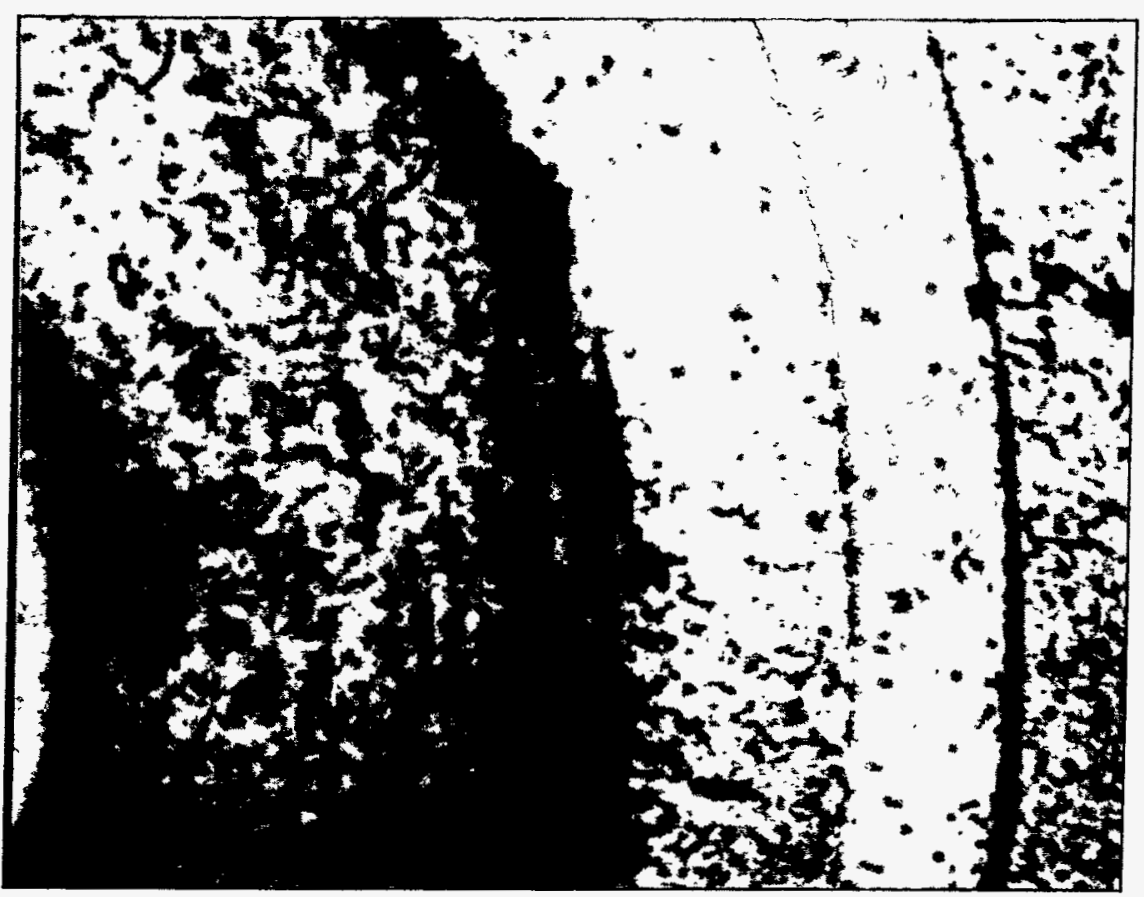

Representative Metallography From As Received NPR-5 Fuel Beads

Figure 6

(Continued) 
WAPD-TM-1633

Page 28

$(50 x)$

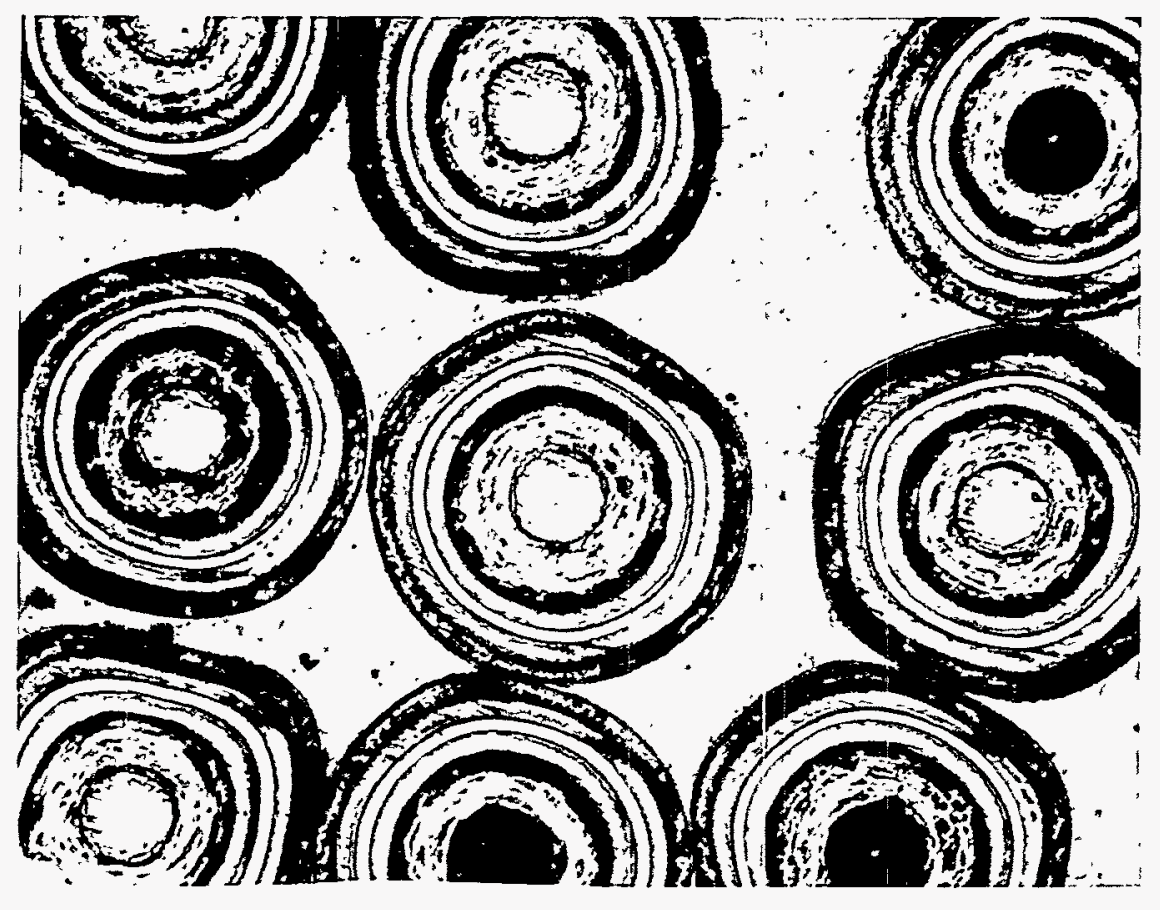

$(200 X)$

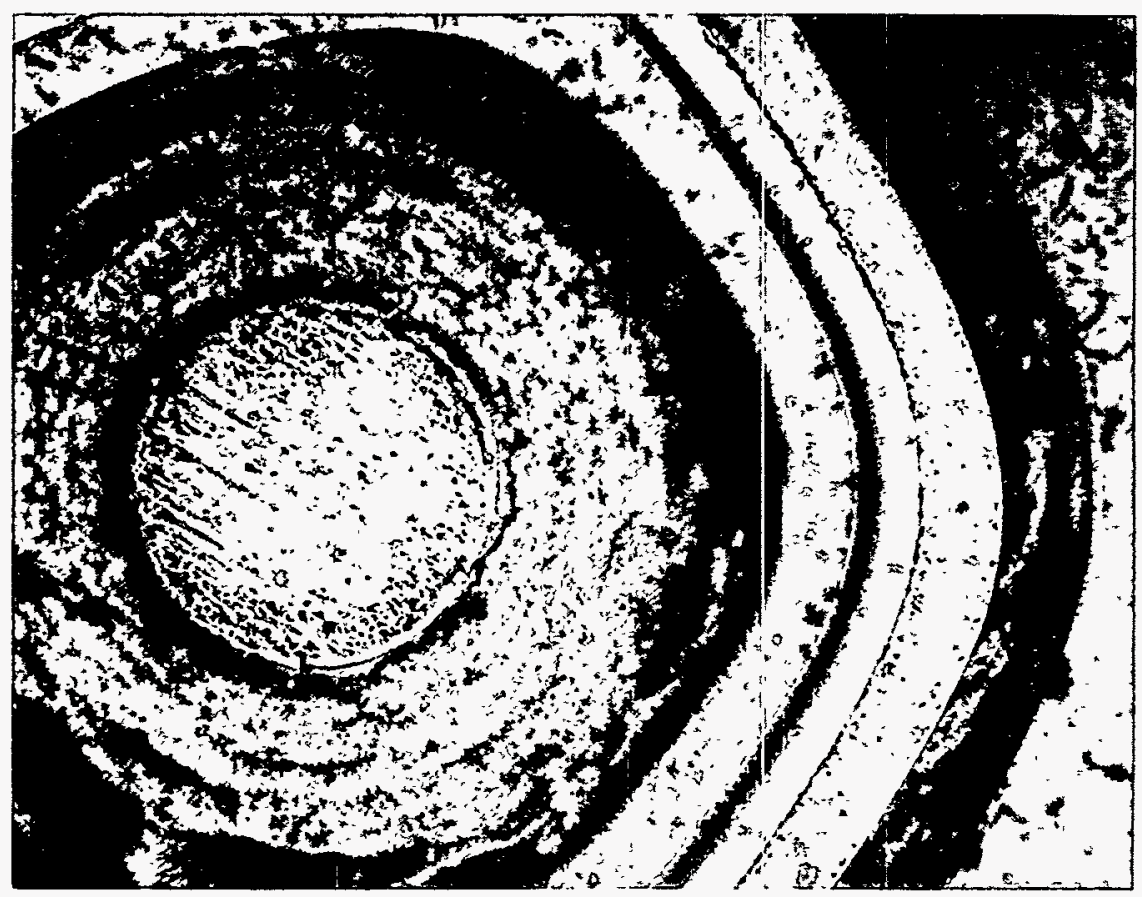

Representative Metallography From As Received NPR-8 Fuel Beads 
$(200 X)$

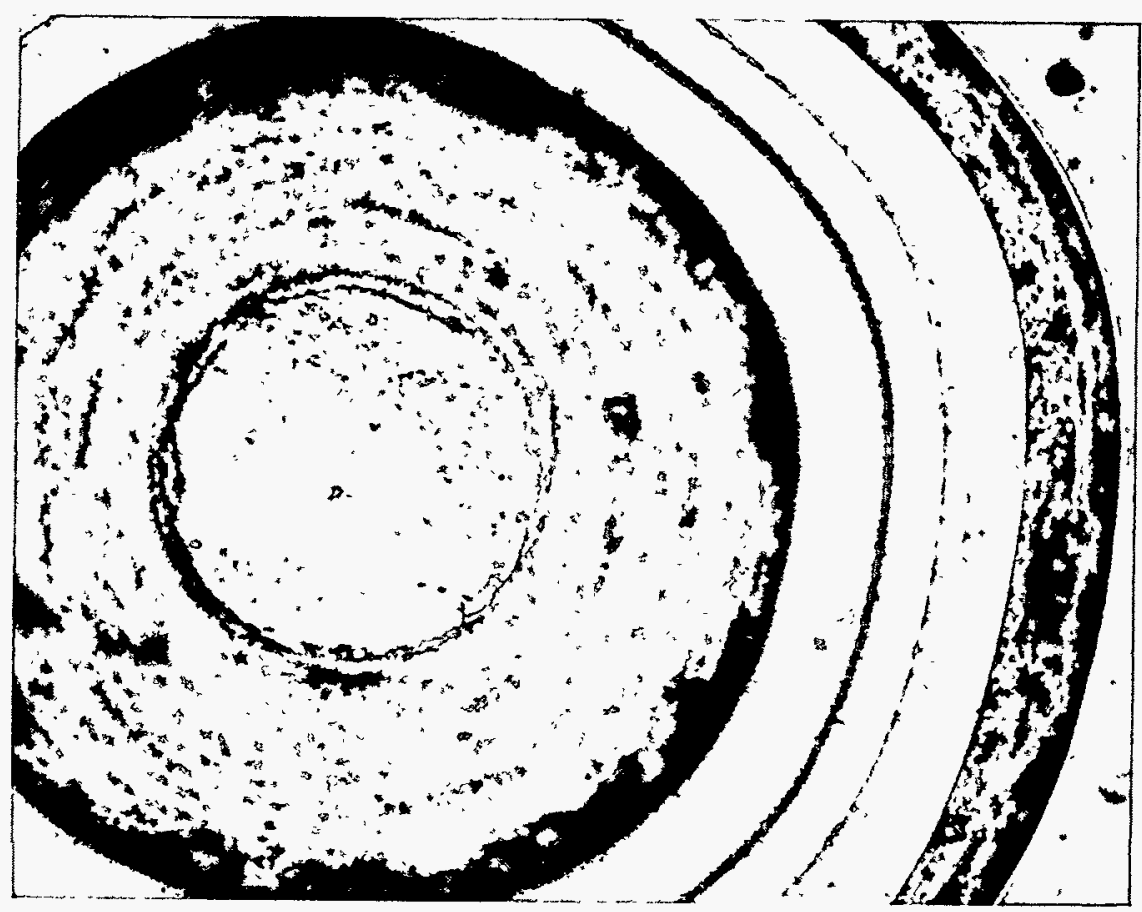

$(500 X)$

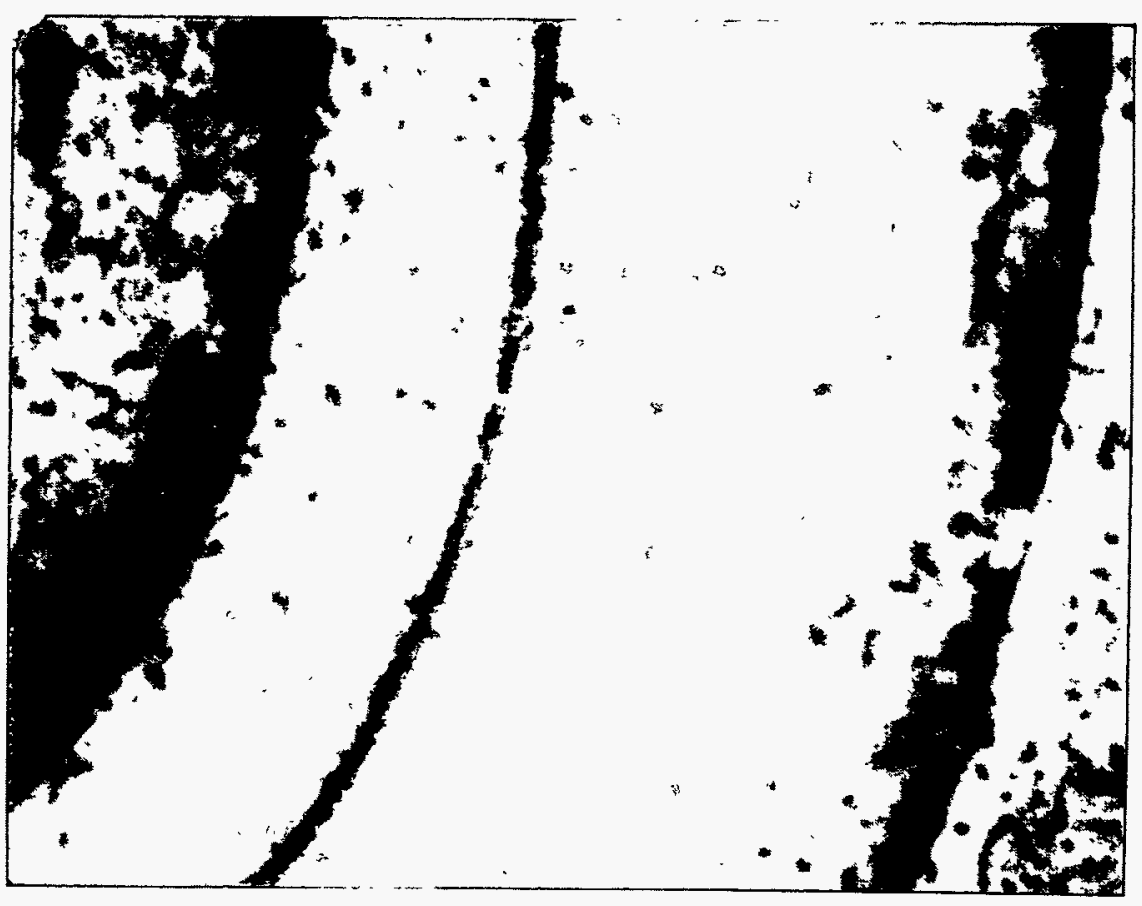

Representative Metallography From As Received NPR-8 Fuel Beads

Figure 7

(Continued) 


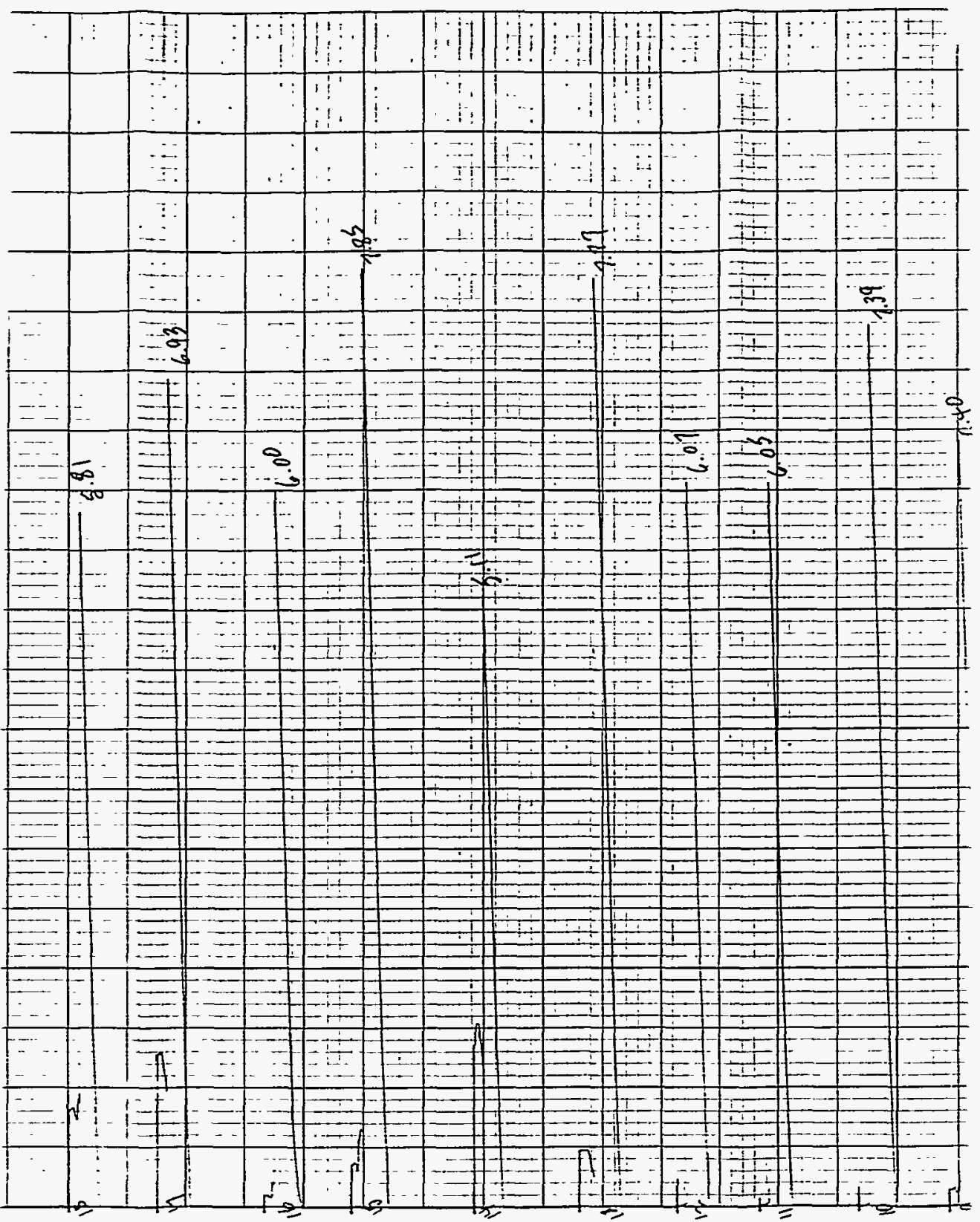

\section{Increasing Load} (2"/min. Chart Speed)

Representative Loading Curves from NPR-5 Fuel Used to Determine Crush Strength

Figure 8 


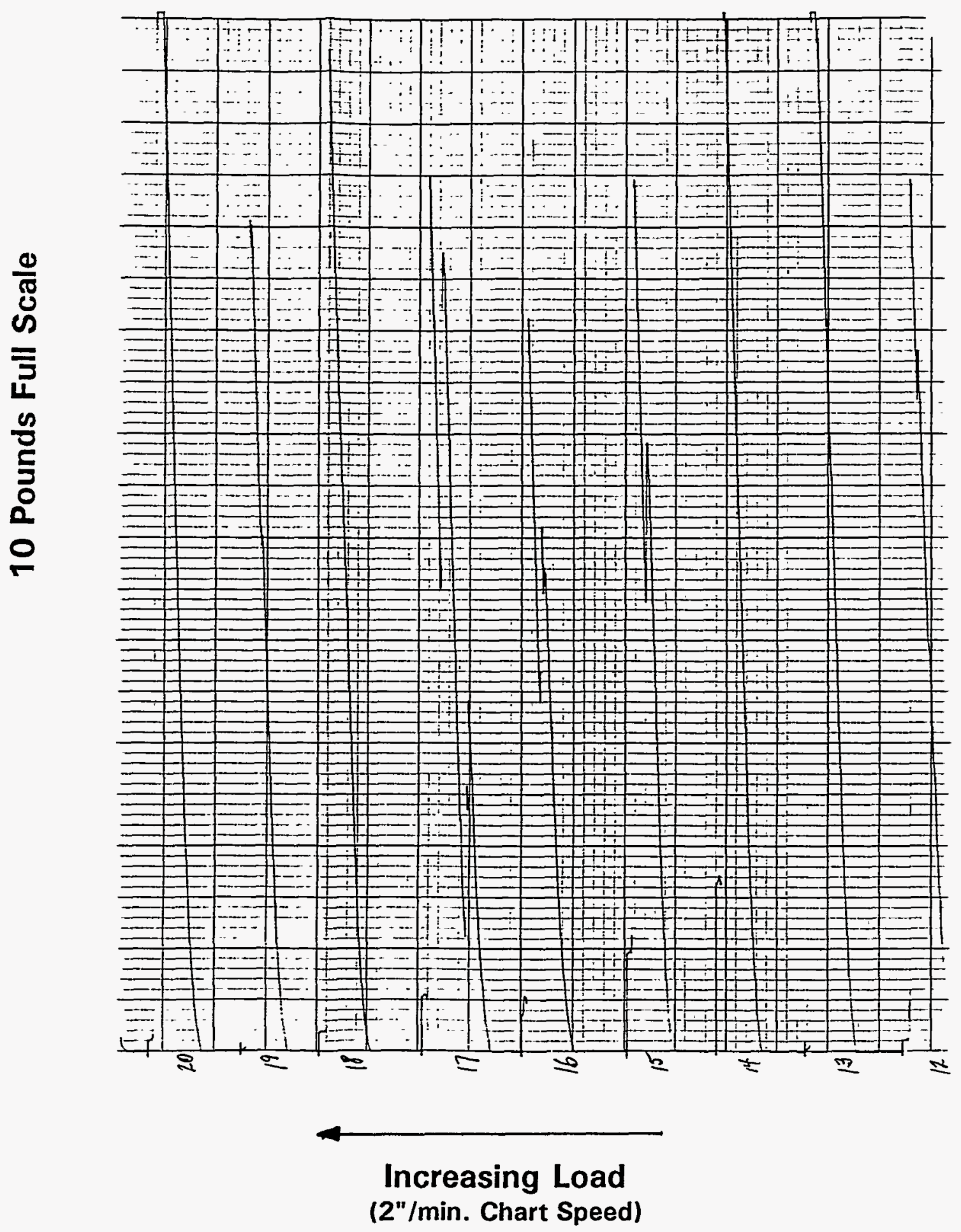

Representative Loading Curves from NPR-8 Fuel Used to Determine Crush Strength

Figure 9 


\section{RC918769 SN1

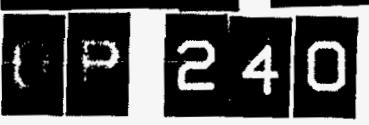
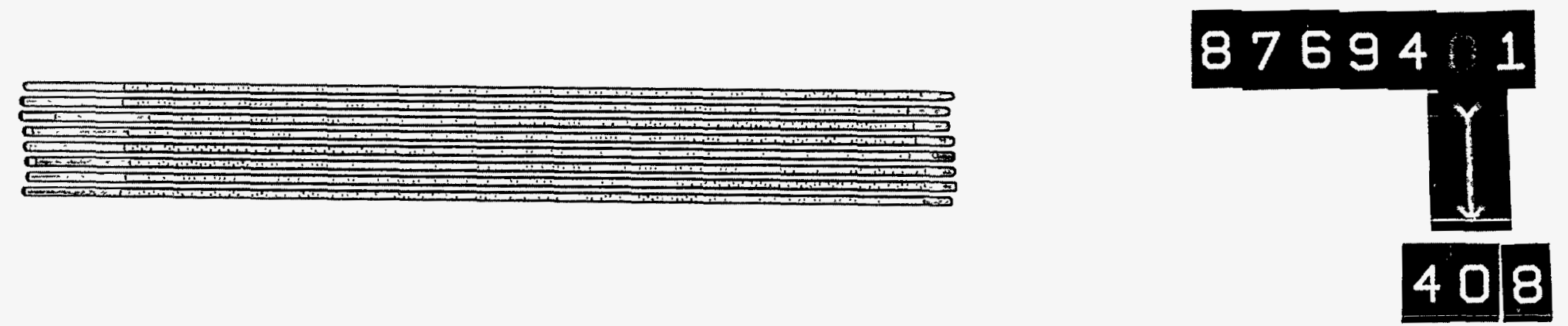

Radiograph (Positive of Tube Assemblies

Containing NPR-5 Fuel (S/N's 8769-401 thru 8769-408)

Figure 10 


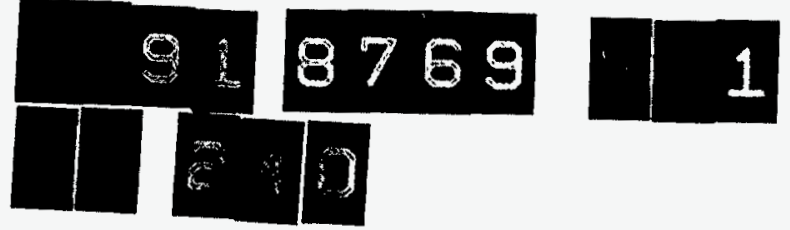
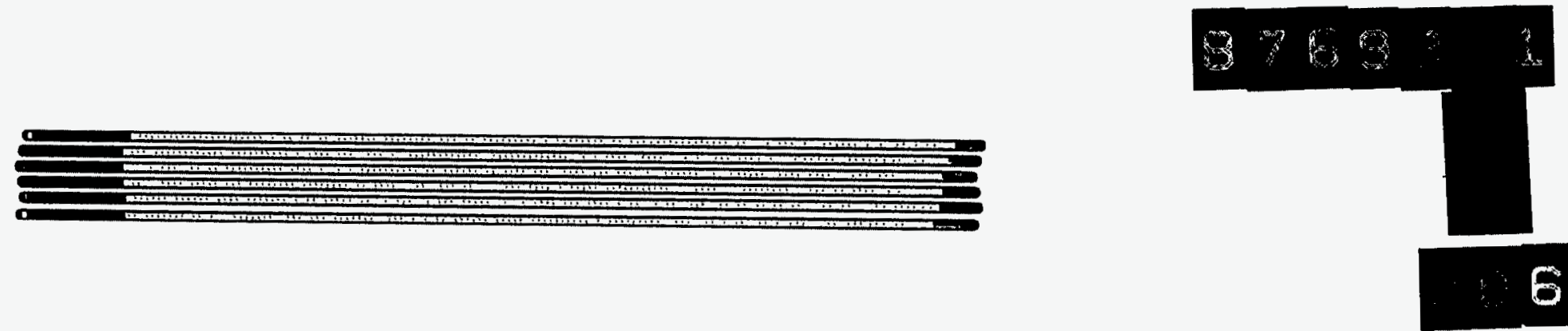

Radiograph (Positive) of Tube Assemblies Containing NPR-8 Fuel (S/N's 8769-301 thru 8769-306)

Figure 10

(Continued) 
WAPD-TM-1633

Page 34
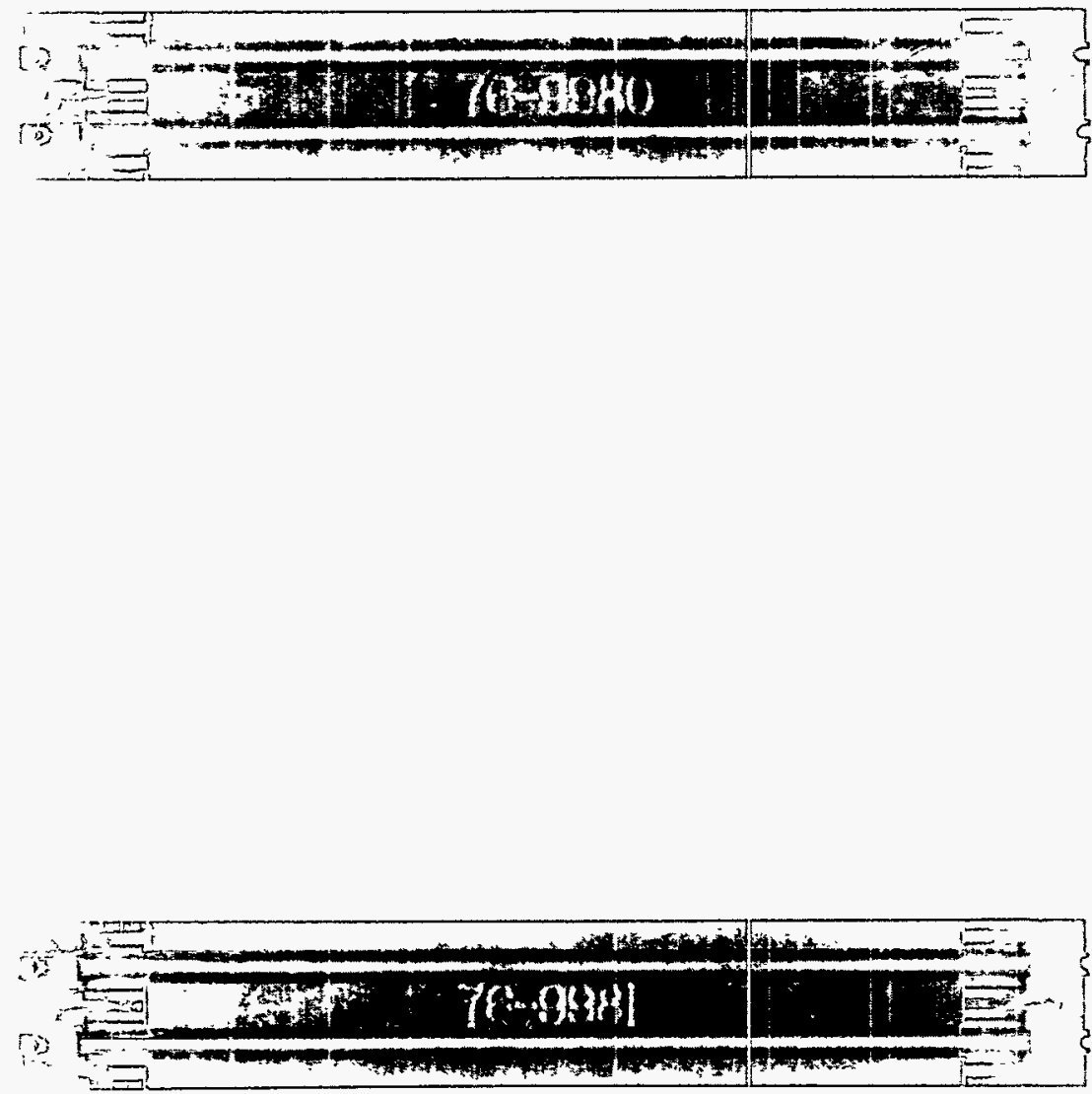

Assembled HTGR GRIT-\| Fueled Specimens 
WAPD-TM-1633

Attachment 1

Page 1

ELECTRON MICROPROBE EXAMINATION OF

HIGH TEMPERATURE GAS REACTOR (HTGR) FUEL BEADS

F. W. Page

J. L. Hollenbeck 
WAPD-TM-1633

Attachment 1

Page 2

Intentionally Blank 
WAPD-TM-1633

Attachment 1

Page 3

\section{ELECTRON MICROPROBE EXAMINATION OF HIGH TEMPERATURE GAS REACTOR (HTGR) FUEL BEADS}

One mounted sample of NPR-8 High Temperature Gas Reactor (HTGR) fuel was submitted for examination using Electron Microprobe techniques. The fuel beads consisted of a uranium "oxycarbide" (UCO) kernel and various layers of CVD-deposited carbon, pyrocarbon, and silicon carbide (Figure 1). Other fuel beads from the same fuel lot as the sample are scheduled for insertion into the Advanced Test Reactor (ATR) as part of the Gas Reactor Irradiation Test (GRIT-II). The Microprobe Lab was requested to obtain X-ray images for the samples as part of the initial characterization of HTGR fuel materials. The results will subsequently be compared with data from post-irradiation examinations.

The sample was coated with carbon to provide an electrically conductive surface. Low magnification optical photomicrographs were first obtained for the sample. The photomicrographs show the majority of the fuel beads in the sample (Figures 2) as well as the two fuel beads that were examined by energy dispersive X-ray spectrometry (EDS) and X-ray imaging (Figures 3 and 4). The EDS system is capable of detecting elements with atomic numbers $\geq 6$ (C through $U)$. The spectra were recorded while the electron beam was rapidly rastered over areas ranging in size from $700 \mu$ by $700 \mu$ ( 27.6 mils by $\sim 27.6$ mils) to $850 \mu$ by $850 \mu$ ( $\sim 33.5$ mils by $\sim 33.5$ mils). The approximate location of the areas analyzed by EDS are shown in Figure 5.

The results are presented as Spectra 1 through 10. $\mathrm{Al}, \mathrm{C}, \mathrm{O}, \mathrm{Si}, \mathrm{U}, \mathrm{Zr}$, and possibly $\mathrm{S}$ were detected in one or more of the areas. No other elements were detected. Small area EDS spectra for each of the fuel bead layers and for the mounting material (Spectra 1 through 8; suggested that the $S$ detected in the carbon buffer layer and the protective pyrocarbon layer (Spectra 3 and 7, respectively) may be from the mounting material. Mounting material and grinding/polishing compounds often become embedded along material interfaces and in surface depressions during metallographic preparation. Both the carbon buffer layer (Spectrum 3) and the protective pyrocarbon layer (Spectrum 7) have rough surfaces and are likely to entrap material.

Secondary electron and $X$-ray images were obtained for two separate fuel beads in the sample mount. In X-ray imaging, an element's X-ray intensity, as measured using wavelength dispersive X-ray spectrometry (WDS), is used to modulate the brightness of a photographic CRT as the electron beam is rastered over an area on the sample. Areas of high elemental concentration are brighter than areas of low elemental concentration on the resultant X-ray images.

The results are presented as Figures 6 and 7 . Several features should be noted.

1. Two C X-ray images were obtained for the sample: one using a medium speed, medium contrast Polaroid film (Type 52) and another using a high speed, high contrast Polaroid film (Type 57). The former is used to show the variation in C X-ray intensity within the various carbon layers; the latter is used to show the presence of low levels of $C$.

2. Al, O, and Si were detected along the interfaces between the various layers and in surface depressions. $\mathrm{Al}_{2} \mathrm{O}_{3}$ and $\mathrm{SiC}$ are two grinding/polishing compounds that are commonly used to prepare metallographic mounts. These compounds often become 
embedded along material interfaces and in depressions in the mount's surface during metallographic preparation.

3. Except for the $\mathrm{Al}, \mathrm{O}$, and $\mathrm{Si}$ surface contamination mentioned above, all of the layers appear to have compositions that are consistent with their nominal chemistries as stated in Figure 1.

4. Localized decreases in X-ray intensity are found in several areas (e.g., in the C X-ray images near the interfaces between the carbon buffer layers and the inner pyrocarbon layer of sample). These decreases in X-ray intensity are due to topographic effects in which the $X$-rays generated in surface depressions are absorbed by the surrounding material. These decreases in X-ray intensity do not necessarily represent decreases in elemental concentration.

$\mathrm{C}$ and $\mathrm{O}$ are heterogeneously distributed towards the center of the UCO kernel in Figure 6. To investigate thus further, secondary electron and backscattered electron images were obtained for the fuel kernel.

Secondary electron, backscattered electron, and X-ray images were obtained for the kernel shown in Figure 8. The results are presented as Figure 9. Several features should be noted.

1. $\mathrm{Al}, \mathrm{Si}$, and some $\mathrm{C}$ and $\mathrm{O}$ were detected in the holes and surface depressions shown in the secondary electron images. This material is probably mounting material and $\mathrm{Al}_{2} \mathrm{O}_{3}$ and $\mathrm{SiC}$ grinding/polishing compounds that became embedded in these holes and surface depressions during metallographic preparation of the mounts.

2. $C$ and $O$ were heterogeneously distributed in the UCO kernel (Figure 9). The lightcolored regions in the backscattered electron images were comprised primarily of $\mathrm{C}$ and $U$, possibly as uranium carbide, whereas the dark-colored regions contain $U$ and $O$, possibly as uranium oxide. The small amount of $C$ detected in the dark-colored regions could be a constituent of the fuel bead or may be $\mathrm{C}$ from the carbon coating.

EDS spectra were obtained for both the "light-colored" and "dark-colored" phases in Figure 8. The results (Spectra 9 and 10 ) show that the light-colored phase contains primarily $U$ and $C$ whereas the dark-colored phase contains $\mathrm{U}, \mathrm{C}$, and $\mathrm{O}$.

Finally, secondary electron, backscattered electron, and/or X-ray images were obtained for the SiC layer of the samples. The results are presented as Figure 10. Both of the SiC layers examined appear to be uniform without any significant cracks, porosity, or other defects. The one linear indication of the $\mathrm{SiC}$ layer of Figure 10 appears to be a scratch from the metallographic preparation.

In summary, the Electron Microprobe was used to examine a sample of High Temperature Gas Reactor (HTGR) fuel. The results indicate that all of the layers have compositions that are consistent with their nominal chemistries. Al, $\mathrm{O}$, and $\mathrm{Si}$ were found along the interfaces between layers and in surface depressions. These elements are believed to be mounting material and grinding/polishing compounds, such as $\mathrm{Al}_{2} \mathrm{O}_{3}$ and $\mathrm{SiC}$, that became embedded along the interfaces and in surface depressions during metallographic preparation of the mounts. Each of the uranium 'oxycarbide' kernels consist of a multi-phase "core" surrounded by an annulus of material having a more uniform composition. The "core" contained two phases: one containing both $U$ and $\mathrm{C}$, possibly as uranium carbide; the other containing $U$, 
$\mathrm{O}$, and $\mathrm{C}$, possibly as uranium oxide or a uranium/oxygen/carbon compound. The presence of $C$ in the latter $U / O / C$ phase may be due to the $C$ coating that was applied to ensure an electrically conductive surface. The annulus of material surrounding the "core" appears to be composed of the U/O/C material. Finally, the results for the SiC layers show that the SiC layers are uniform, without any evidence of cracks, porosity, or multiple layers. 
WAPD-TM-1633

Attachment 1

Page 6

Figure 1. Schematic cross section of "NPR-8 fuel bead design.

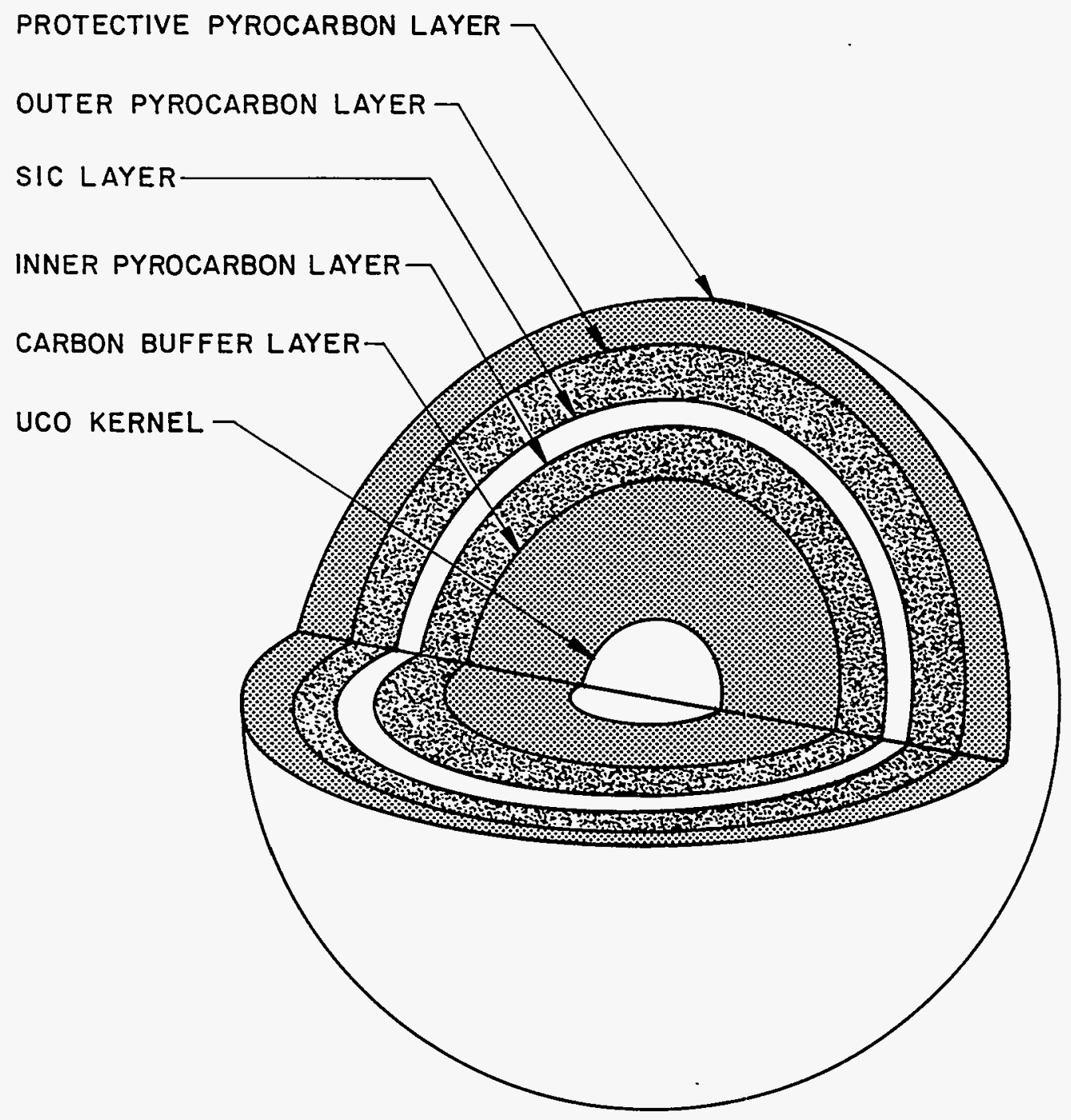

NPR-8 FUEL BEAD 
WAPD-TM-1633

Attachment 1

Page 7

Figure 2. Optical Photomicrograph of NPR-8 Fuel Sample [13.5X]

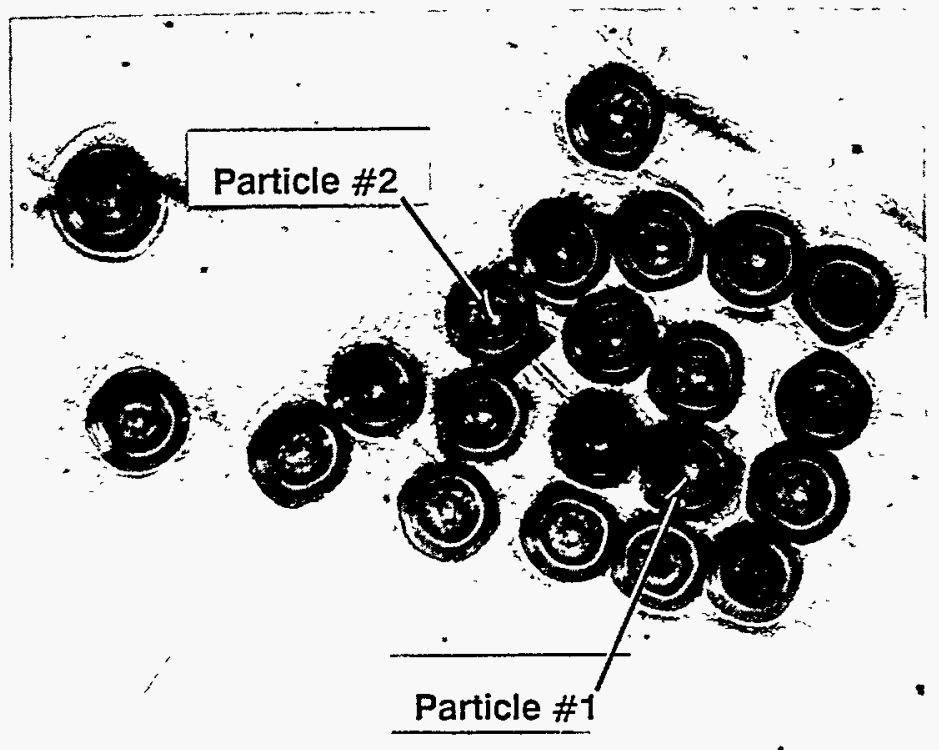

Figure 3. Optical Photomicrograph of Particle \#1, NPR Fuel Sample [100X]
Figure 4. Optical Photomimicrograph of Particle \#2, NPR Fuel Sample. [100X]

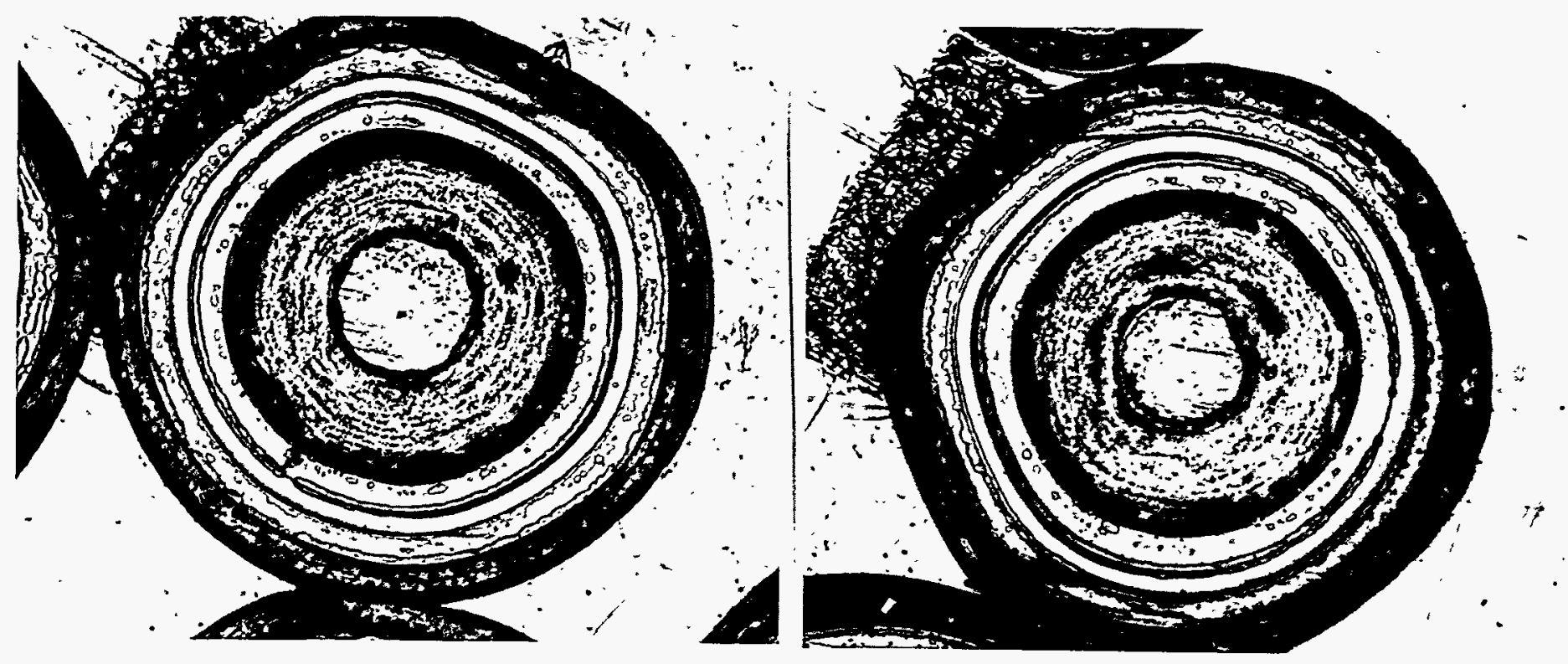


WAPD-TM-1633

Attachment 1

Page 8

Figure 5. Secondary electron image of

Particle \#1, NPR-8 fuel, showing the

approximate locations of the areas analyzed

by EDS (Spectra 1 through 8). [100X]

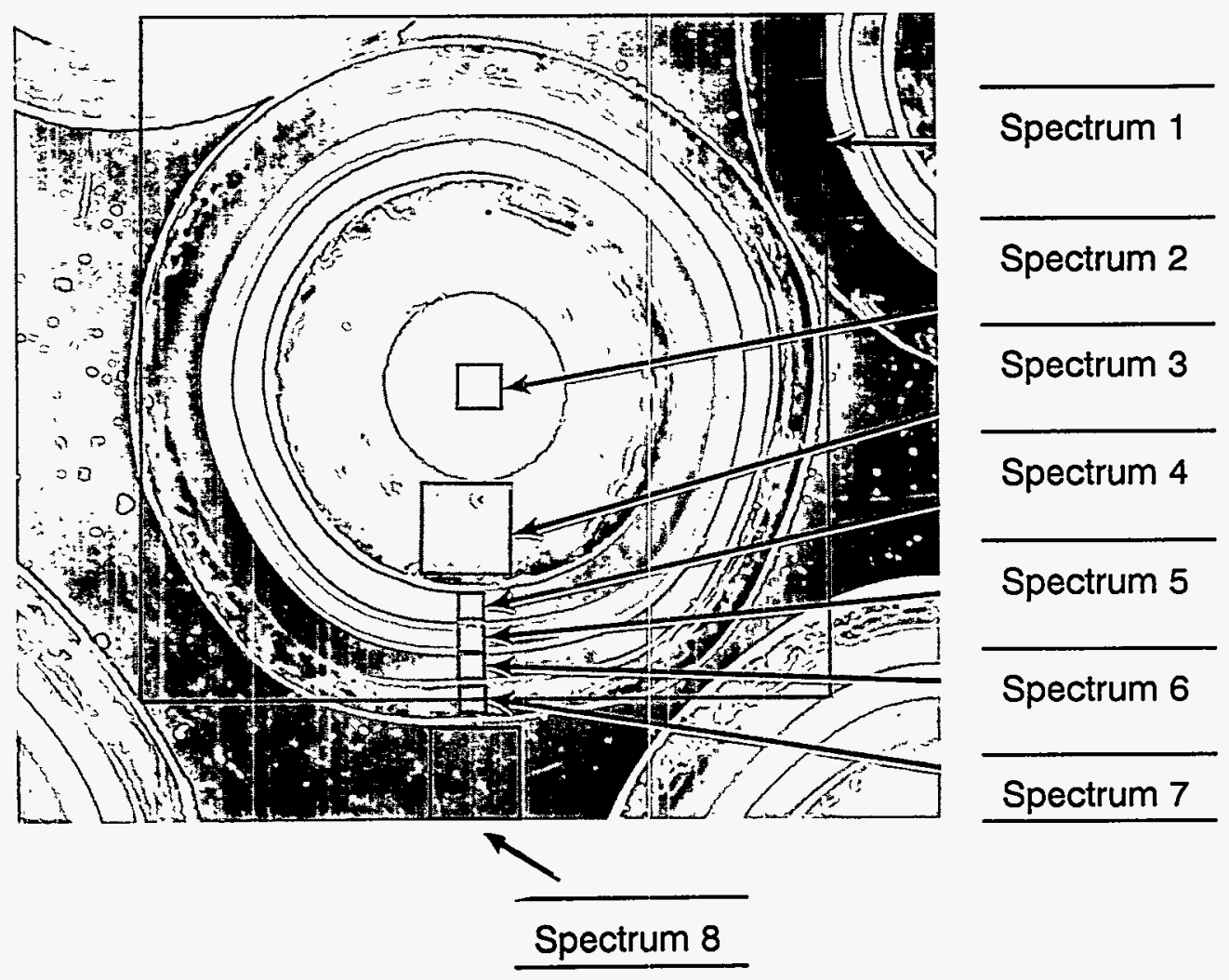


Page 9

Figure 6. Secondary electron and X-ray images of Particle \#1, NPR-8 fuel. [300X]

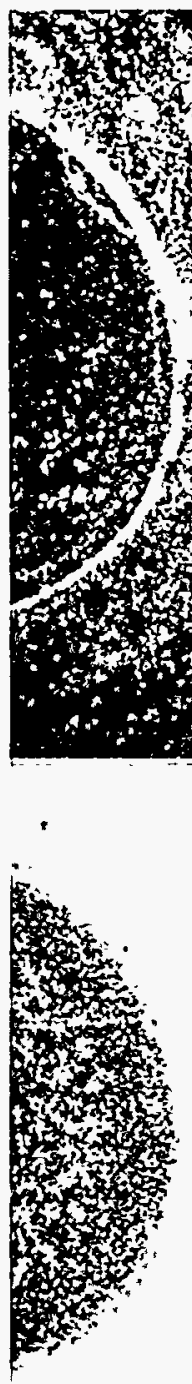

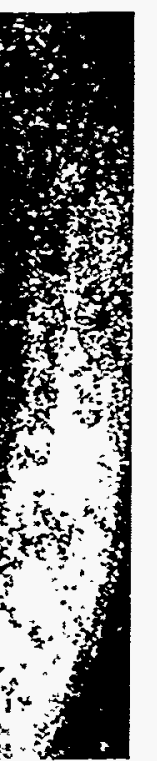

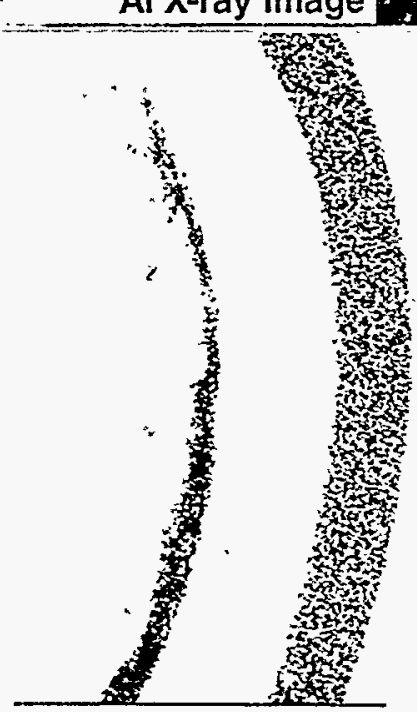

C X-ray Image

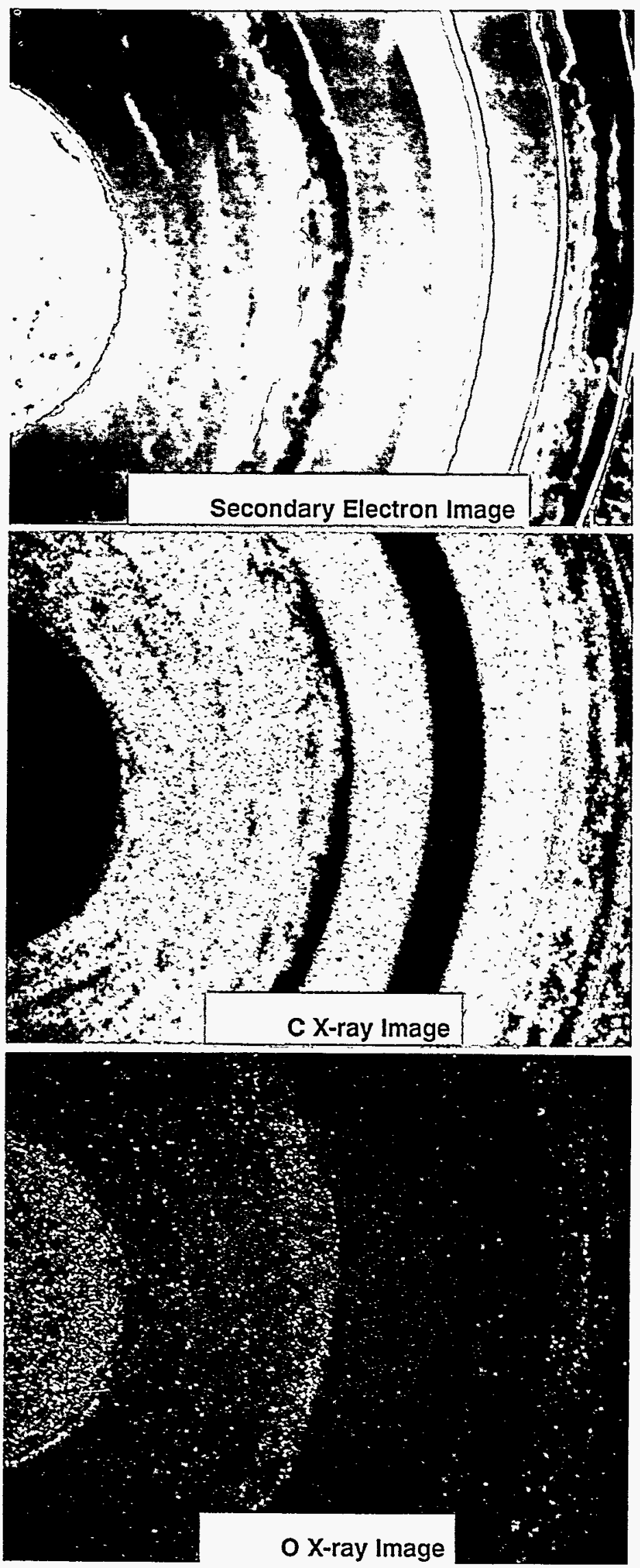


WAPD-TM-1633

Attachment 1

Page 10
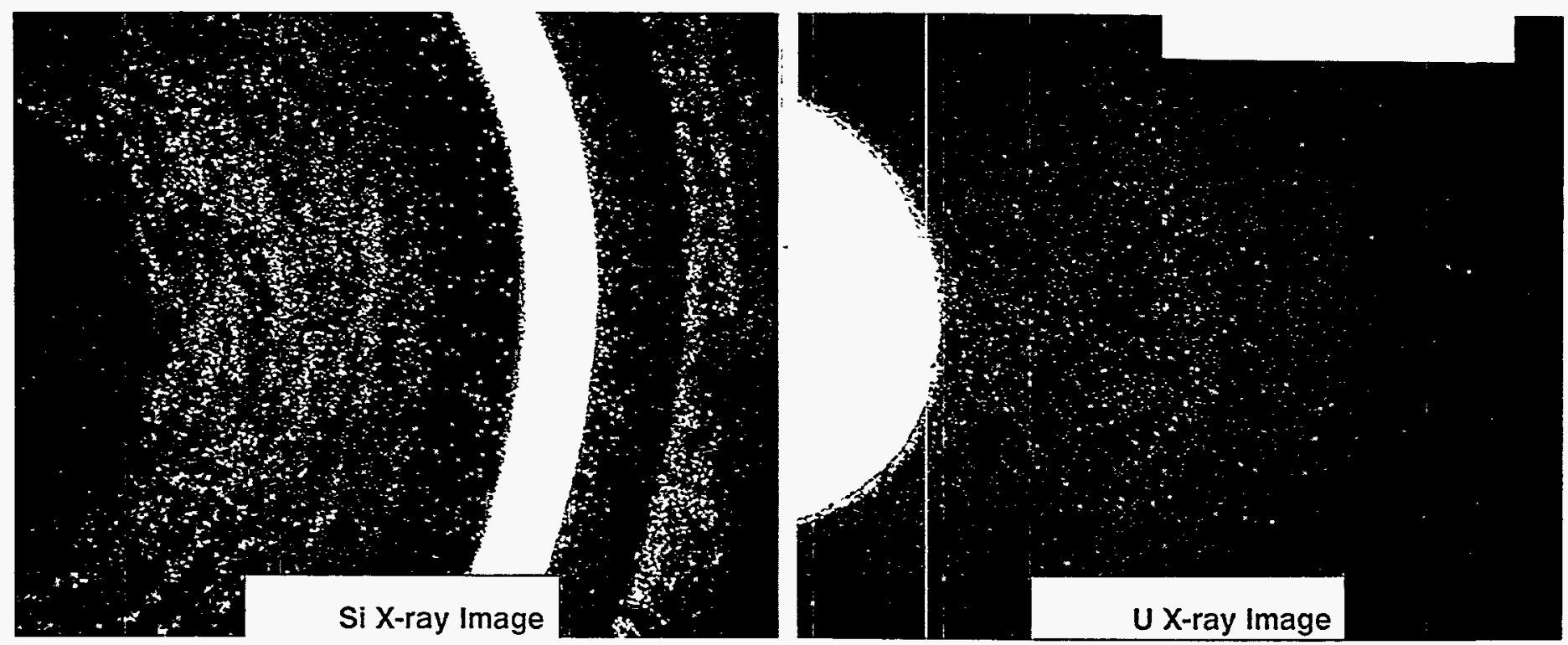
WAPD-TM-1633

Attachment 1

Page 11

Figure 7. Secondary electron and X-ray images of Particle \#2, NPR-8 fuel. [300X]

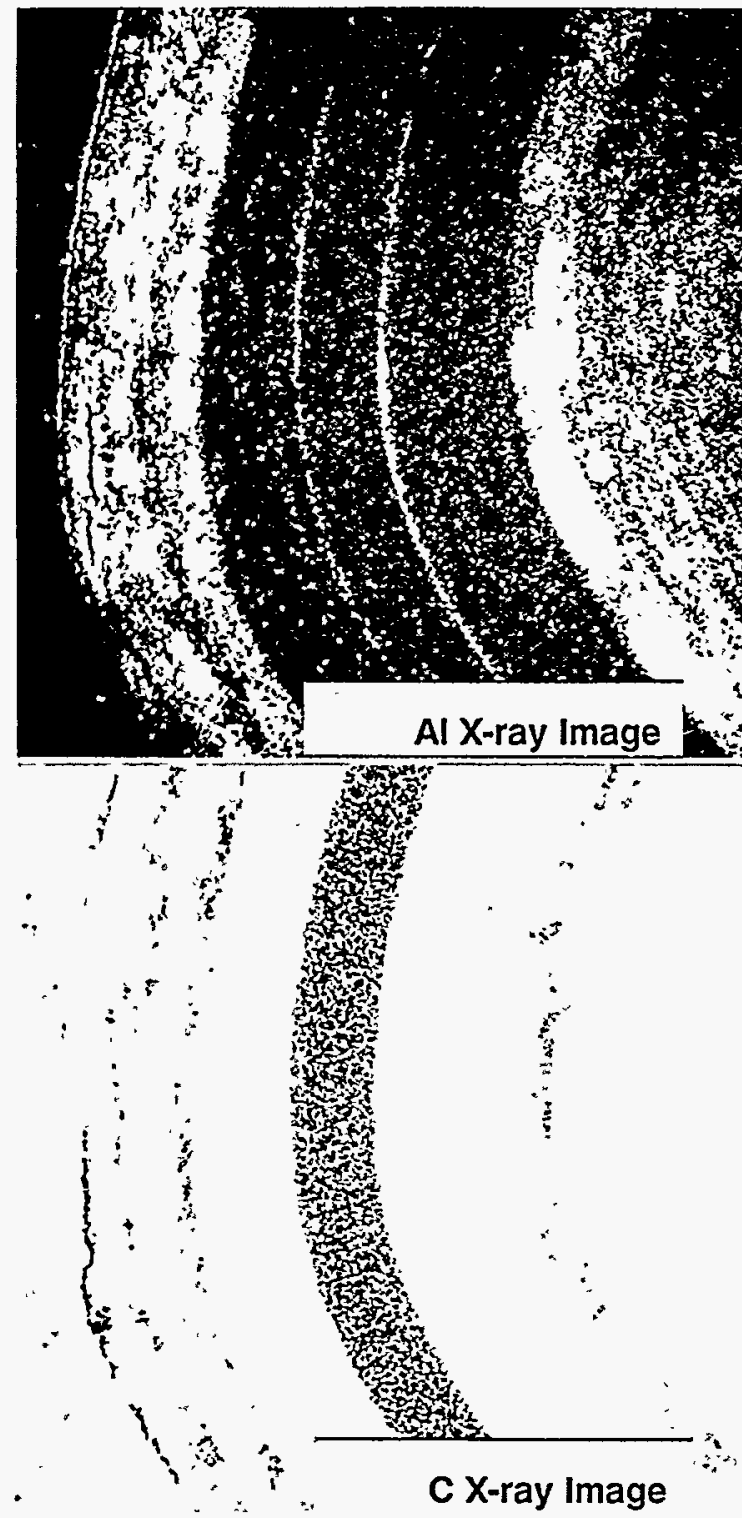

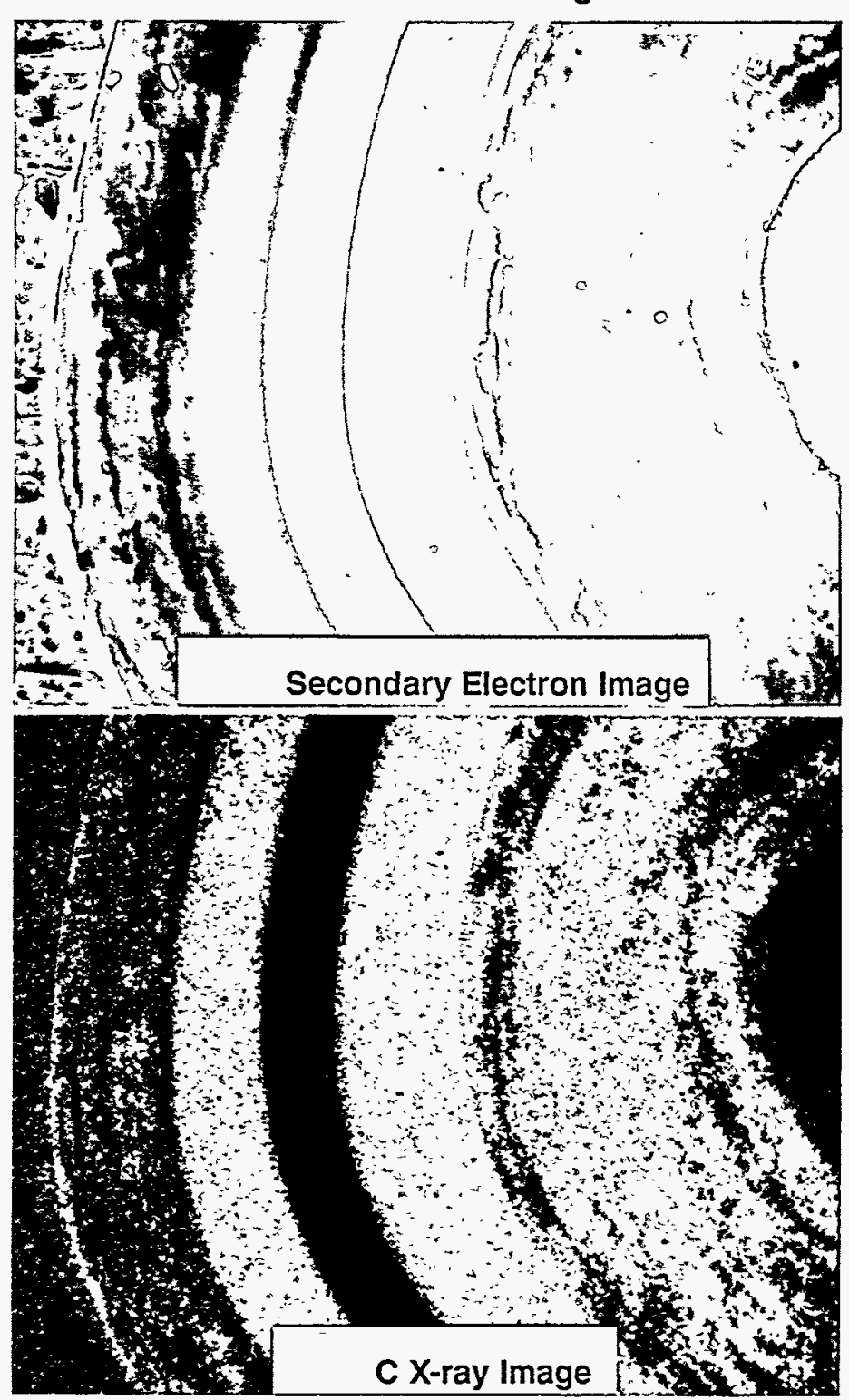
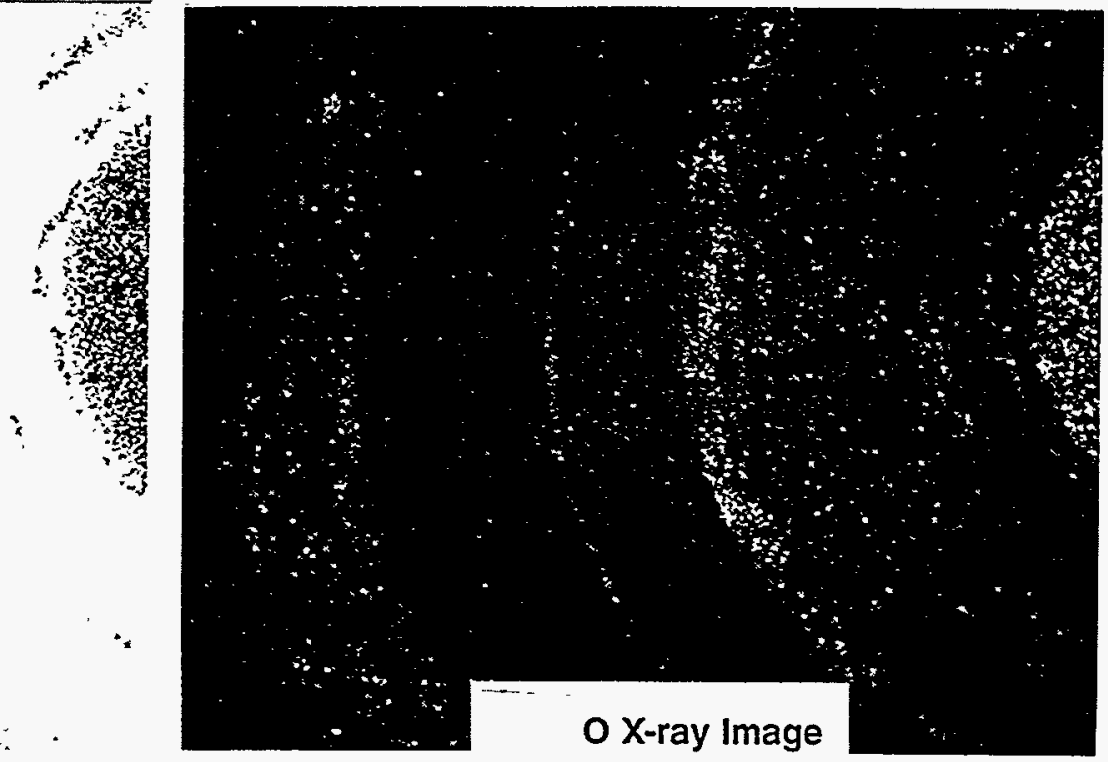
WAPD-TM-1633

Attachment 1

Page 12
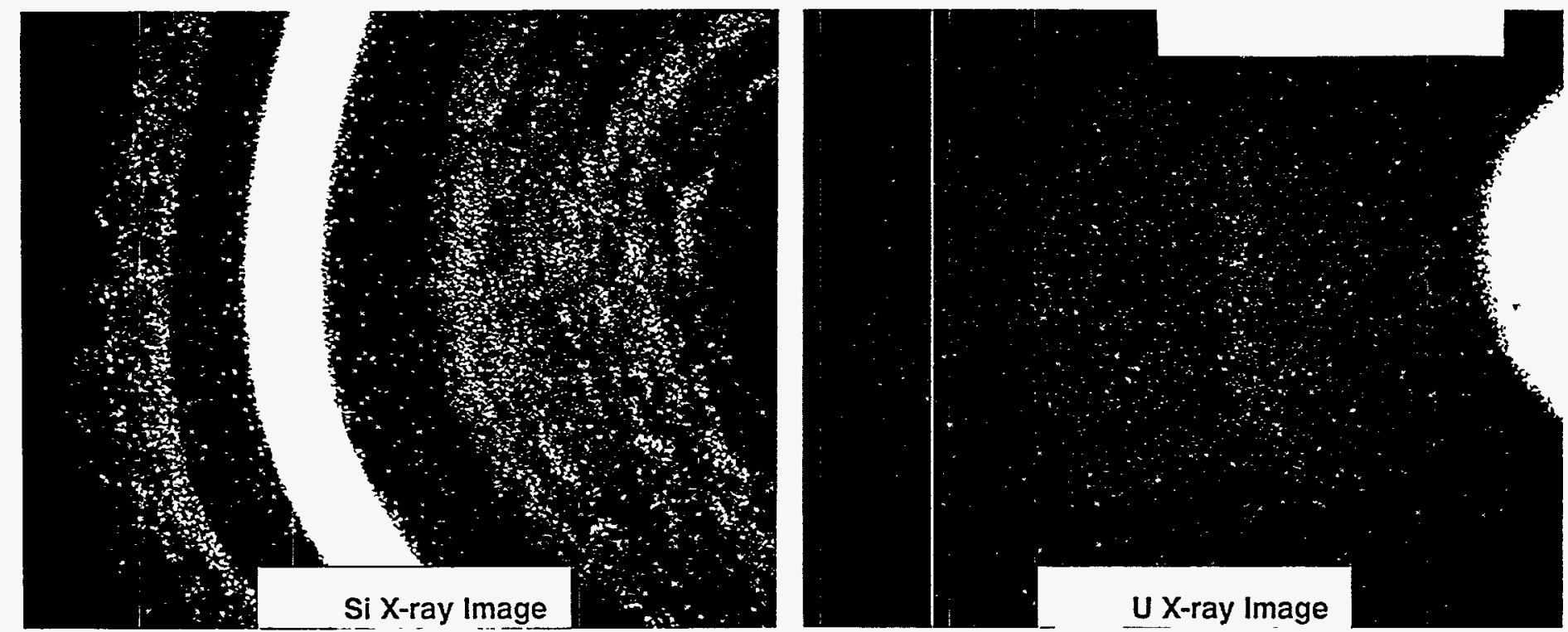
Figure 8. Secondary and backscattered electron images of the UCO kernel in Particle \#1, NPR-8 fuel showing locations of areas analyzed by EDS (Spectra $9 \& 10$ ). [400X]
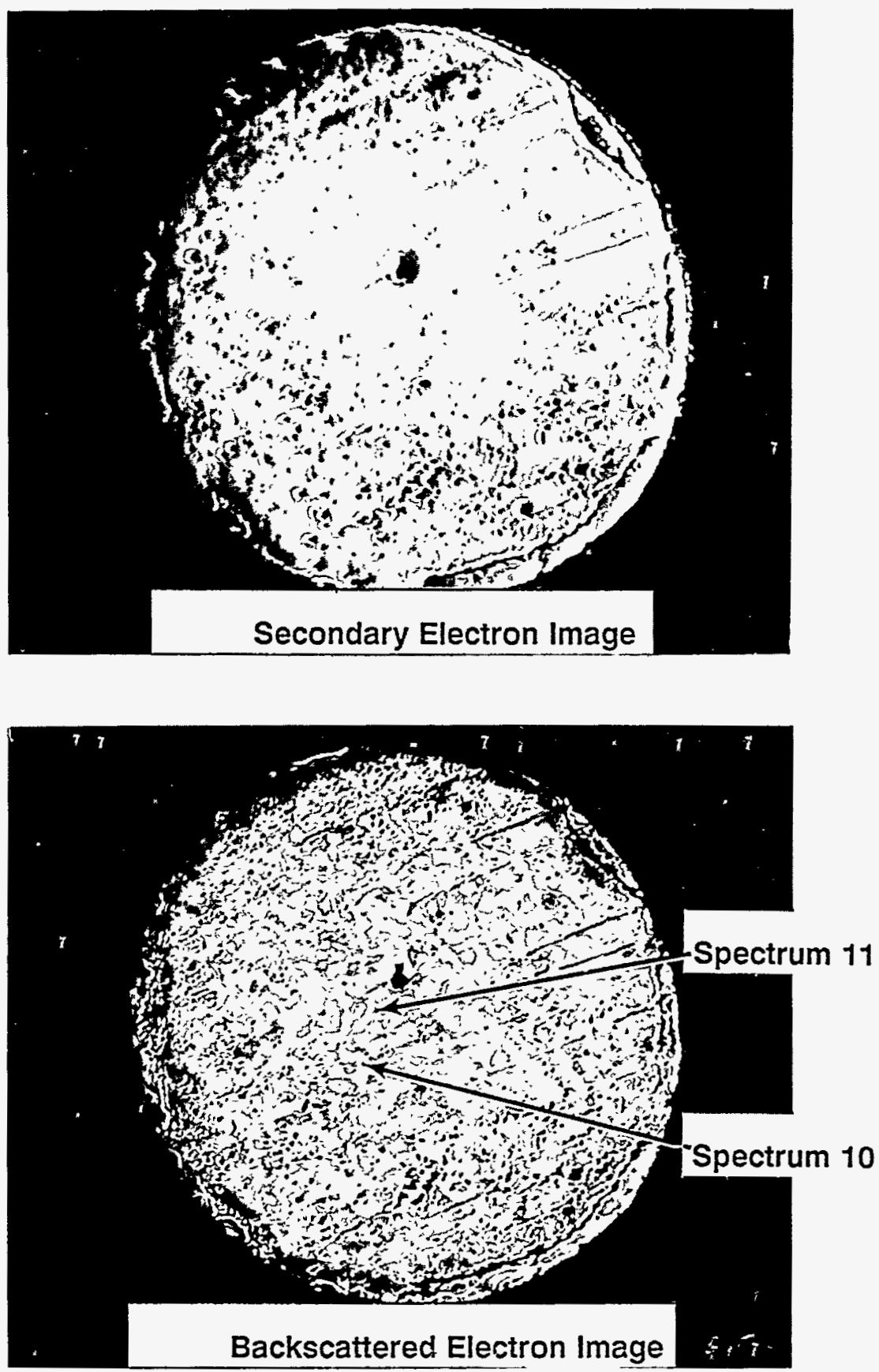
WAPD-TM-1633

Attachment 1

Page 14

Figure 9. Secondary electron, backscattered electron, and X-ray images of the UCO kernel in Particle \#1, NPR-8 fuel. [1000X]
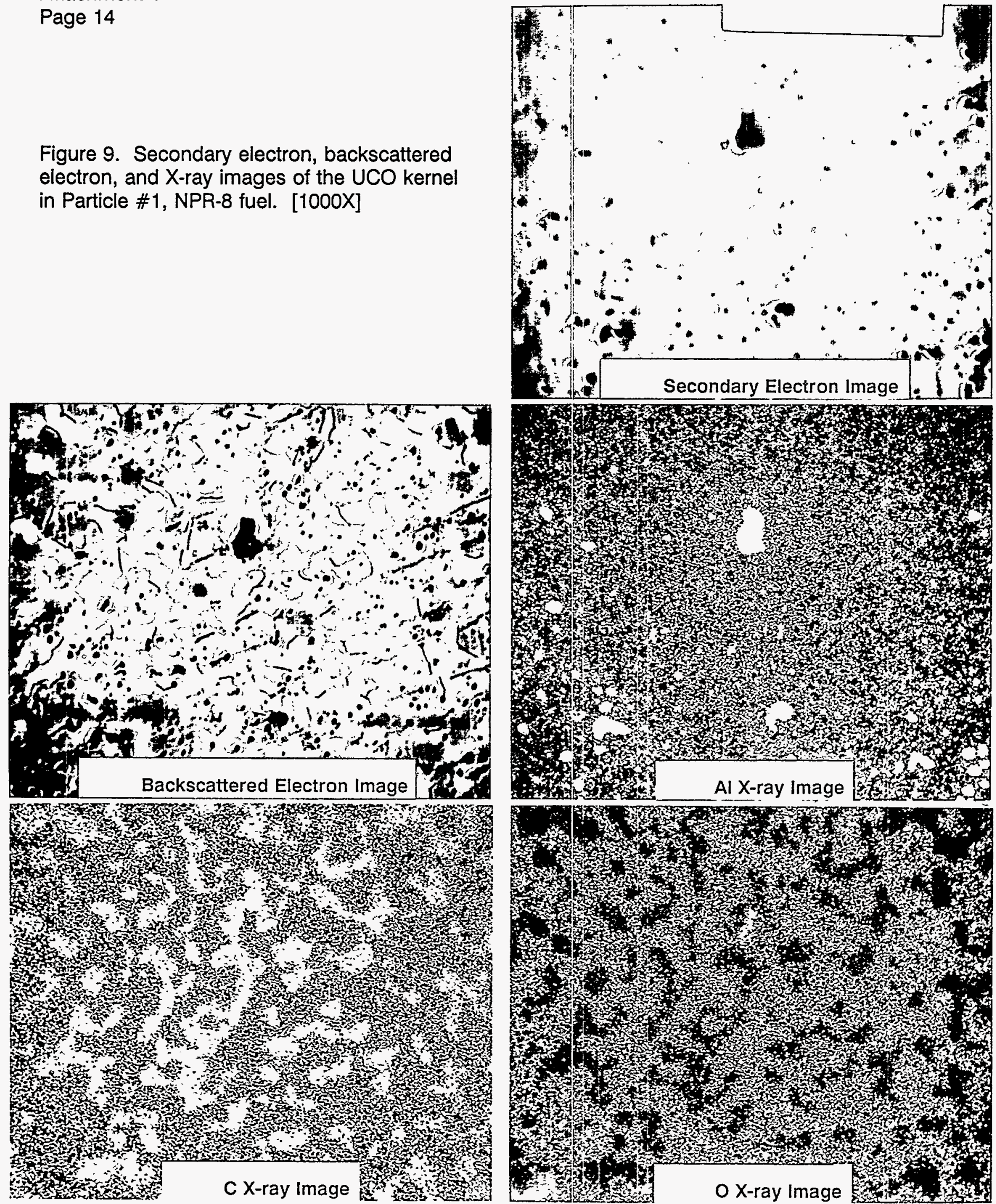
WAPD-TM-1633

Attachment 1

Page 15
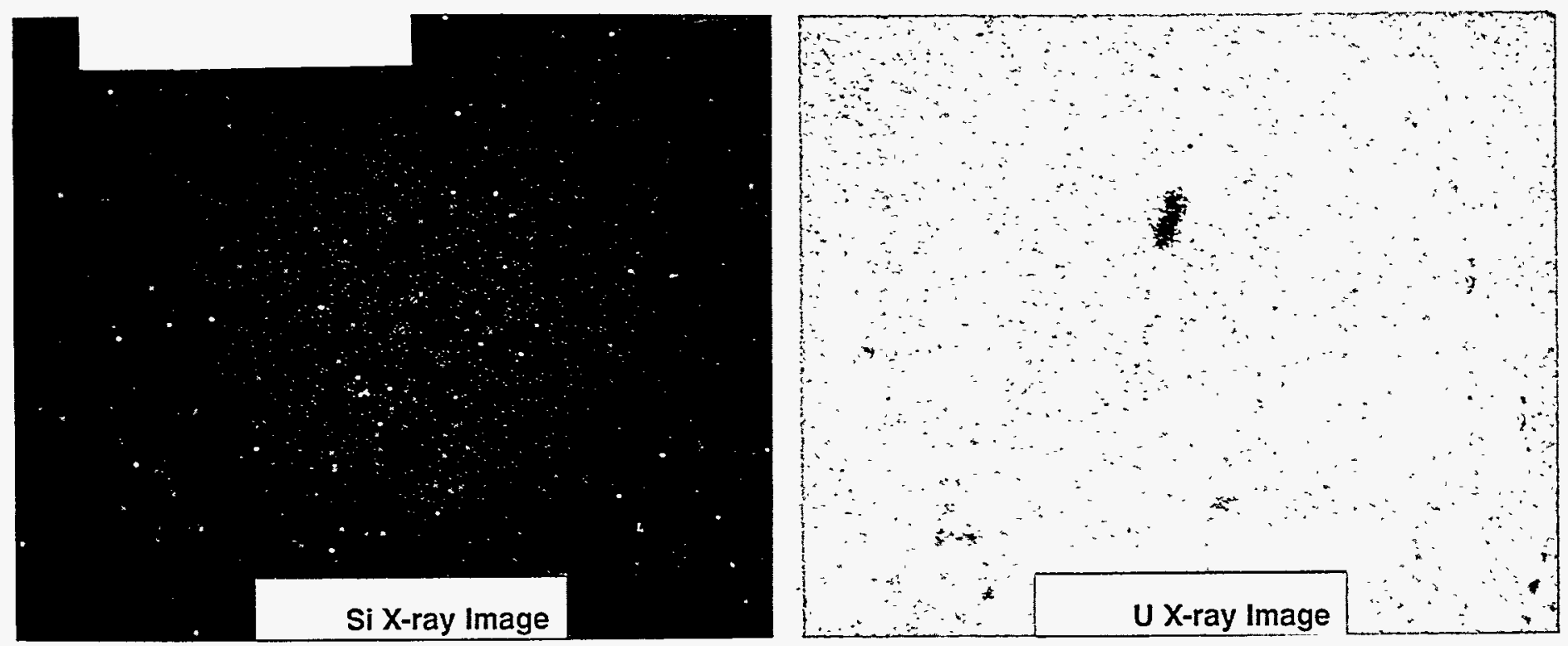
WAPD-TM-1633

Attachment 1

Page 16

Figure 10. Secondary and backscattered

electron images of the $\mathrm{SiC}$ layer (Figure I) in

Particle \#1, NPR-8 fuel. [1000X]
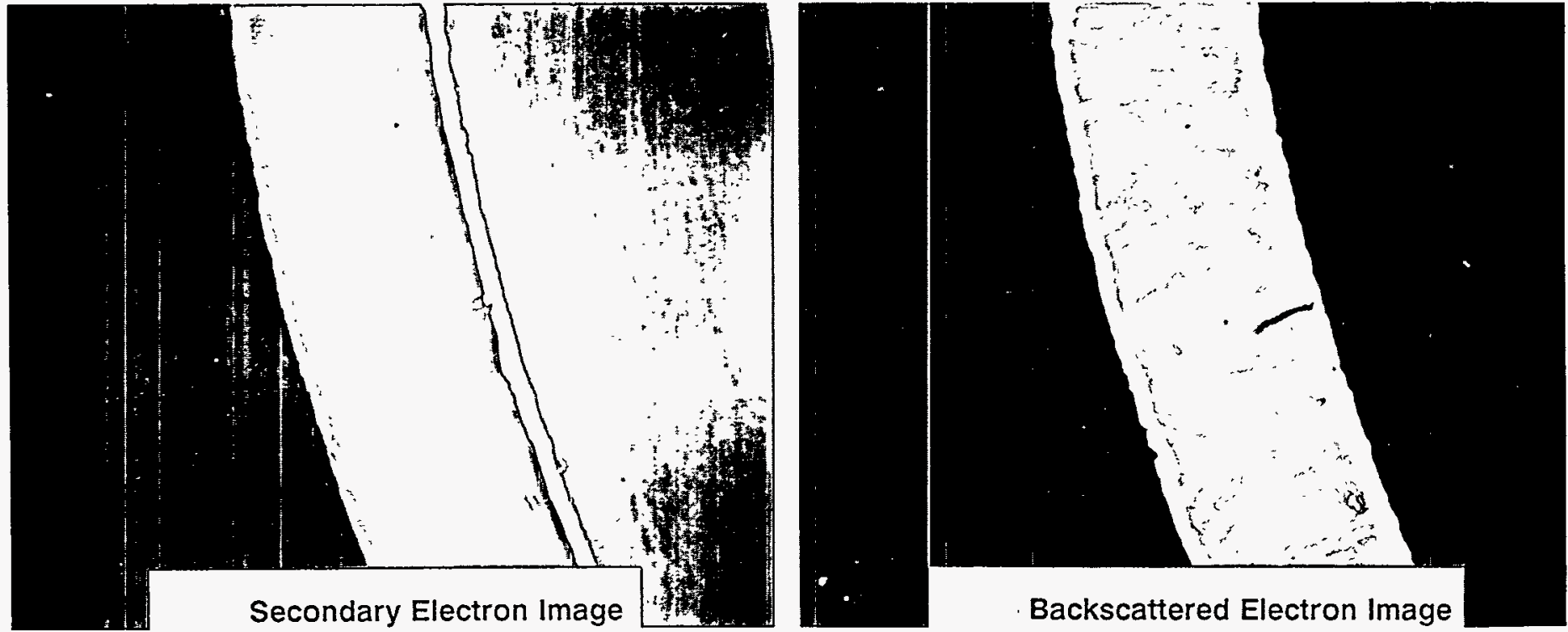

Figure 11. Secondary and backscattered electron images of the SiC layer (Figure I) in

Particle \#2, NPR-8 fuel. [1000X]
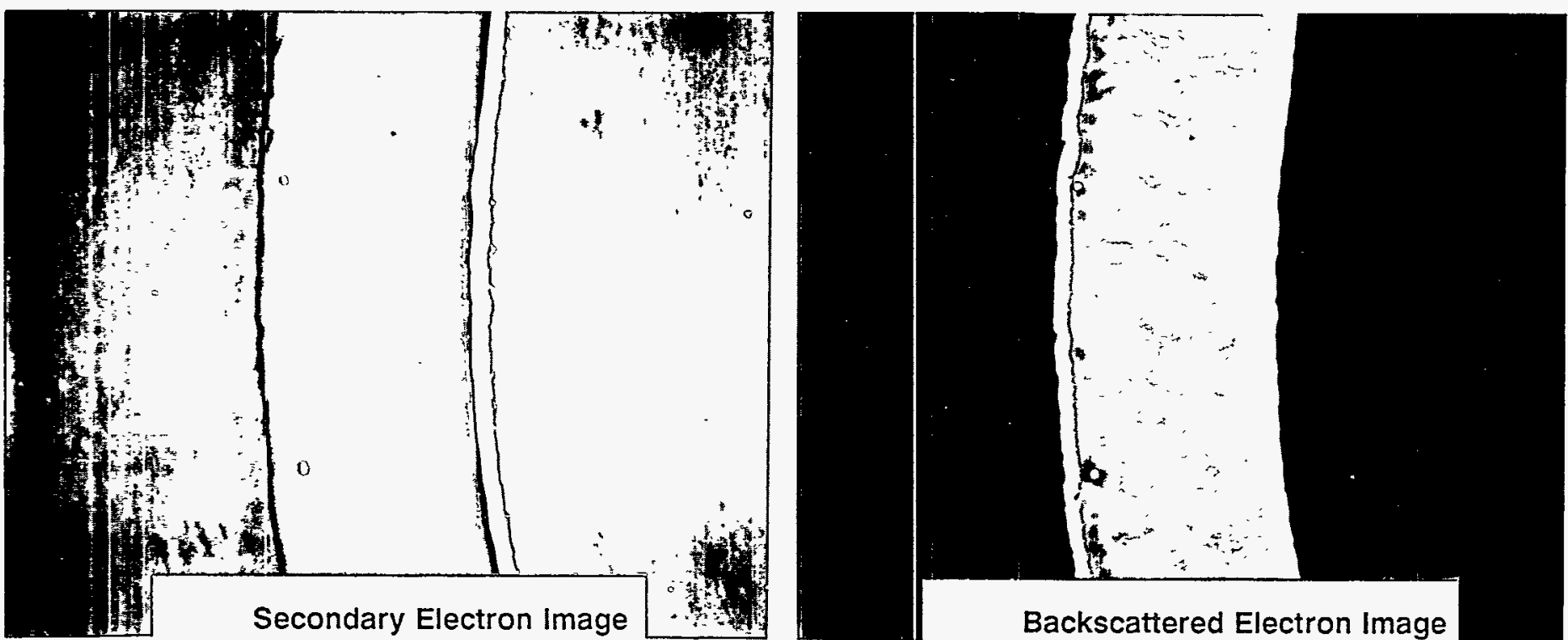
WAPD-TM-1633

Attachment 1

Page 17

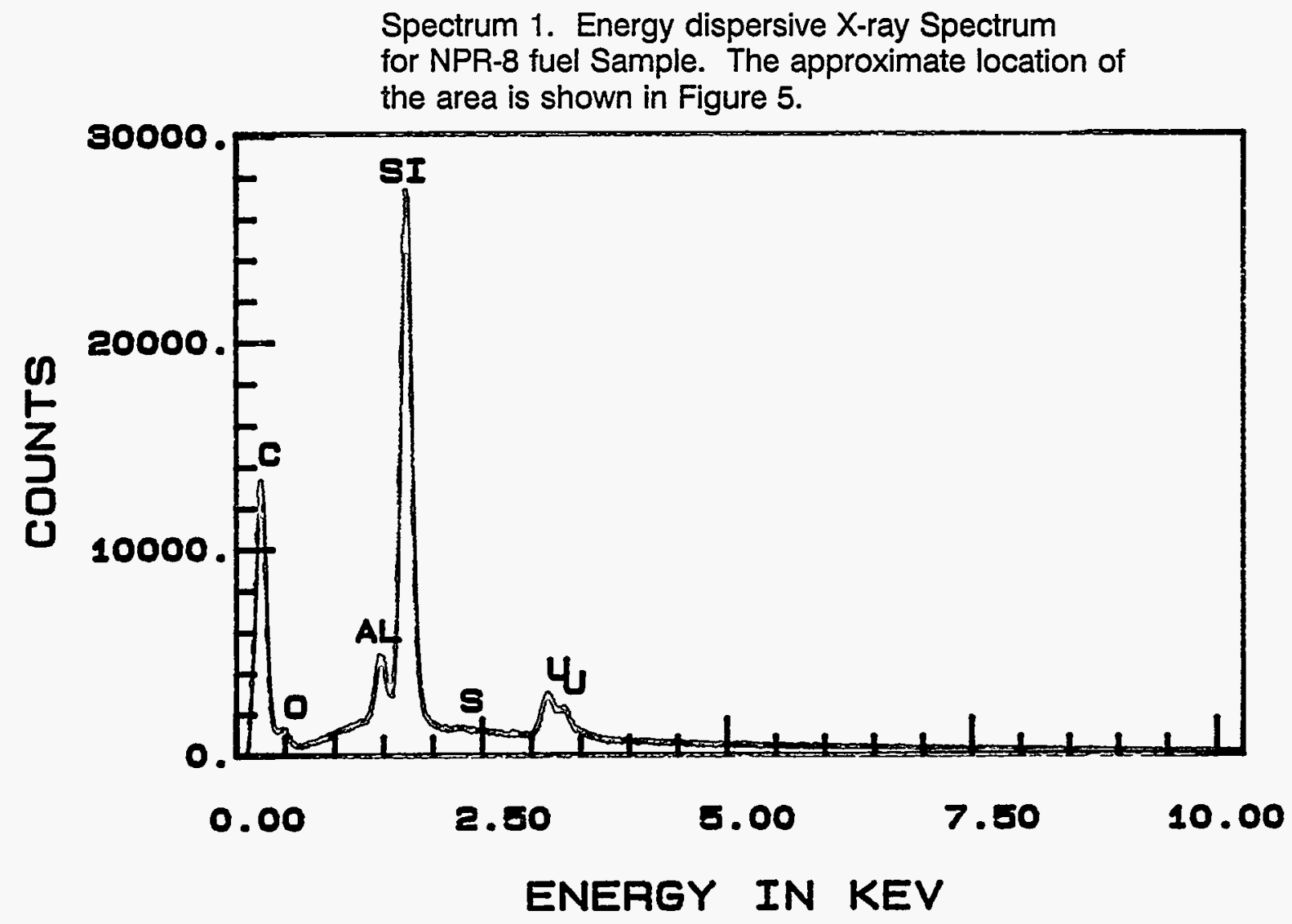

EXPANDED SCALE

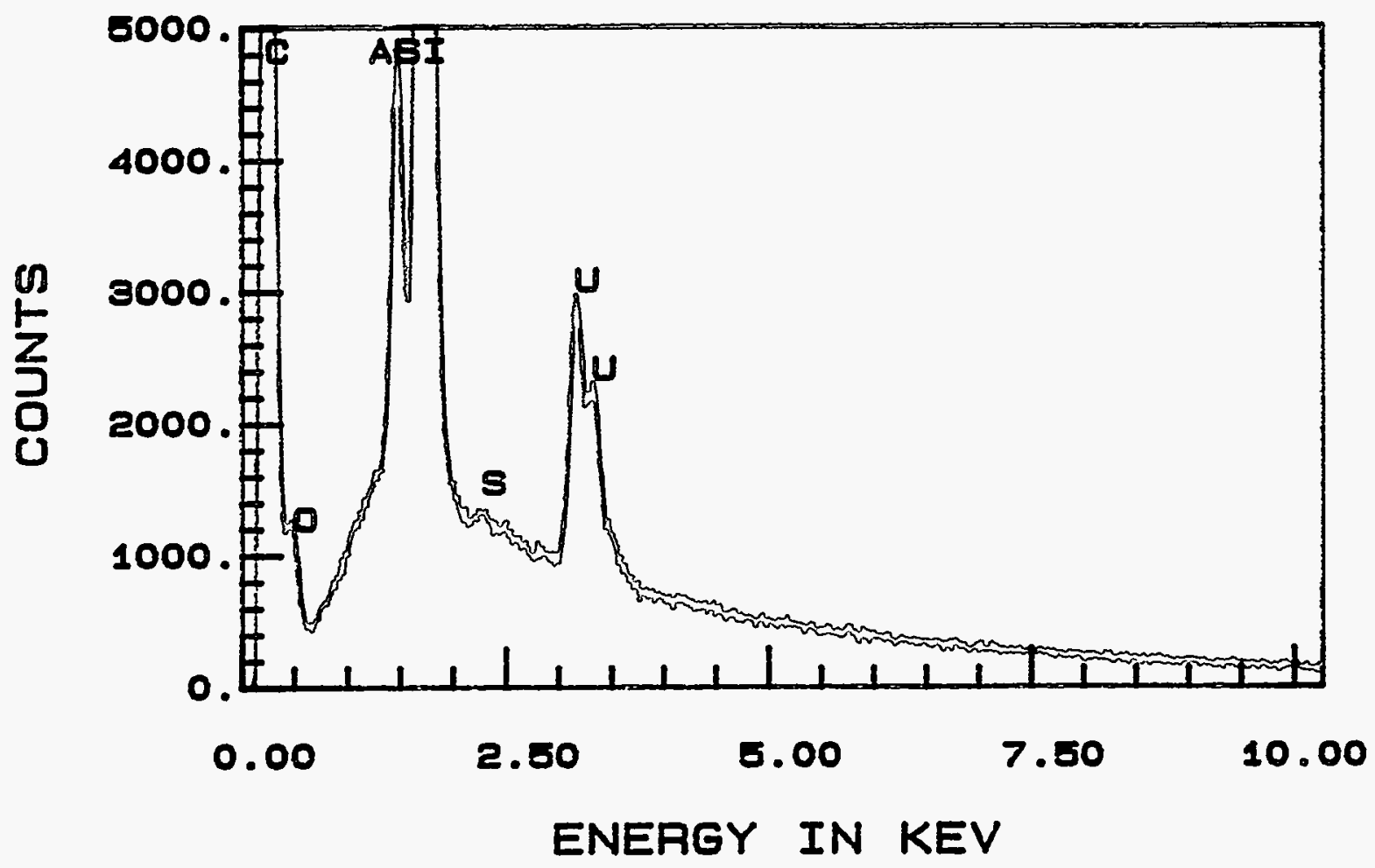


Spectrum 2. Energy dispersive X-ray Spectrum for the UCO kernel in the NPR-8 fuel Sample. The approximate location of the area is shown in Figure 5.

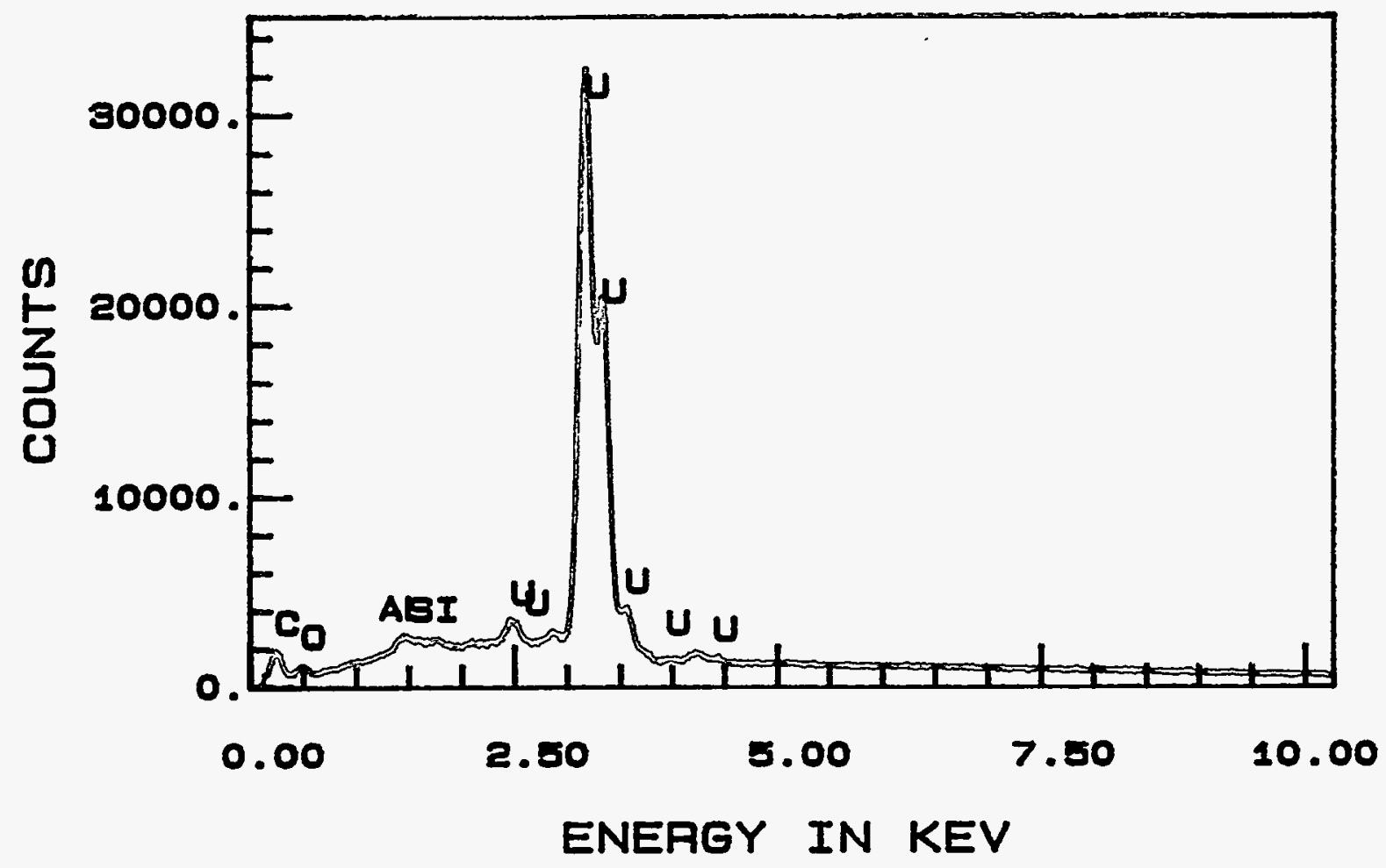

EXPANDED SCALE

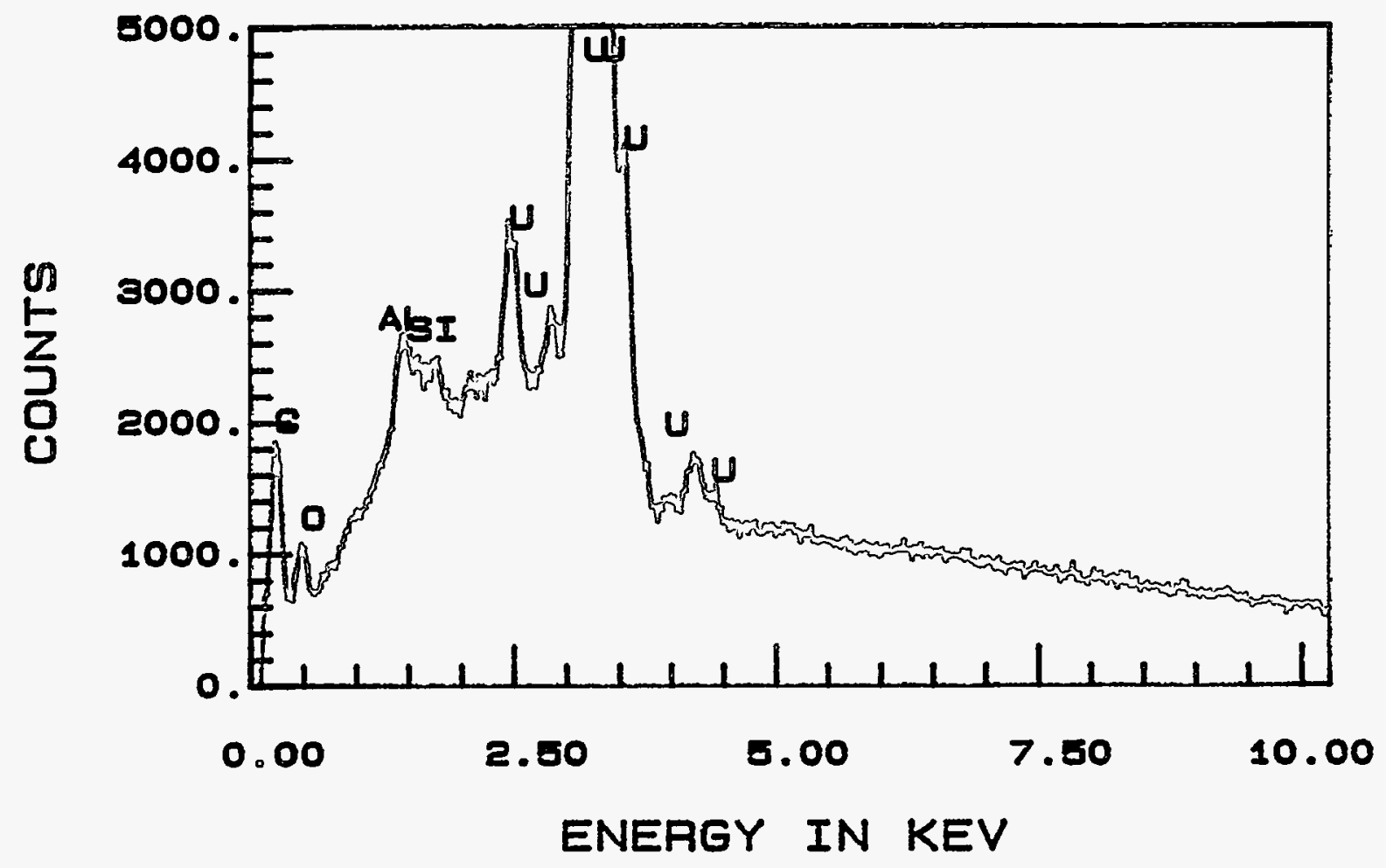


Spectrum 3. Energy dispersive X-ray Spectrum for the carbon buffer layer in NPR-8 fuel Sample. The approximate location of the area is shown in Figure 5.

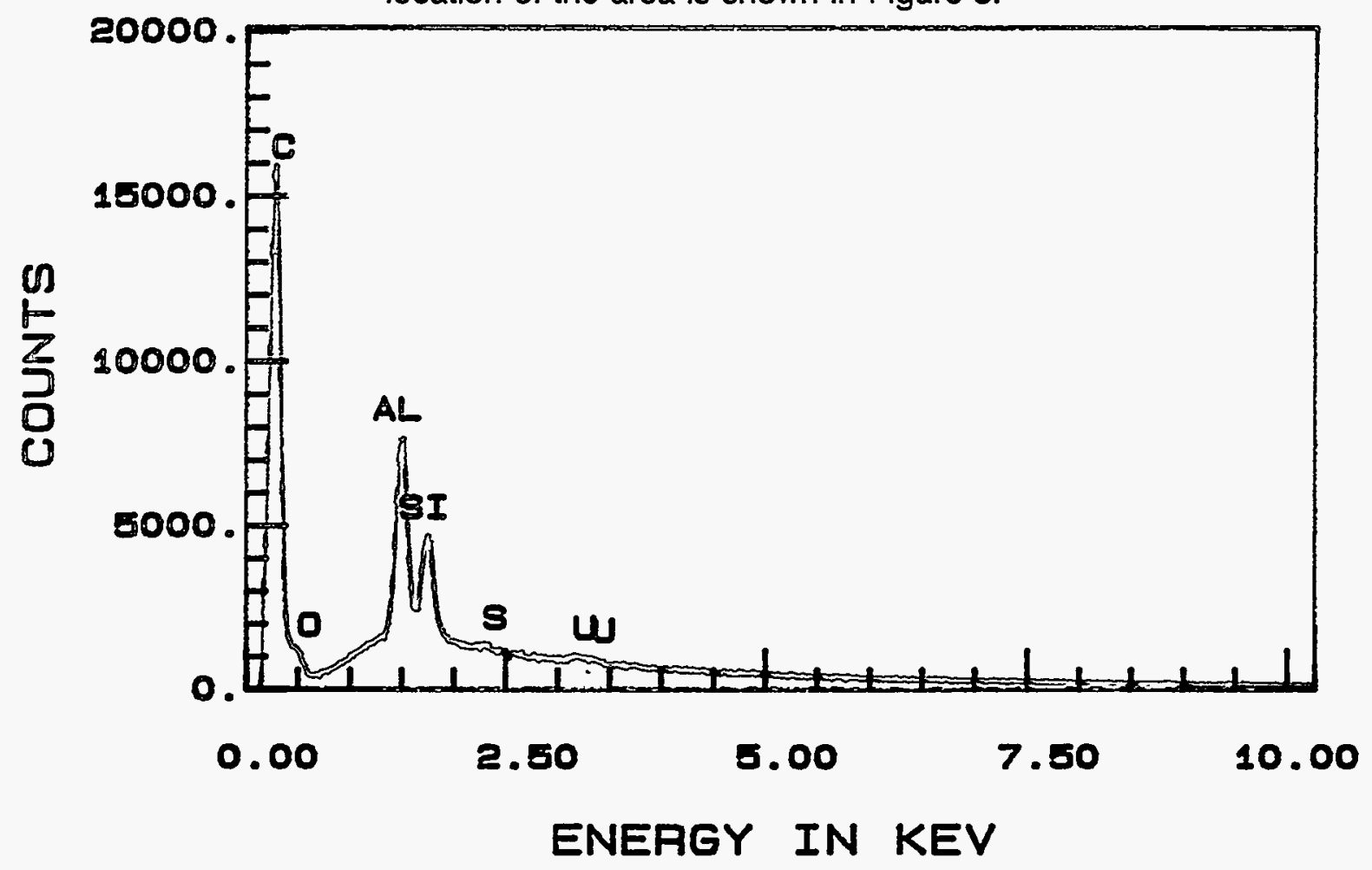

EXPANDED SCALE

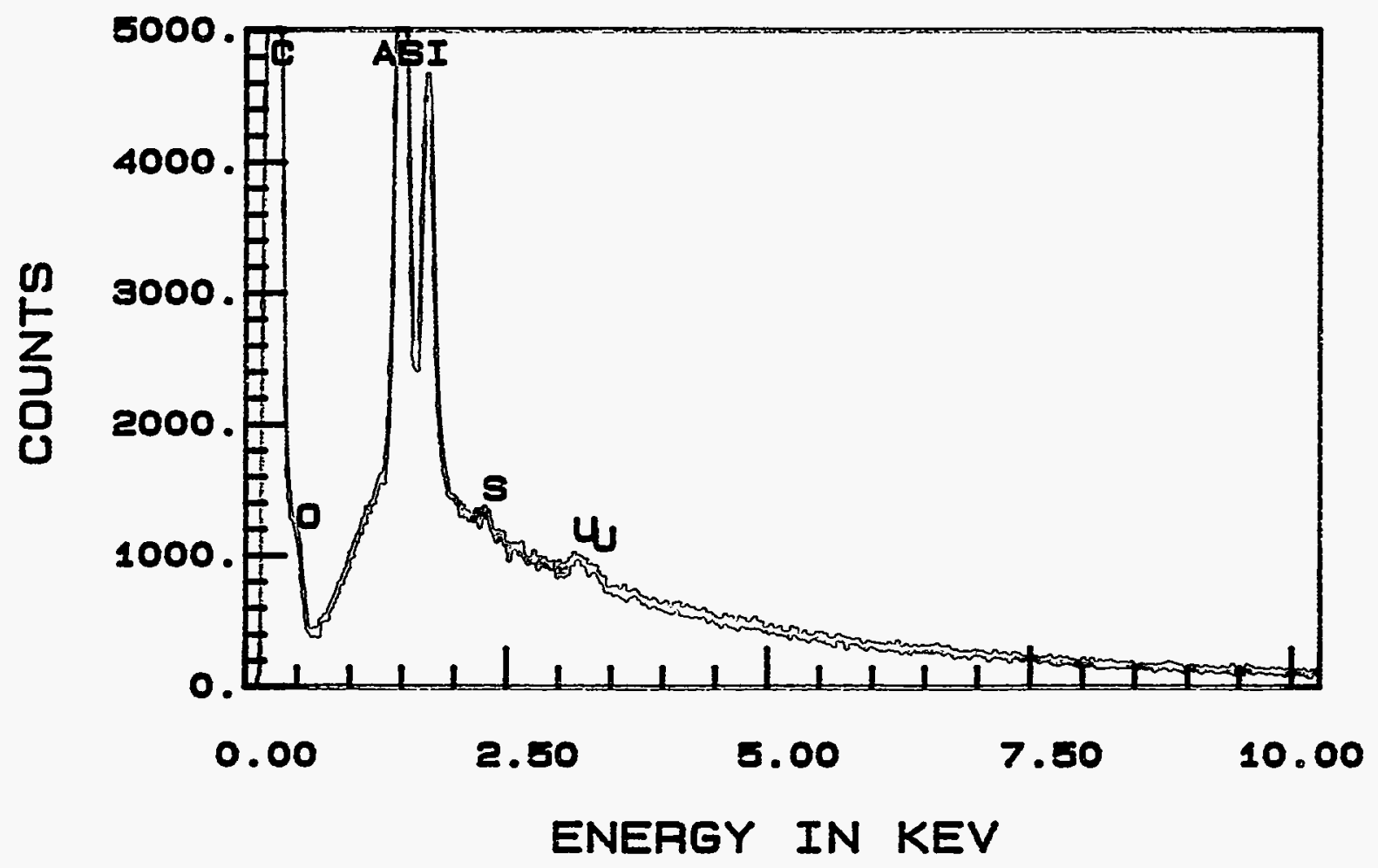


WAPD-TM-1633

Attachment 1

Page 20

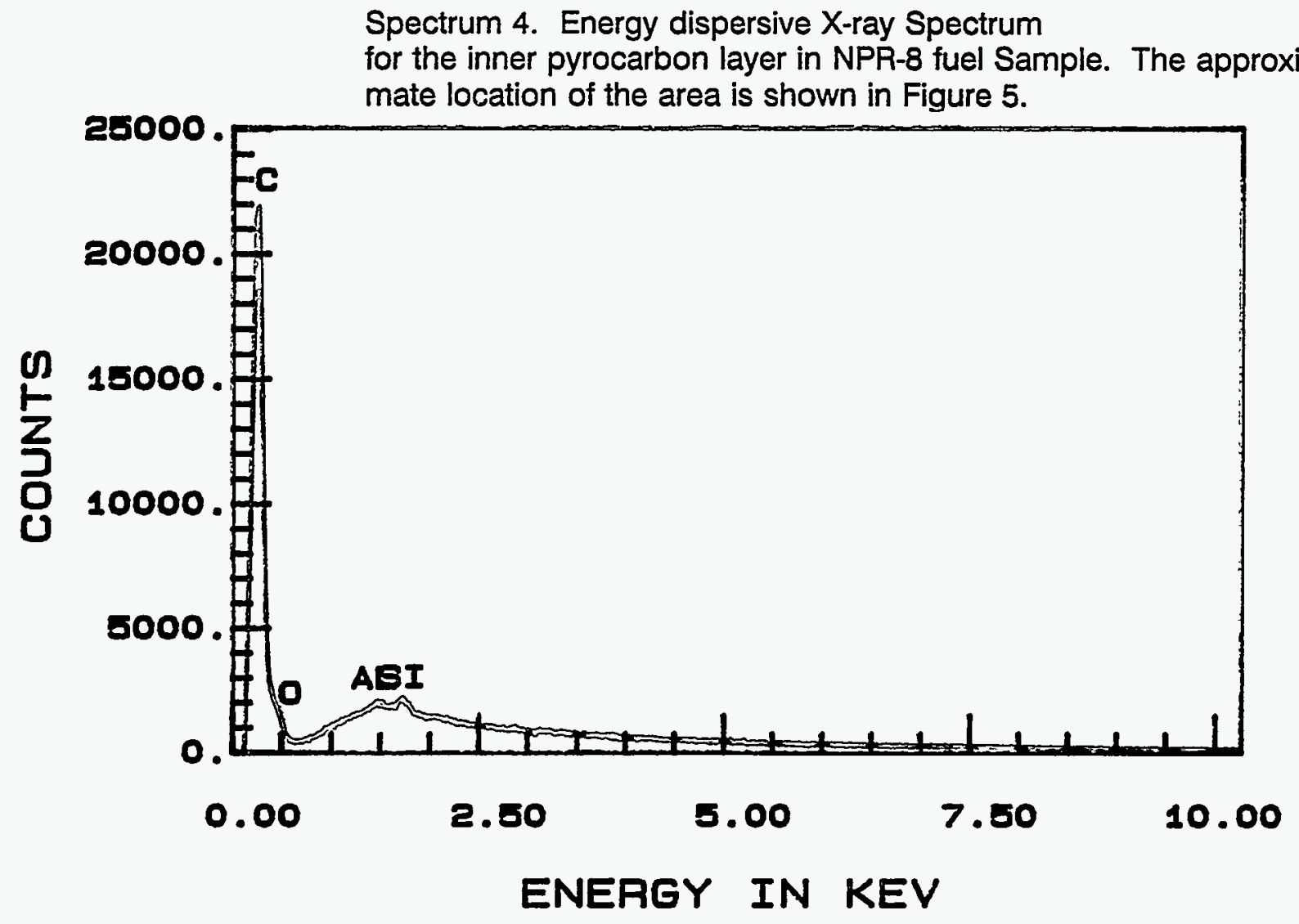

EXPANDED SCALE

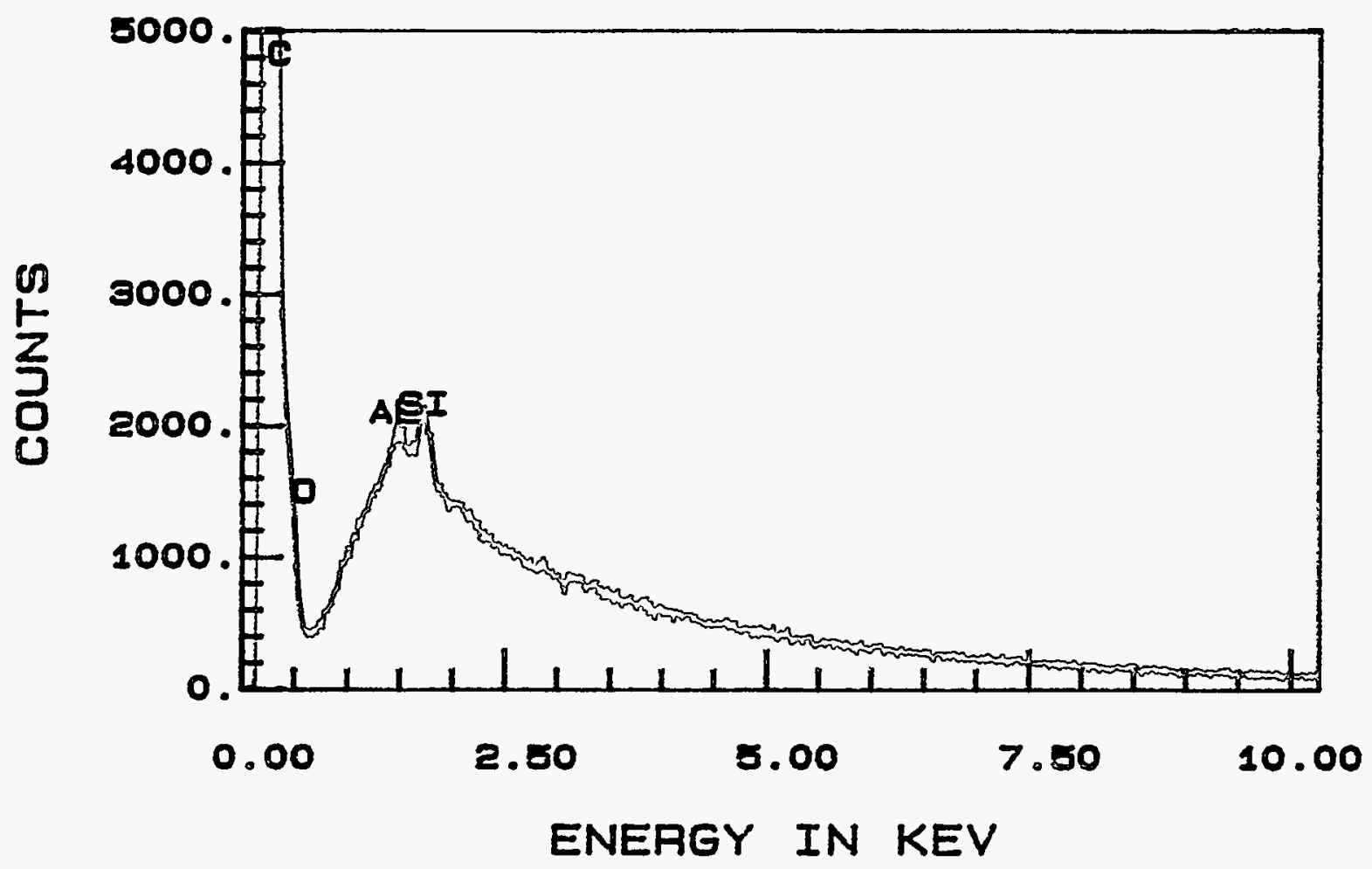


WAPD-TM-1633

Attachment 1

Page 21

Spectrum 5. Energy dispersive X-ray Spectrum

for the SiC layer in the NPR-8 fuel Sample. The approximate location of the area is shown in Figure 5.

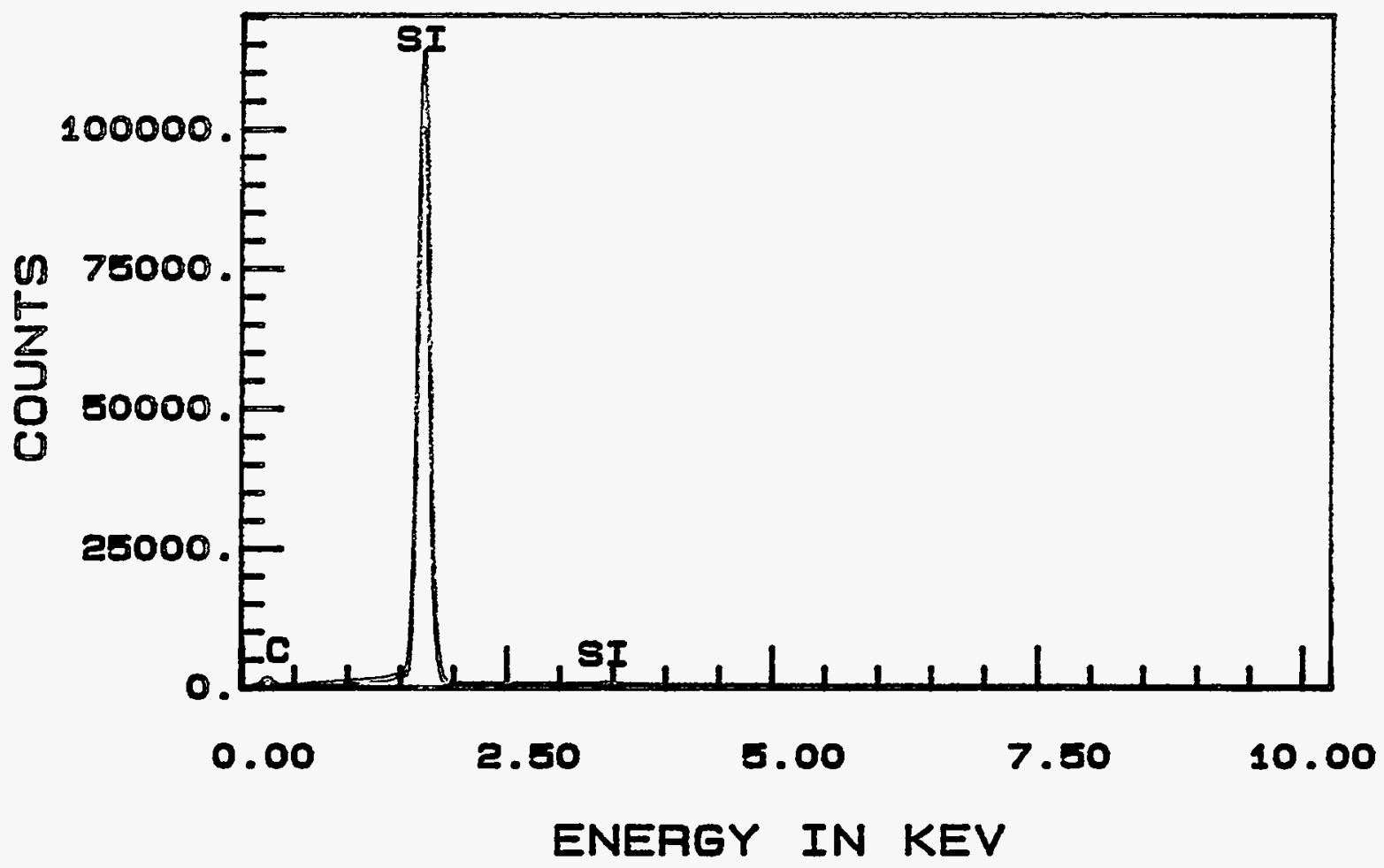

EXPANDED SCALE

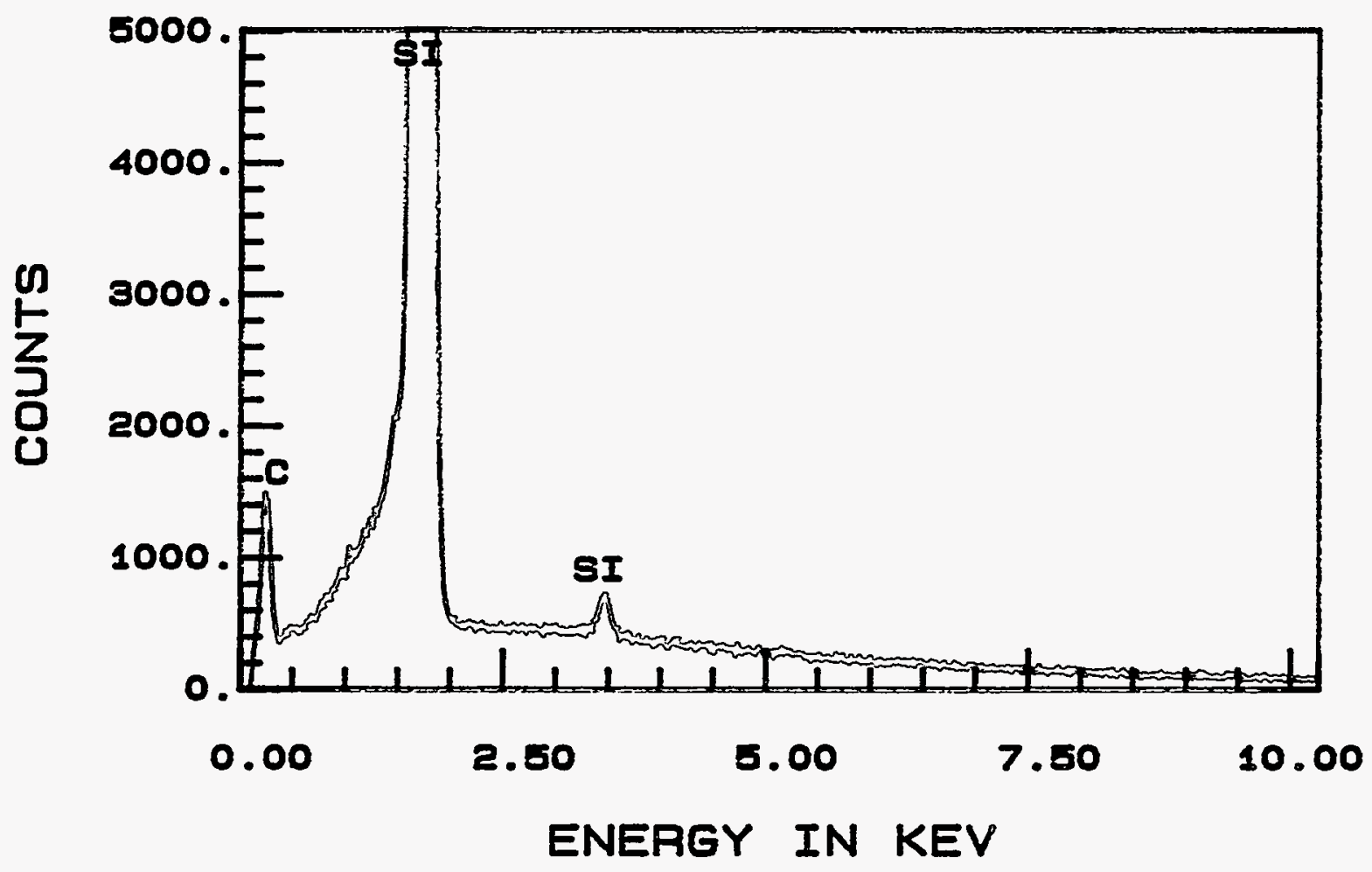


Spectrum 6. Energy dispersive X-ray Spectrum for the outer pyrocarbon layer in the NPR-8 fuel Sample. The approximate location

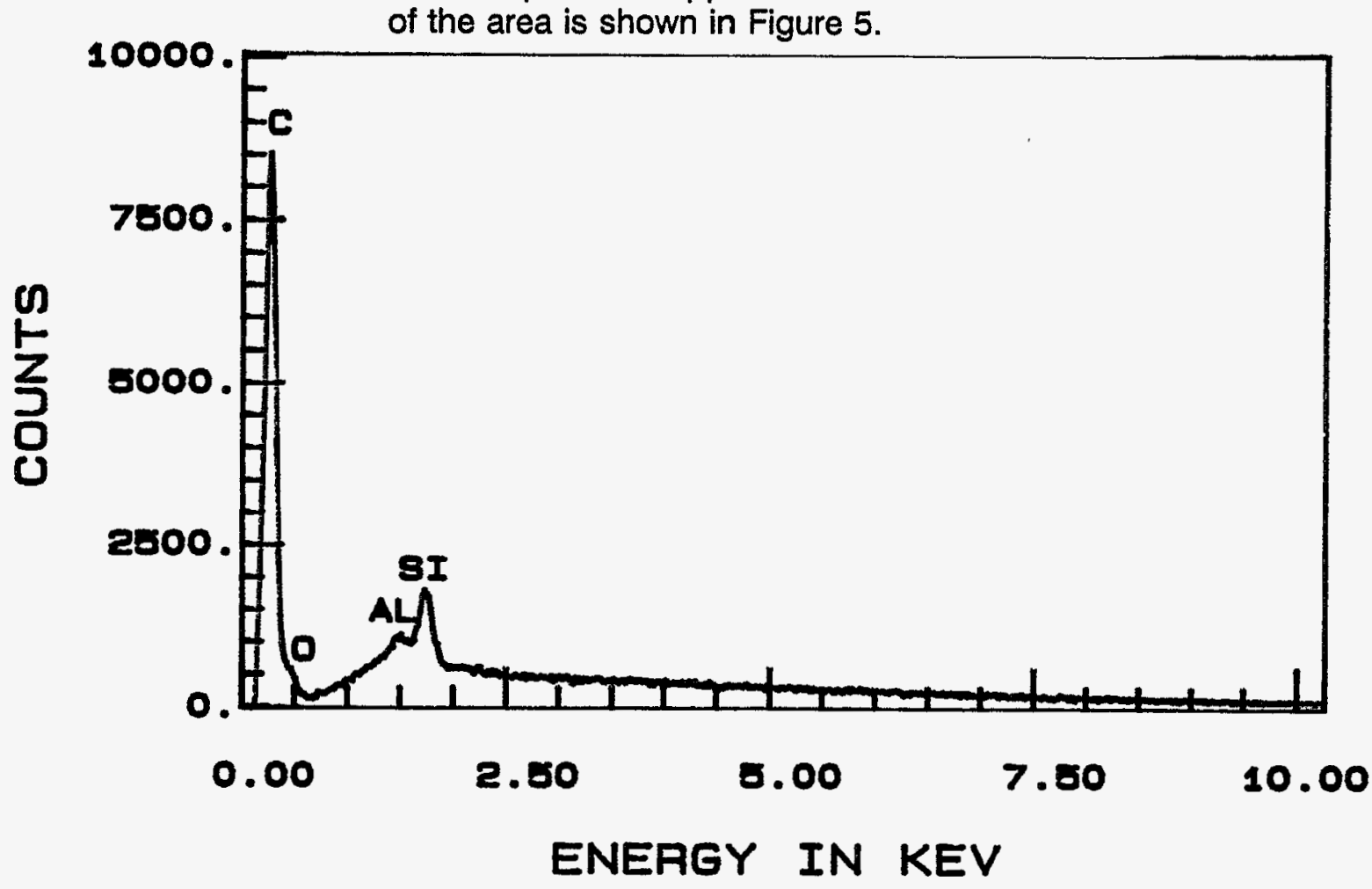

EXPANDED SCALE

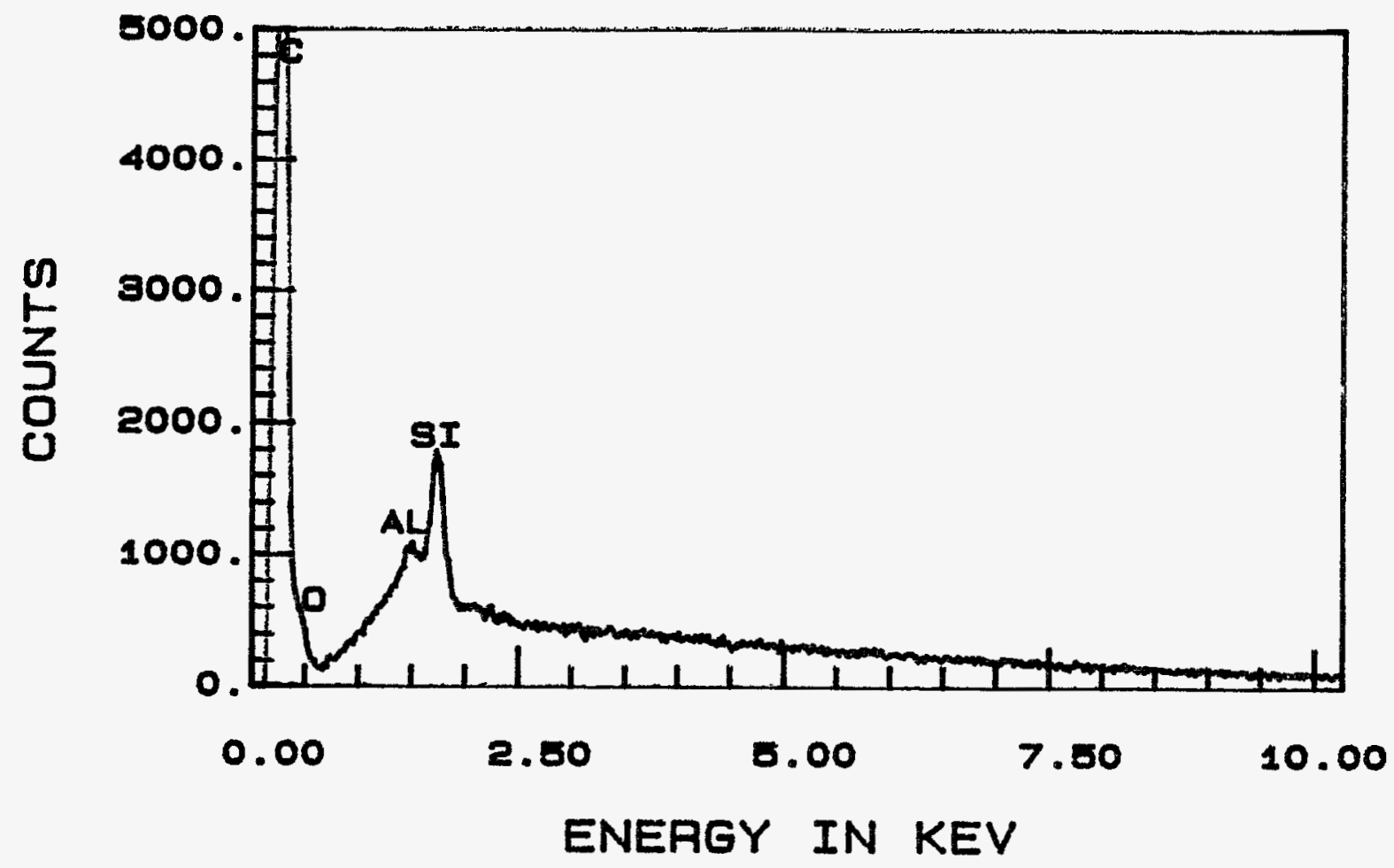


WAPD-TM-1633

Attachment 1

Page 23

Spectrum 7. Energy dispersive X-ray Spectrum for the protective pyrocarbon layer in the NPR-8 fuel Sample. The approximate location of the area is shown in Figure 5.

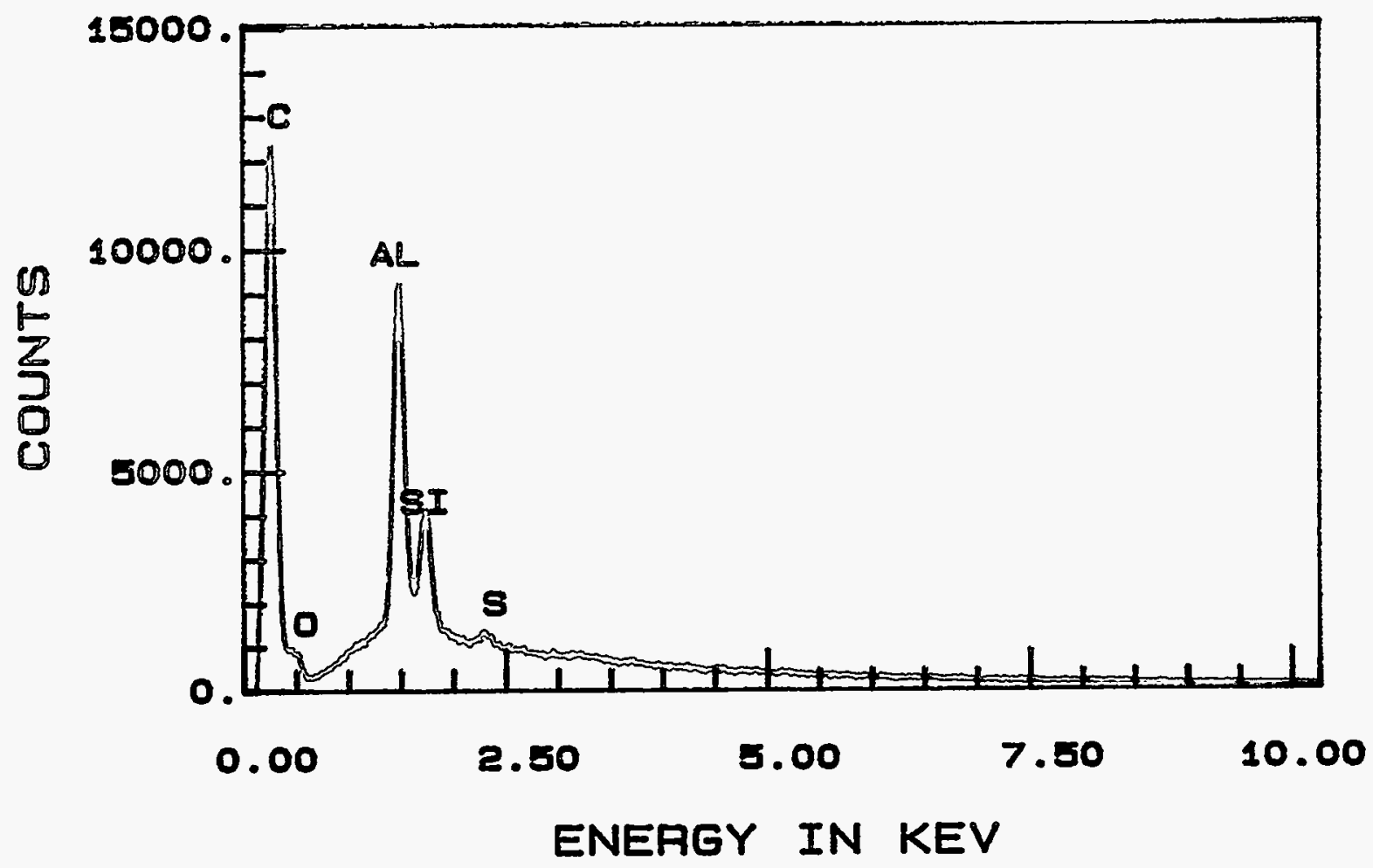

EXPANDED SCALE

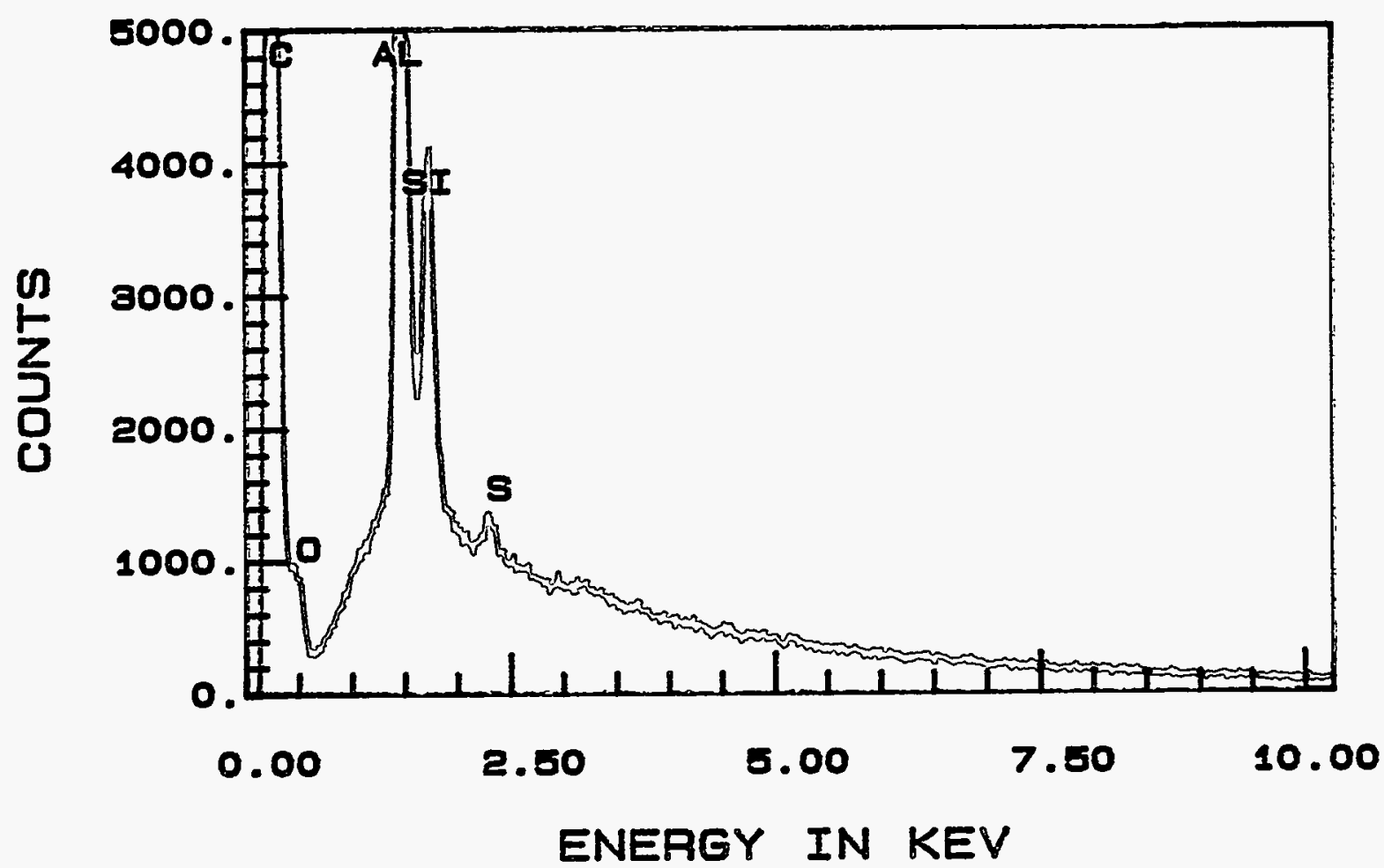


WAPD-TM-1633

Attachment 1

Page 24

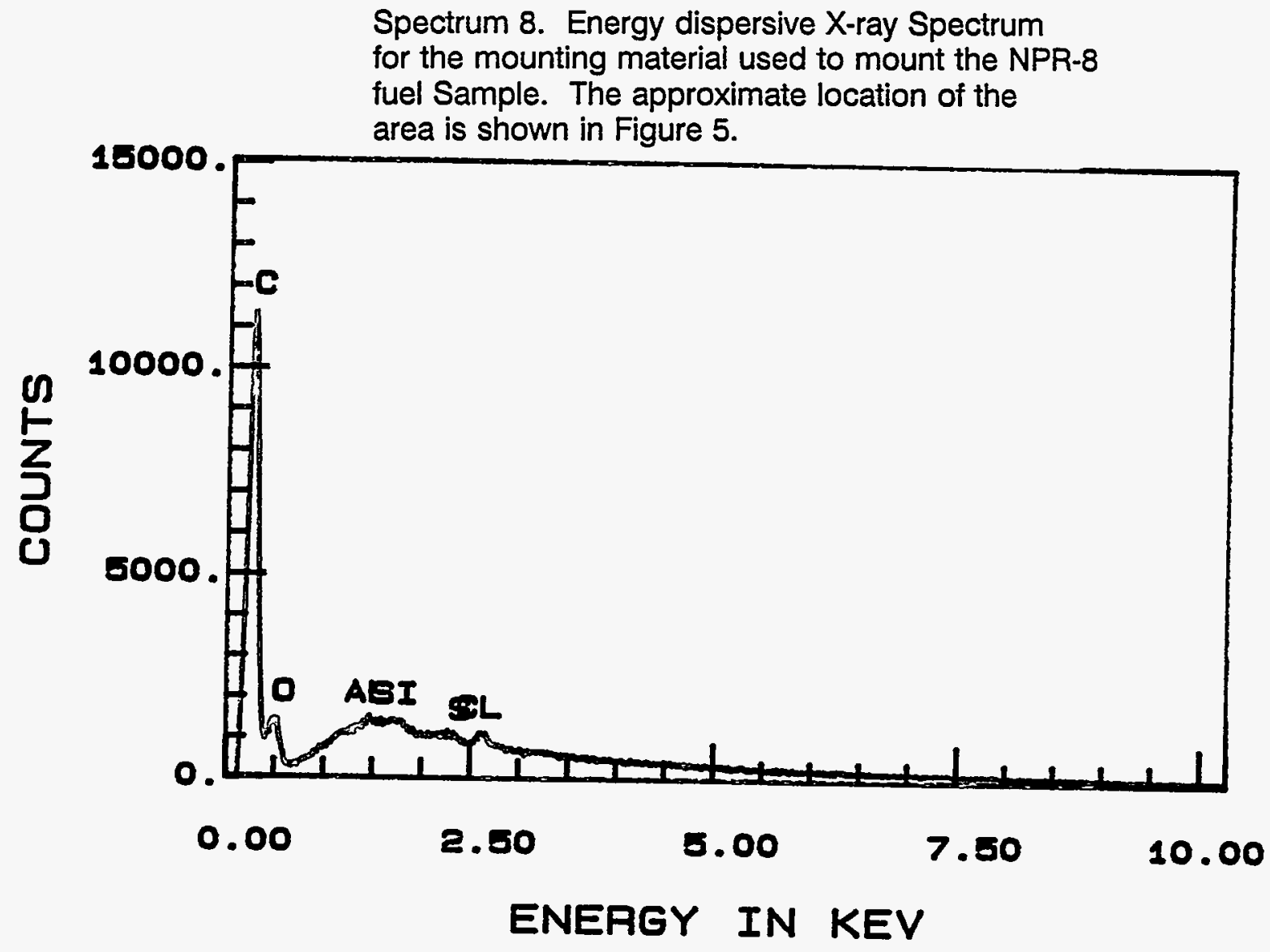

EXPANDED SCALE

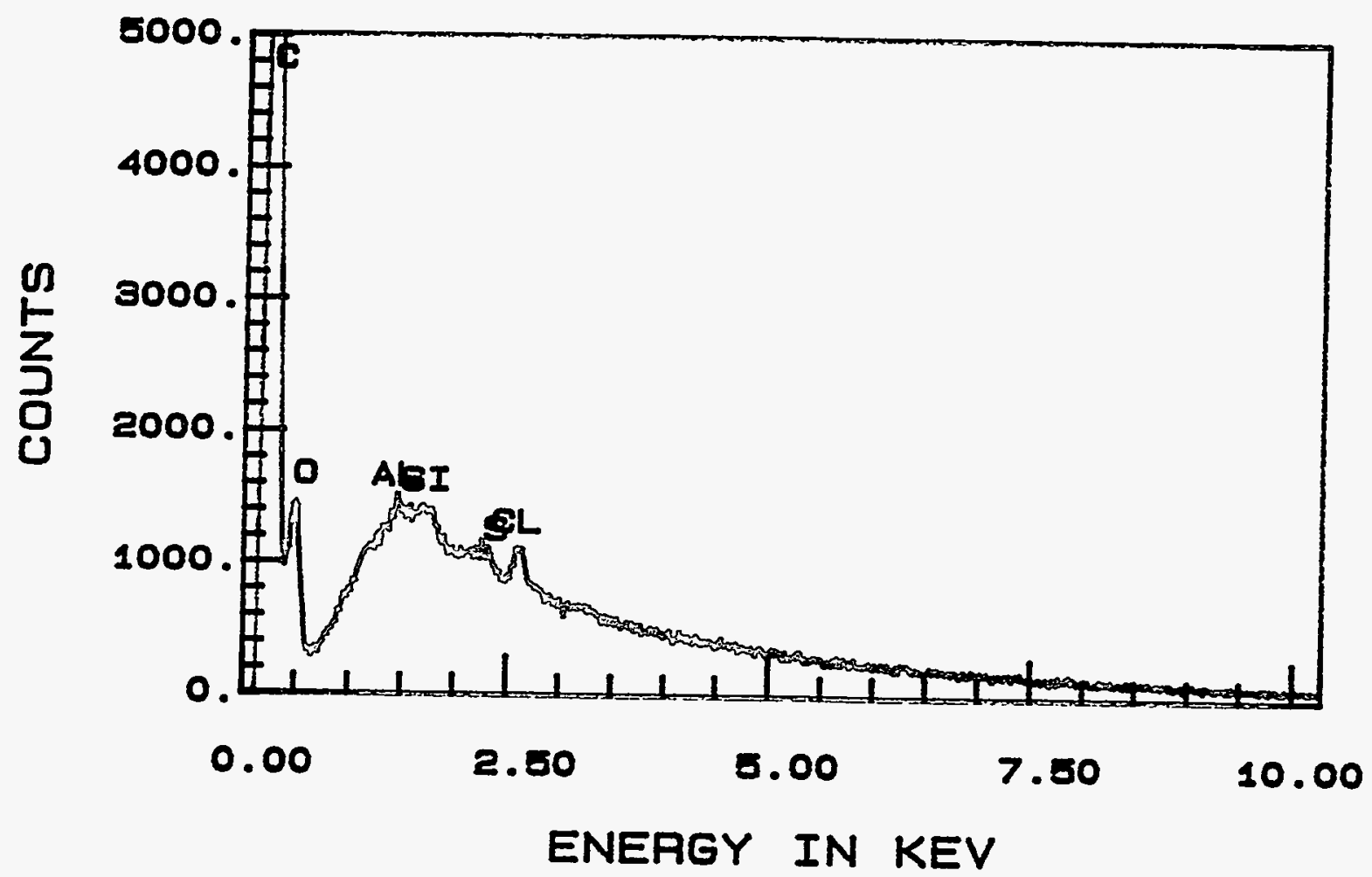


Spectrum 9. Energy dispersive X-ray Spectrum for the light-colored phase in the UCO kernel of NPR-8 fuel Sample. The approximate location of

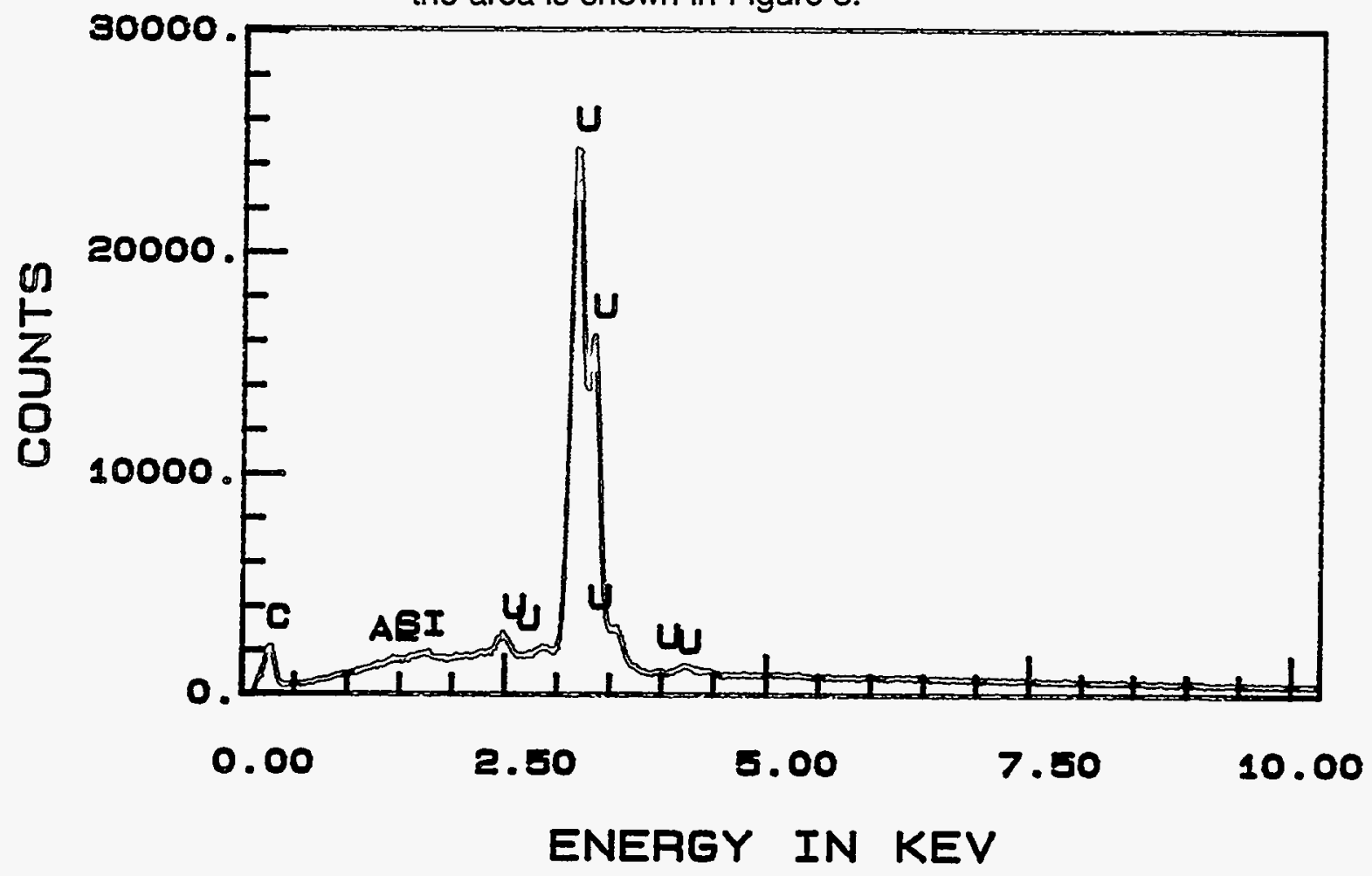

EXPANDED SCALE

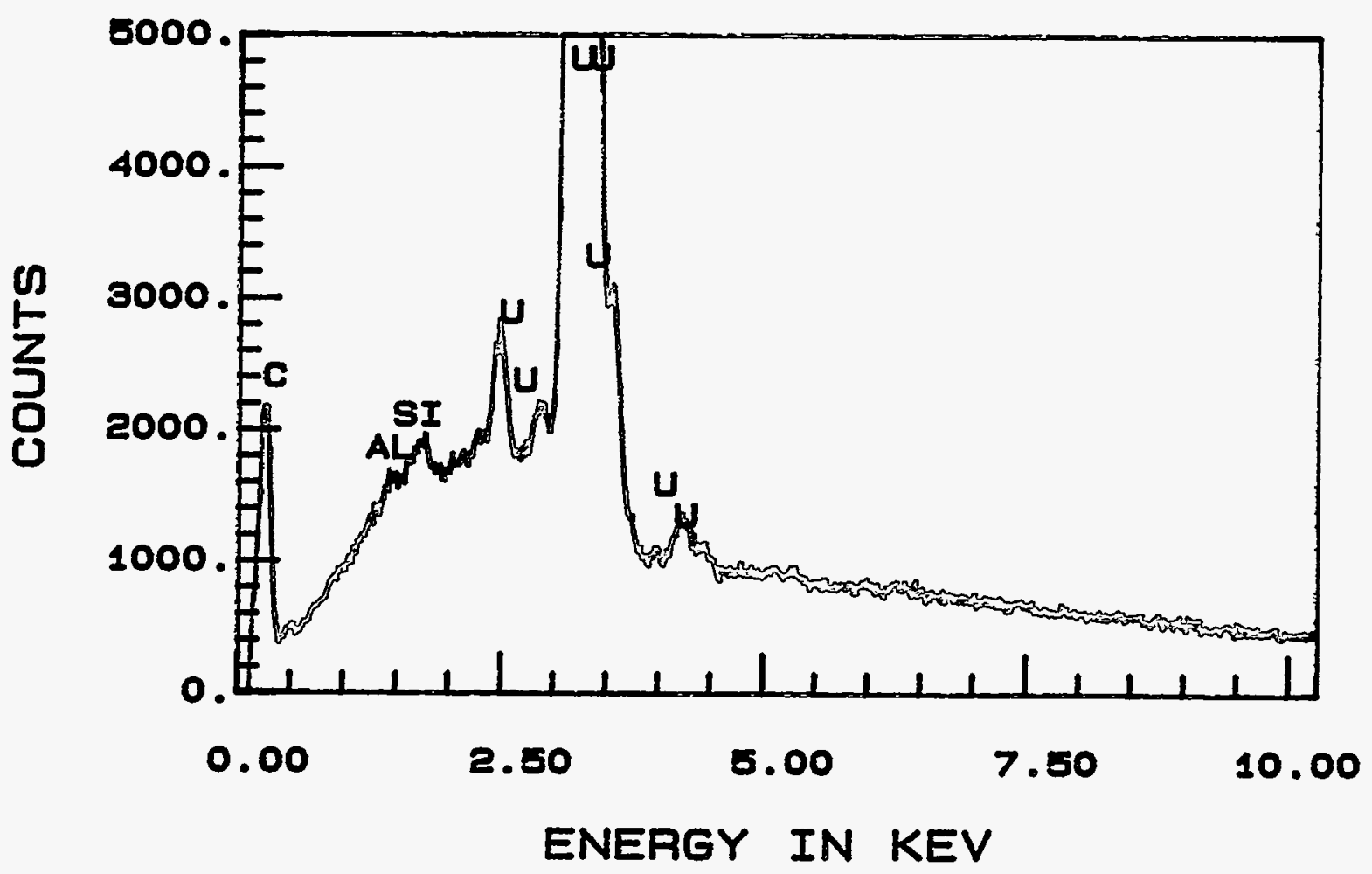


WAPD-TM-1633

Attachment 1

Page 26

Spectrum 10. Energy dispersive X-ray Spectrum for the dark-colored phase in the UCO kernel of Sample LB-3. The approximate location of the area is shown in Figure 8.

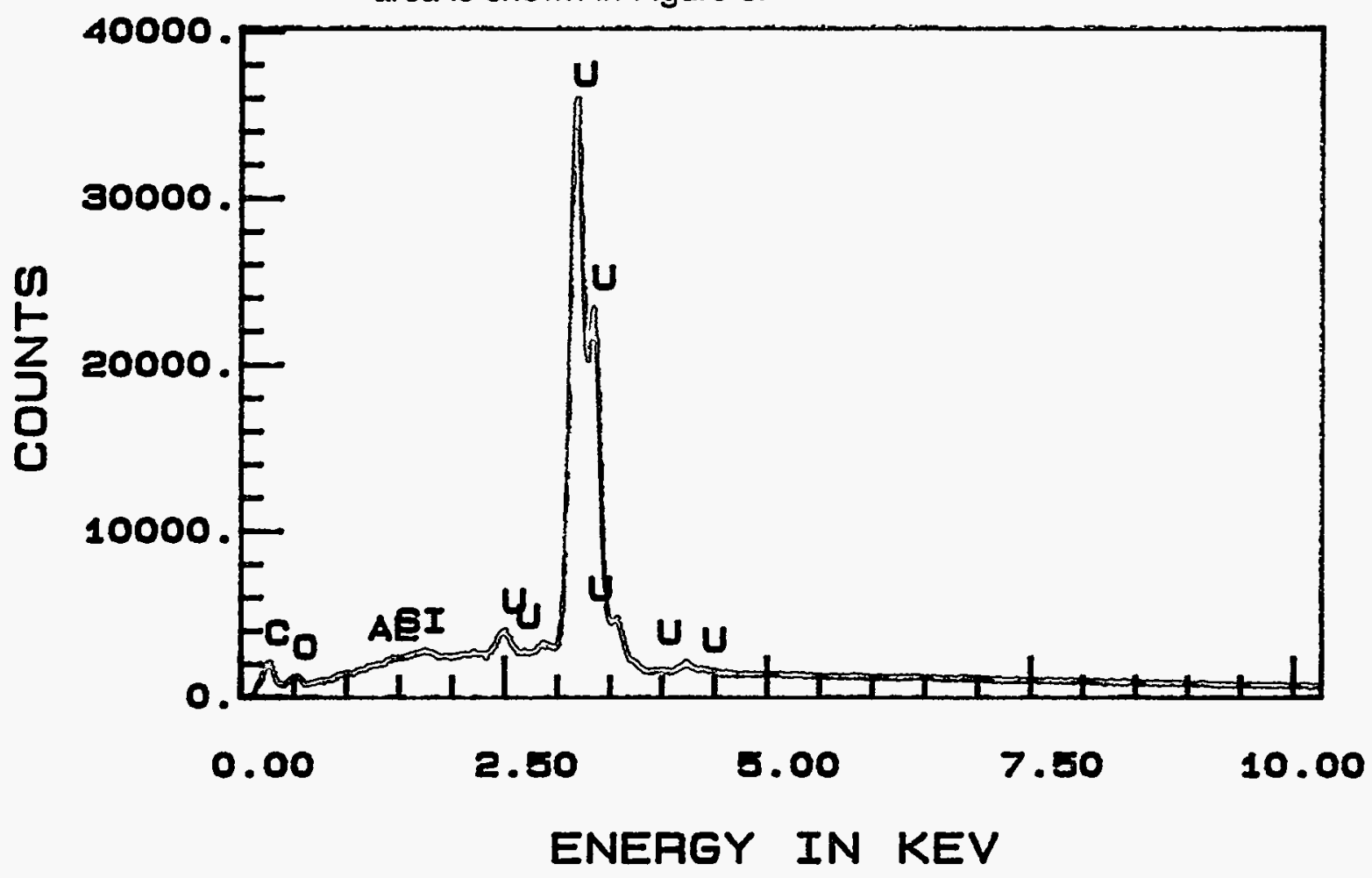

EXPANDED SCALE

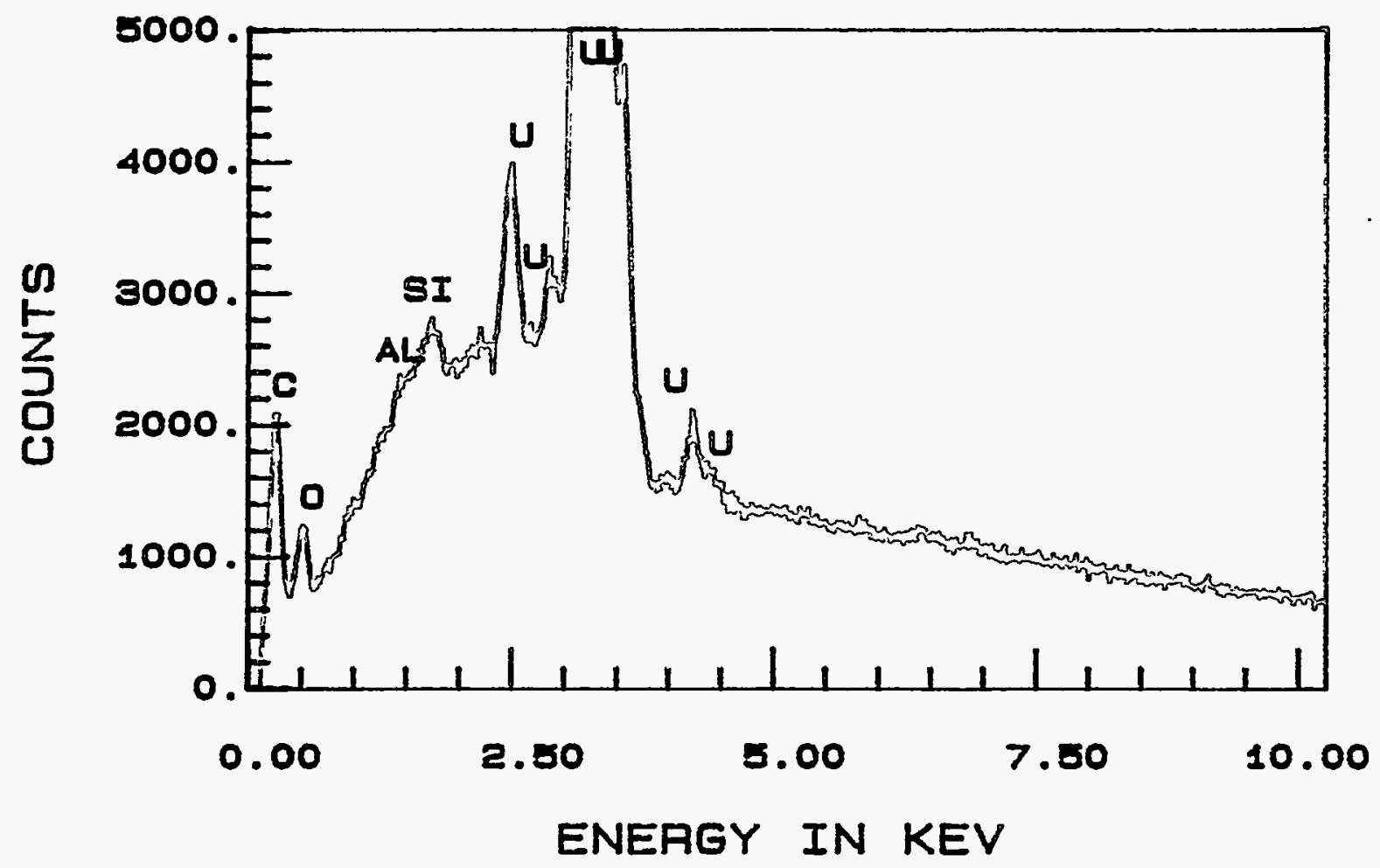

